\title{
MODELO \\ SEMIPARAMÉTRICO \\ DE FRAGILIDADE GAMA
}

\section{Maria Paula Zanardi Chicarino}

\author{
DISSERTAÇÃO APRESENTADA AO \\ INSTITUTO DE MATEMÁTICA E ESTATÍSTICA \\ DA UNIVERSIDADE DE SÃO PAULO \\ PARA OBTENÇÃO DO GRAU DE \\ MESTRE EM ESTATÍSTICA
}

\author{
Área de concentração: Estatística \\ Orientador: Prof. Dr. Antonio Carlos Pedroso de Lima
}

Durante o curso de Mestrado e elaboração desse trabalho autor recebe apoio financeiro do $\mathrm{CNPq}$

- São Paulo, novembro de 1999 - 


\section{MODELO SEMIPARAMÉTRICO DE FRAGILIDADE GAMA}

Este exemplar corresponde à redação final da dissertação devidamente corrigida

e defendida por Maria Paula Zanardi Chicarino e aprovada pela comissão julgadora.

São Paulo, 26 de novembro de 1999.

Comissão Julgadora:

- Professor Dr. Antonio Carlos Pedroso de Lima (Orientador) - IME-USP

- Professor Dr. Heleno Bolfarine - IME-USP

- Professora Dra. Cicilia Wada - IMECC - UNICAMP 
“Os caminhos que trilhamos são repletos de dificuldades. Cabe a nós encará-los como obstáculos ou ensinamentos."

Maria Silvia Z. Chicarino 
Aos meus pais Sônia e Joaquim, meus irmãos Gustavo, Frederico e Maria Silvia, minha avó Ruth, meu tio Silvio e ao meu namorado Paulo de Tarso 


\section{Agradecimentos}

Quero agradecer em primeiro lugar, aos meus pais, que durante toda a vida sempre me proporcionaram as melhores oportunidades de vivência e estudo. Devo tudo que sou e conquistei até hoje a eles. A vocês dois o meu eterno obrigado.

Também agradeço a minha vó, meu tio e irmãos que sempre estiveram ao meu lado me dando força. Agradeço a Deus por ter essa família maravilhosa,

Ao meu querido amigo e namorado Paulo de Tarso por todo amor, carinho, incentivo e compreensão.

Ao Prof. Antonio Carlos pela orientação dedicada e pela confiança que depositou em mim e no meu trabalho. Aprendi muito com a sua forma de trabalhar.

À Profa. Cicilia Wada e ao Prof. Heleno Bolfarine pela colaboração e contribuição dadas a esse trabalho.

À Profa. Clélia que sempre me incentivou e aconselhou nos momentos e decisões mais difíceis.

Ao Paulo Silva e Silva que me auxiliou a rodar, nas estações de trabalho do IME-USP, o programa fornecido pelo Dr. Gert Nielsen.

A minha querida amiga Carine que há mais de 13 anos vem me acompanhando em todos os momentos da vida e também aos seus pais Tia Inês e Tio Silvio pelo amor, amizade e apoio.

Aos meus queridos amigos e colegas de mestrado Lílian, Alessandra, Rodrigo, Luís, Esteban, Delhi pela amizade e companheirismo. Também agradeço aos meus amigos de faculdade Liliam Pereira, Ângela, Fernando, Gilberto, Nelson e a todos os amigos que fiz nesses anos de convivência no IME.

Aos professores do IME pela oportunidade de aprender e poder construir minha sólida formação acadêmica.

Enfim, o meu sincero obrigado a todos que estiveram comigo e colaboraram para a realização de mais essa conquista. 


\section{Resumo}

As técnicas inicialmente desenvolvidas em Análise de Sobrevivência supõem independência entre os tempos de ocorrência do evento de interesse. Em problemas multivariados, contudo, é razoável assumirmos que exista dependência entre as observações. Uma das formas para incorporar essa dependência é introduzir um efeito aleatório na modelagem da função de risco. Esses modelos são chamados de modelos de fragilidade e têm sido amplamente estudados desde o início da década de 80. Nesse trabalho consideramos modelos de fragilidade supondo distribuição Gama para o efeito aletório, no contexto do modelo de riscos proporcionais de Cox. Apresentamos quatro diferentes métodos de estimação descritos na literatura e os comparamos através de três conjuntos de dados diferentes. Além disso, avaliamos o uso das três estatísticas mais populares para testes de hipótese: Wald, Escore e Razão de Verossimilhanças no caso específico do modelo semiparamétrico com fragilidade Gama.

\section{Abstract}

The usual methodology in Survival Analysis assume that the times to event are independent. When considering a multivariate framework, such a assumption may not be tenable. One way of incorporating a possible dependence is to consider a random effect acting multiplicatively on the risk function. The resulting models are called frailty models and have been studied since the begining of the 80 's. This work focus on models which assume a Gamma distribution for the random effects, in the context of a Cox proportional hazards model. We present four different estimation methods and compare them using three data sets. We also consider the applicability of popular procedures for testing hypothesis in Survival Analysis: Wald, Score and Likelihood Ratio. 


\section{Sumário}

1 Introdução Geral

1.1 Motivação . . . . . . . . . . . . . . . . . . . . . . 1

1.2 Introdução ao modelo . . . . . . . . . . . . . . . . . . . . . 4

2 Revisão Bibliográfica $\quad 9$

2.1 Introdução . . . . . . . . . . . . . . . . . . . . . . 9

2.2 Histórico dos modelos de fragilidade Gama . . . . . . . . . . . . . . . . . 10

2.3 Métodos de estimação e teoria assintótica para os modelos de fragilidade Gama 13

2.4 Algumas generalizações dos modelos de fragilidade . . . . . . . . . . . . . . 15

3 Modelo Semiparamétrico de Fragilidade Gama 20

3.1 Dados Independentes . . . . . . . . . . . . . . . . . . . . . . 20

3.1 .1 Estimação e Testes de hipóteses . . . . . . . . . . . . . . . . . . . . 24 
3.2 Dados Dependentes . . . . . . . . . . . . . . . . . . . . . 27

3.2 .1 Definição do Modelo . . . . . . . . . . . . . . . . . . . . 27

3.2 .2 Estimação dos parâmetros . . . . . . . . . . . . . . . . . . . . . 28

3.2 .3 Estimação sugerida por Klein (1992) . . . . . . . . . . . . . . . . . 32

3.2 .4 Proposta de um novo método de estimação . . . . . . . . . . . . . . 36

3.2 .5 Estimação da variância . . . . . . . . . . . . . . . . . 38

3.2 .6 Testes de Hipóteses . . . . . . . . . . . . . . . . . . . . . . . . 38

3.2.7 Verossimilhança Penalizada . . . . . . . . . . . . . . . . . 43

4 Aplicações 48

4.1 Introdução . . . . . . . . . . . . . . . . . . . . . . . . . . . . . 48

4.2 Exemplo dos ratos . . . . . . . . . . . . . . . . 50

4.3 Exemplo dos dentes . . . . . . . . . . . . . . . . . . . 53

4.4 Exemplo do vírus da hepatite $\mathrm{C} \ldots \ldots \ldots \ldots \ldots$

5 Conclusão 


\section{Capítulo 1}

\section{Introdução Geral}

\subsection{Motivação}

As técnicas mais usadas em Análise de Sobrevivência supõem independência entre as observações. Entretanto, muitas vezes podemos estar interessados em estudar, por exemplo, o tempo até a ocorrência de alguma doença em indivíduos de uma mesma família. Nessa situação é esperado que o comportamento dos tempos observados entre irmãos apresente certas semelhanças que não seriam observadas entre pessoas sem laços familiares. Esse é um caso típico onde a suposição de independência entre as variáveis que representam os tempos de ocorrência não é válida para todos os indivíduos.

Motivada por eventos do tipo descrito acima, essa dissertação tem como objetivo abordar uma das possíveis maneiras de se solucionar o problema da falta de independência através de modelos de fragilidade ("frailty models").

Antes de introduzir esses modelos, vamos descrever três exemplos em que essa teoria pode ser aplicada. 
Exemplo 1: Dados publicados por Mantel, Bohidar \& Ciminera (1977) sobre um experimento com ratos para se estudar o efeito de uma droga carcinogênica. No experimento, foram utilizadas 50 ninhadas de ratos e de cada uma foram selecionadas 3 ratas sendo que duas receberam placebo e a outra recebeu a droga. Foi observado o tempo, em semanas, até o aparecimento do tumor. Devido às características genéticas que as ratas de uma mesma ninhada compartilham, é esperado que os tempos correspondentes a elas sejam correlacionados. Dessa forma, é necessário ajustar o efeito do tratamento por essa possível dependência entre as observações. Em Nielsen, Gill, Andersen \& Ṣørensen (1992) esses dados foram analisados utilizando os modelos de fragilidade.

Exemplo 2: Um estudo na área de odontologia com o intuito de comparar a retenção de dois tipos de selantes: Delton, já existente no mercado e Optibond um produto novo. Foram avaliadas 37 crianças com média de 14 anos de idade sendo 23 meninas e 15 meninos. O experimento consistiu em aplicar os dois selantes na mesma criança da seguinte forma: em metade dos dentes foi aplicado o Delton e na outra metade o Optibond (via aleatorização). Assim, cada criança serviu como seu próprio controle. Através de uma avaliação periódica, os pesquisadores classificaram o estado do selante de cada dente por um escore: 1 - se o selante estava perfeito, 2 - se houve perda parcial e 3 - se houve perda total do selante. A variável de interesse foi o tempo, em meses, até a ocorrência de uma perda, seja ela parcial ou total, do selante. Outras variáveis também foram observadas como tipo do dente (prémolar ou molar), idade e sexo. No artigo Grande, Lima, Rodrigues Filho \& Witzel (1999) foi feita uma análise utilizando o estimador de Kaplan-Meier para a função de sobrevivência e o modelo de riscos proporcionais de Cox. Esta análise assumiu que todas as observações eram independentes e os resultados mostraram que o selante Optibond teve uma melhor retenção nos dentes do qưe o Delton $(p<0,001)$. Além disso, os dentes pré-molares tiveram uma retenção melhor do selante do que os dentes molares $(p<0,001)$. Não foram encontradas diferenças significativas para as outras variáveis (sexo e idade). Entretanto, pelo fato dos dois selantes terem sido aplicados no mesmo indivíduo é provável que essas observações sejam correlacionadas fazendo com que a análise usual não seja a mais adequada.

Exemplo 3: Trata-se de um conjunto de dados de 15 indivíduos positivos para o 
vírus HCV (hepatite C) fornecidos pelo Centro de Imunologia e Imunogenética Ltda. O critério usado para determinar a seleção dos pacientes foi o resultado do teste PCR, que é tido como um teste confiável pois consegue detectar parte do vírus no sangue. Dessa forma, o indivíduo só entrava para o estudo se o resultado do PCR era positivo. O interesse principal é comparar nove testes imunoenzimáticos do tipo ELISA que existem no mercado e que são mais baratos que o PCR. Esses testes apresentam um princípio diferente, pois avaliam a quantidade de anticorpos que o indivíduo possui contra o vírus. Para isto, foram retiradas várias amostras de sangue dos pacientes e para cada amostra foi aplicado um teste para detectar a positividade com relação ao HCV. Através do painel de soroconversão foi determinado o tempo, em dias, até a deteç̧ão de positividade para cada um dos testes. Devido a grande quantidade de testes e ao pouco número de observações, os pesquisadores agruparam os testes em 3 grupos (1: testes de $1^{a}$ geração, 2: testes de $2^{a}$ geração e 3 : testes de $3^{a}$ geração). Uma outra variável observada foi a presença ou não de CORE no sangue do indivíduo, que é uma proteína que está presente no vírus. Para classificar o indivíduo como com ou sem CORE foi utilizado o teste RIBA que avalia a quantidade de anticorpos para essa proteína presente no sangue. Suspeita-se de que quando o indivíduo tem CORE, alguns testes tendem a detectar a positividade mais rapidamente. Nesse exemplo, fica claro que deve existir uma dependência entre os tempos observados em cada teste, já que as observações são feitas em amostras obtidas no mesmo indivíduo.

No último capítulo apresentamos os resultados desses três conjuntos de dados utilizando os modelos de fragilidade. Além disso, comparamos esses resultados com os obtidos através de um modelo considerando que os dados são independentes.

Os três conjuntos de dados estão disponíveis no endereço: ftp://ftp.ime.usp.br/pub/acarlos/frailty juntamente com o programa desenvolvido no software NTIA da Embrapa para implementação de um dos algoritmos de estimação do modelo de fragilidade gama. 


\subsection{Introdução ao modelo}

Primeiro vamos relembrar algumas das notações usadas em Análise de Sobrevivência e definir variáveis e funções que estaremos usando ao longo do texto.

Considere uma amostra de $n$ grupos, sendo que cada grupo é composto por $n_{i}$ ( $i=$ $1, \ldots, n)$ observações. No caso dos exemplos 2 e 3 citados na seção anterior, o grupo é representado por observações de um mesmo indivíduo. Mas existem estudos onde o grupo é formado por observações de indivíduos diferentes mas que apresentam alguma relação entre si. Esse é o caso do Exemplo 1 envolvendo famílias, onde as características genéticas e ambientais que os indivíduos de uma mesma família compartilham podem gerar uma estrutura de dependência entre os tempos de evento.

A variável de interesse será denominada $T_{i j}\left(i=1, \ldots, n\right.$ e $\left.j=1, \ldots, n_{i}\right)$ e representa o tempo até a ocorrência de um determinado evento. Além disso, somente vamos considerar o caso de modelos com covariáveis e elas serão representadas pelo vetor $\mathbf{X}_{i j}$ com $p$ colunas. No caso do Exemplo 2, $T_{i j}$ é definido como o tempo até que o $j$-ésimo dente do indivíduo $i$ apresente um desgaste do selante e as covariáveis são o tipo de selante (Optibond ou Delton), o tipo de dente (molar ou pré-molar), idade e sexo. No Exemplo 3, a variável de interesse é o tempo até o teste $j$ do indivíduo $i$ dar positivo para HCV e as covariáveis são o tipo de teste (1,2 ou 3) e CORE (sim ou não). Já no Exemplo 1, $T_{i j}$ representa o tempo até o surgimento do tumor na $j$-ésima rata da ninhada $i$ e como covariável temos apenas o tipo de tratamento (droga ou placebo).

Entretanto, nem sempre conseguimos observar o valor de $T_{i j}$, por diversos motivos como, por exemplo, o término do estudo, perda de contato com o indivíduo ou até mesmo a falha por outra causa não relacionada com a variável de interesse. Entenda por falha quando o evento ocorre para aquela observação. Nesse caso, a única informação que temos é que o tempo de evento é maior que um certo valor $C_{i j}$, denominado tempo de censura.

Para caracterizar melhor os tempos de falha, suponha que $\left\{T_{i j}, i=1, \ldots, n\right.$ e $j=$ 
$\left.1, \ldots, n_{i}\right\}$ é uma sequência de variáveis aleatórias independentes não-negativas com função distribuição $F_{i j}(\cdot)$ e função de risco definida por

$$
\alpha_{i j}\left(t \mid \mathrm{X}_{i j}\right)=\lim _{\Delta t \rightarrow 0} \frac{1}{\Delta t} P\left(T_{i j} \in[t, t+\Delta t) \mid T_{i j} \geq t, \mathrm{X}_{i j}\right),
$$

que é interpretada como a intensidade de uma observação falhar no tempo $t$ dado que ela ainda não falhou. A quantidade (1.1) também é conhecida como a taxa instantânea de falha.

Observe que podemos resumir os dados efetivamente observados através de um par de variáveis $\left(V_{i j}, \delta_{i j}\right)$ definidas por:

$$
\begin{aligned}
V_{i j} & =\min \left(T_{i j}, C_{i j}\right) \\
\delta_{i j} & =I\left(T_{i j} \leq C_{i j}\right)
\end{aligned}
$$

ou seja, $\delta_{i j}=1$ se uma falha foi observada e $\delta_{i j}=0$ se foi uma censura.

O modelo de fragilidade é caracterizado pelo uso de um efeito aleatório, ou seja, de uma variável aleatória não observável, que representa as informações que não podem ser observadas, como fatores ambientais e genéticos, ou informações que por algum motivo não foram consideradas no planejamento. Uma das maneiras encontradas para incorporar esse efeito, que chamaremos de variável de fragilidade, é introduzí-lo na modelagem da função de risco $\alpha_{i j}(t)$. A forma mais comum é através do uso do modelo de regressão de Cox (Cox 1972). Assim, definimos a função de risco para $T_{i j},\left(i=1, \ldots, n\right.$ e $\left.j=1, \ldots, n_{i}\right)$ como:

$$
\alpha_{i j}\left(t \mid Z_{i}, \mathbf{X}_{i j}\right)=Z_{i} \alpha_{0}(t) \exp \left(\boldsymbol{\beta}^{\prime} \mathbf{X}_{i j}\right), t \geq 0
$$

com

$\alpha_{0}$ : função de risco padrão arbitrária,

$\boldsymbol{\beta}$ : vetor de coeficientes de regressão desconhecidos de dimensão $p \times 1$,

$\mathrm{X}_{i j}$ : vetor de covariáveis para o indivíduo $j$ do grupo $i$ de dimensão $p \times 1 \mathrm{e}$

$Z_{i}$ : variáveis positivas independentes e identicamente distribuídas, com distribuição conhecida.

Note que, as observações de um mesmo grupo apresentam o mesmo valor da variável de fragilidade $Z_{i}, i=1, \ldots, n$. Vamos supor que, condicional a um valor específico da 
variável de fragilidade $Z_{i}$, todas as observações daquele grupo são independentes. Como consequência, $\alpha_{i j}\left(t \mid Z_{i}, \mathrm{X}_{i j}\right)$ segue o modelo de riscos proporcionais, quando estiver valendo o modelo de Cox.

Na formulação proposta acima, a variável de fragilidade não varia com o tempo, o que representa uma das limitações desses modelos. Chang \& Hsiung (1995), Yau \& McGilchrist (1998) e Paik, Tsai \& Ottman (1994) já propuseram modelos com variáveis de fragilidade dependentes do tempo.

O fato da variável de fragilidade atuar de maneira multiplicativa na função de risco é, em princípio, arbitrária, mas tem sido usada como base para a maioria dos trabalhos de Análise de Sobrevivência com dependência entre as observações. Dessa forma, quanto maior for o valor da variável de fragilidade, maior será a chance de uma falha ocorrer. Daí o nome de modelo de fragilidade, pois, quanto maior for o valor de $Z_{i}$, mais "frágeis" as observações pertencentes ao grupo $i$ estão para falhar.

Podemos fazer um paralelo do modelo de fragilidade (1.3) com o modelo de regressão linear com efeito aleatório. Sem perda de generalidade, suponha que $\alpha_{0}(t)=1, \forall t \geq 0$. Aplicando o log em (1.3) temos que:

$$
\log \alpha_{i j}\left(t \mid Z_{i}, \mathbf{X}_{i j}\right)=\log Z_{i}+\boldsymbol{\beta}^{\prime} \mathbf{X}_{i j}
$$

ou seja, $\log Z_{i}$ representa o intercepto aleatório de uma regressão linear do log da função de risco.

Os modelos de fragilidade permitem incorporar a variabilidade dos tempos observados vinda de duas fontes distintas. A primeira é a variabilidade natural que é explicada pela função de risco e a segunda é a variabilidade comum a indivíduos de um mesmo grupo ou a variabilidade comum a vários eventos de um mesmo indivíduo, que é explicada pela variável de fragilidade.

Na maior parte dos estudos feitos até hoje, a distribuição Gama foi a mais usada para modelar a variável de fragilidade (Clayton \& Cuzick 1985, Nielsen et al. 1992 e Klein 1992). 
Essa preferência não aconteceu por acaso, e sim, porque ela é uma distribuição de tratamento algébrico conveniente e, além disso, como a variável de fragilidade não pode ser negativa, a distribuição Gama, juntamente com as distribuições log-normal e Weibull, é uma das mais usadas para atuar de forma direta na função de risco, que é necessariamente positiva. Um dos pioneiros nessa área foi Clayton (1978), que estudou a incidência de doenças crônicas de tendência familiar entre pais e filhos. No Capítulo 2 apresentamos um histórico dos modelos de fragilidade onde a preferência pelo uso da distribução Gama pode ser confirmada.

Para dar uma idéia mais clara do modelo de fragilidade com distribuição Gama, considere novamente o modelo (1.3) onde $Z_{i} \sim \operatorname{Gama}(\nu, \eta)$ independentes com $\nu \geq 0, \eta \geq 0 \mathrm{e}$ $\nu=\eta=\theta^{-1}$, ou seja, $E\left(Z_{i}\right)=1$ e $\operatorname{Var}\left(Z_{i}\right)=\theta$. A variância da distribuição Gama, $\theta$, é o parâmetro de dependência. Observe que, se $\theta=0$, temos que todas as variáveis de fragilidade são iguais a 1, ou seja, a distribuição Gama fica degenerada no ponto 1 e aí voltamos para o modelo de riscos proporcionais padrão (para dados independentes).

O fato da média da distribuição Gama ser igual a 1 ocorre para que o modelo seja identificável. Por exemplo, quando os parâmetros são desconhecidos, o modelo não é identificável se uma relação entre os parâmetros $\nu$ e $\eta$ não for imposta, já que é possível dividir e multiplicar $Z_{i}$ e $\alpha_{0}$ pela mesma constante e continuar com um modelo Gama que terá um novo parâmetro de escala apesar do parâmetro de forma não se alterar. Portanto, se a suposição de que $E\left(Z_{i}\right)=1$ (que no caso de distribuição Gama é equivalente a $\nu=\eta$ ) não for usada o modelo não estará totalmente identificado, mesmo que a função de risco não esteja sendo modificada. Isso não acontece só com a a distribuição Gama, mas para qualquer distribuição que seja utilizada em modelos de fragilidade semiparamétricos (Liang, Self, Bandeen-Roche \& Zeger 1995).

A organização deste trabalho é a seguinte: no Capítulo 2, fazemos um breve histórico dos modelos de fragilidade e dos processos de estimação descritos na literatura. No Capítulo 3, abordamos o modelo usual de regressão de Cox para dados independentes e o modelo de fragilidade Gama baseado no artigo de Nielsen et al. (1992). Apresentamos também mais três outros processos de estimação, um desenvolvido por Klein (1992), uma nova proposta suge- 
rida por Andersen, Klein, Knudsen \& Palacios (1997) e por último um processo utilizando a teoria de verossimilhança penalizada introduzida por Therneau \& Grambsch (1998). Ainda nesse capítulo mostramos os testes de hipóteses para os parâmetros $\beta$ e $\theta$. No Capítulo 4 , comparamos os programas desenvolvidos por Nielsen et al. (1992), Klein (1992), Therneau \& Grambsch (1998) e o programa que desenvolvemos considerando uma nova proposta de estimação dos parâmetros dada por Andersen et al. (1997). Aplicamos toda a teoria descrita no Capítulo 3 nos três conjuntos de dados descritos no Capítulo 1 e comparamos os resultados da análise usual para dados independentes com os da análise para dados dependentes utilizando os 4 programas. 


\section{Capítulo 2}

\section{Revisão Bibliográfica}

\subsection{Introdução}

Nesse capítulo apresentamos um retrospecto do que já existe na literatura sobre os modelos de fragilidade, relatando de maneira resumida alguns dos resultados mais importantes. Para descrever os modelos vamos utilizar a abordagem de processos de contagem (Aalen 1978) onde os tempos de falha são modelados por um processo de contagem multivariado $\mathrm{N}$, caracterizado por um processo de intensidade $\lambda$, o qual incorpora a função de risco associada ao tempo de falha.

Para introduzir essa abordagem, vamos precisar definir dois processos que contêm a mesma informação que o par $\left(V_{i j}, \delta_{i j}\right)$ dados por 1.2. O primeiro é o processo multivariado $\mathrm{N}(t)=\left\{N_{i j}(t), i=1, \ldots, n\right.$ e $\left.j=1, \ldots, n_{i}\right\}, t \geq 0$, contínuo à direita, tal que:

$$
N_{i j}(t)=I\left(V_{i j} \leq t, \delta_{i j}=1\right)
$$

ou seja, $N_{i j}(t)=0$ até a ocorrência de uma falha e salta para 1 quando ocorre uma falha em $V_{i j}$.

O segundo processo é contínuo à esquerda e identifica o processo de intensidade cor- 
respondente a $\mathrm{N}(t)$ e é definido por

$$
Y_{i j}(t)=I\left(V_{i j} \geq t\right)
$$

ou seja, $Y_{i j}(t)=1$ se o indivíduo $j$ do grupo $i$ está em risco até $t^{-}$(tempo imediatamente anterior a $t$ ). O processo $Y_{i j}(t)$ é previsível, o que significa que seu valor é conhecido no instante $t^{-}$.

O processo de intensidade é calculado multiplicando-se a função de risco pelo processo previsível, ou seja, para o $j$-ésimo indivíduo do grupo $i$ temos que $\lambda_{i j}(t)=Y_{i j}(t) \alpha_{i j}(t)$. Detalhes podem ser vistos em Andersen, Borgan, Gill \& Keiding (1993).

\subsection{Histórico dos modelos de fragilidade Gama}

Como mencionado anteriormente, o fato de considerarmos apenas um efeito aleatório introduzido na função de risco faz com que o modelo englobe dois tipos de fontes de variação para os dados. A primeira delas, que gera a heterogeneidade entre as observações, é causada por covariáveis individuais não observadas que não foram incluídas no planejamento do estudo por circunstâncias práticas, ou por não serem conhecidas como sendo fatores de risco. Foi daí que surgiu originalmente o termo fragilidade usado por Vaupel, Manton \& Stallard (1979) em um estudo com dados demográficos.

A segunda fonte de variação é proveniente das covariáveis comuns a indivíduos de um mesmo grupo ou família que, quando não são observadas, geram dependência entre os tempos de evento.

Como ilustração para a primeira fonte de variação tome o estudo de Vaupel et al. (1979). Nesse artigo, os autores construíram um modelo baseado na função de risco em uma análise univariada utilizando o método da tábua de vida (Lawless 1982). Eles enfatizaram que a variável de fragilidade pode ser definida de várias formas. A opção escolhida foi a de introduzir a variável de maneira multiplicativa usando a distribuição Gama, conforme 
descrito no Capítulo 1. O modelo que eles usaram para incorporar a heterogeneidade causada pelas covariáveis não observadas foi:

$$
\lambda_{i j}\left(t \mid Z_{i j}\right)=Z_{i j} Y_{i j}(t) \alpha_{0}(t) \quad i=1, \ldots, n \text { e } j=1
$$

Note que, nesse caso, o grupo é formado por apenas um indivíduo, $n_{i}=1$, com sua própria variável de fragilidade e $n$ é o tamanho total da amostra. Logo, os tempos de eventos associados a indivíduos diferentes são independentes.

Através da aplicação do modelo (2.3) a um conjunto de dados, os autores concluíram que as análises usuais utilizando o método de tábua de vida levam à superestimação da expectativa de vida dos indivíduos quando existe heterogeneidade entre as observações. E mais, que a superestimação é maior conforme aumenta a heterogeneidade, que é medida através da variância da distribuição Gama $(\theta)$.

A segunda fonte de variação foi estudada por vários autores. Um dos primeiros foi Clayton (1978), que analisou a incidência de doenças crônicas de tendência familiar entre pais e filhos. Da mesma forma que Vaupel et al. (1979), Clayton (1978) supôs um modelo sem covariáveis onde a variável de fragilidade afeta a função de risco de maneira multiplicativa, de tal forma que se um indivíduo tem valor da variável de fragilidade igual a $Z$ a sua função de risco terá valor $Z \alpha_{0}(t)$. O modelo estudado foi:

$$
\lambda_{i j}\left(t \mid Z_{i}\right)=Z_{i} Y_{i j}^{\prime}(t) \alpha_{0 h}(t) \quad i=1, \ldots, n, j=1,2 e h=1, \ldots, K
$$

onde $K$ indica o número de estratos. No artigo eles usaram $K=2$, um estrato para pai e outro para filho. Note que agora cada grupo é formado por dois indivíduos com o mesmo valor da variável de fragilidade, pai e filho, identificados pelas suas respectivas funções de risco padrão.

Alguns anos depois, Clayton \& Cuzick (1985) estenderam o modelo de Clayton para incluir covariáveis fixas. O modelo estudado por eles foi o modelo (1.3), descrito no Capítulo 1, com distribuição Gama para as variáveis de fragilidade. Reescrevendo esse modelo em termos de processo de contagem obtemos um processo de intensidade para $N_{i j}(t)$ dado por

$$
\lambda_{i j}\left(t \mid Z_{i}, \mathbf{X}_{i j}\right)=Z_{i} Y_{i j}(t) \alpha_{0}(t) \exp \left(\boldsymbol{\beta}^{\prime} \mathbf{X}_{i j}\right)
$$


onde

$Y_{i j}$ definido em (2.2),

$\alpha_{0}(t)$ é a função de risco padrão, arbitrária,

$\boldsymbol{\beta}$ é o vetor de coeficientes de regressão desconhecidos de dimensão $p \times 1$,

$\mathrm{X}_{i j}$ é vetor de covariáveis para o o indivíduo $j$ do grupo $i$, de dimensão $p \times 1 \mathrm{e}$

$Z_{i} \sim \operatorname{Gama}(\nu, \eta)$ independentes $\operatorname{com} \nu \geq 0, \eta \geq 0$ e $\nu=\eta=\theta^{-1}$, ou seja, $E\left(Z_{i}\right)=1 \mathrm{e}$ $\operatorname{Var}\left(Z_{i}\right)=\theta$.

Esse modelo considera um risco relativo constante, condicional a um valor específico da variável de fragilidade. Entretanto, a função de risco marginal, dada por $\alpha_{i j}\left(t \mid Z_{i}, \mathbf{X}_{i j}\right)=$ $E_{z}\left(Z_{i} \alpha_{0}(t) \exp \left(\boldsymbol{\beta}^{\prime} \mathbf{X}_{i j}\right)\right)$ não segue mais o modelo de riscos proporcionais. Por causa disso, os parâmetros de dependência $\theta$ e de regressão ficam confundidos, o que implica que $\theta$ mede algo além da dependência entre as observações.

Oakes (1982) discute uma reparametrização do modelo introduzido por Clayton (1978) através de tábuas de vida bivariadas. Além disso, propõs uma alternativa de estimador nãoparamétrico baseado no coeficiente de concordância $\tau$ de Kendall (Kendall 1962) e calculou sua variância assintótica. Para isso, ele considerou o caso bivariado sem covariadas e mostrou que o valor esperado do $\tau$ de Kendall, calculado a partir de uma amostra não censurada ou de uma amostra censurada à direita, é igual a:

$$
\theta /(\theta+2)
$$

Esse estimador, no contexto dos modelos (1.3) ou (2.4), é uma medida de correlação dentro dos grupos e quanto maior for seu valor maior é a dependência entre os grupos.

Posteriormente, alguns autores utilizaram a formulação de processos de contagem para estudar o modelo de fragilidade Gama considerando o modelo semiparamétrico de Cox. Entre eles podemos citar Self \& Prentice (1986), Nielsen et al. (1992) e Andersen et al. (1993). O processo de intensidade de $\mathrm{N}$, que eles estudaram, satisfaz o modelo (2.4).

Para esse mesmo modelo, Commenges \& Andersen (1995) derivaram a estatística de escore para testar se existe dependência entre as observações. Ou seja, ela testa se a variância 
associada à variável de fragilidade é igual a zero, ou, que $H_{0}: \theta=0$. Ela é simples de ser calculada e tem como maior vantagem não depender da distribuição da variável de fragilidade pois é calculada sob a hipótese nula (modelo de Cox usual). Logo ela pode ser usada para outros modelos além do modelo de fragilidade Gama. Os autores sugerem como estratégia de análise primeiro aplicar a estatística escore e verificar se existe dependência entre as observações e se ela existir quantificá-la através de um modelo de fragilidade Gama, por exemplo.

\subsection{Métodos de estimação e teoria assintótica para os modelos de fragilidade Gama}

Em seu artigo, Clayton \& Cuzick (1985) aplicaram um processo de máxima verossimilhança no modelo (1.3) com distribuição Gama, usando a distribuição do vetor de postos generalizados (Prentice 1978) para estimar $\theta$ e $\boldsymbol{\beta}$. Nesse processo de estimação. as observações atuais são substituídas por estatísticas de ordem esperadas, calculadas sob a suposição de um modelo paramétrico para o vetor de postos generalizados. A verossimilhança é maximizada assumindo que os dados foram amostrados do modelo paramétrico e o processo continua iterativamente. A implementação computacional do procedimento é bem complicada.

Para esse mesmo modelo, reescrito sob a abordagem de processos de contagem pelo modelo (2.4), Self \& Prentice (1986) desenvolveram um outro processo de estimação, usando a abordagem de processos de contagem, onde o efeito aleatório com distribuição Gama é substituído pela sua esperança, dada a história gerada pelo processo de falha e censura (filtragem). Eles construíram a verossimilhança usando o processo de intensidade esperado. A estimação foi feita através de iterações que se alternavam entre a solução das equações de verossimilhança baseada na estimativa atual da função de risco padrão, obtida pelo estimador de Nelson-Aalen, e a estimação da intensidade usando as estimativas atuais da variável de fragilidade e dos efeitos das covariáveis. 
Utilizando o algoritmo EM e a abordagem clássica, Klein (1992) propôs um outro processo de estimação que estende as técnicas de verossimilhança parcial descritas em Cox (1972). Essa idéia foi proposta originalmente por Gill (1985) e também foi utilizada por Nielsen et al. (1992) e Andersen et al. (1993). O método de estimação usado por Klein se inicia com a verossimilhança completa, que é função dos tempos observados e das variáveis de fragilidade não observáveis. No passo E do algoritmo, a esperança dessa verossimilhança é calculada com relação aos dados observados e no passo M, uma verossimilhança parcial é construída utilizando as variáveis de fragilidade fixas e conhecidas, para estimação dos parâmetros associados às covariáveis. A verossimilhança parcial resultante, no caso do modelo de fragilidade Gama, é muito parecida com a obtida pela regressão de Cox padrão. Klein (1992) usou a caracterização de verossimilhança parcial dada em Johansen (1983) para estimar $\boldsymbol{\beta}$, enquanto que a estimação da função de risco acumulada (parâmetro nuisance) foi feita através do estimador de Nelson-Aalen. A diferença do método utilizado por Nielsen et al. (1992) e Andersen et al. (1993) é que eles fazem uma procura unidimensional da verossimilhança enquanto que Klein (1992) utiliza uma implementação completa do algoritmo EM.

Murphy (1994 e 1995) apresentou distribuições assintóticas para esses estimadores, além de mostrar a consistência dos estimadores das variâncias assintóticas. Estudos de simulação indicaram que esses estimadores são bem comportados em amostras finitas, porém, o estimador de $\theta$ (parâmetro de dependência) mostrou-se viciado. Provavelmente, isso ocorre devido ao fato do estimador da função de risco acumulada ser discreto. Murphy (1995) mostra resultados para o modelo de fragilidade Gama sem covariáveis e fornece indicações de como tratar o caso em que há covariáveis.

Recentemente, Therneau \& Grambsch (1998) sugeriram o uso da teoria de verossimilhança penalizada para fazer inferências sobre os parâmetros de interesse. Usando o algoritmo EM como Klein (1992), os autores mostraram que o modelo de fragilidade Gama pode ser escrito exatamente como uma regressão penalizada e sendo assim utilizaram a teoria de testes de hipóteses desenvolvida para esses modelos. 


\subsection{Algumas generalizações dos modelos de fragilidade}

Clayton (1991) introduziu o primeiro modelo bayesiano semiparamétrico usando o modelo de fragilidade Gama. Para modelar a função a priori de $\alpha_{0}(t)$, ele usou o processo de Levy e o método de Monte Carlo com Amostrador de Gibbs. Seu trabalho pode ser aplicado apenas para dados contínuos e uma extensão para dados censurados por intervalo não é imediata. Além disso, sua modelagem não permite empates. Sinha \& Dey (1997) apresentaram um histórico do que já existe na literatura e o que está sendo desenvolvido em termos de métodos bayesianos para os modelos de fragilidade. Recentemente, ainda no contexto bayesiano, Ducrocq \& Sölkner (1994 e 1998) elaboraram um programa chamado "The Survival Kit" para estimar o modelo de fragilidade usando a aproximação de Laplace para a densidade marginal a posteriori dos hiper parâmetros da distribuição da variável de fragilidade.

Alguns autores, entretanto, discutiram as desvantagens de se utilizar a distribuição Gama. Além daquela já apresentada (apenas um parâmetro para controlar a dependência e a heterogeneidade), a distribuição Gama também possui uma propriedade bem limitadora em termos de modelagem, de que a associação entre indivíduos de um mesmo grupo é constante ao longo do tempo. Se o objetivo for estudar grupos de irmãos, o modelo com distribuição Gama torna-se apropriado quando for razoável assumir que a associação entre irmãos, devido a fatores genéticos, não se altera com o tempo. Entretanto, existem situações em que outras distribuições são mais apropriadas. Por exemplo, se o interesse for estudar casais, é razoável supor que a associação entre pessoas casadas aumente conforme aumenta o tempo de convivência. Uma maneira de incorporar essa tendência no modelo é considerar uma outra distribuição para a variável de fragilidade que possua tal propriedade. Esses modelos encontram-se em estágio inicial de desenvolvimento. As associações crescentes podem ser modeladas através de distribuições como a normal inversa e a estável positiva ("positive stable") (Feller 1971).

Hougaard (1984) foi um dos primeiros autores a abordar o impacto do uso de diferentes distribuições para a variável de fragilidade. Nesse mesmo artigo, ele comentou sobre o 
uso da distribuição normal inversa. Outros autores que estudaram essa distribuição foram Klein, Moeschberger, Li \& Wang (1992). Já a distribuição estável positiva foi apresentada em Hougaard (1986a e 1986b) através de modelos semiparamétricos e paramétricos com distribuição Weibull para a função de risco. O modelo Weibull tem propriedades matemáticas interessantes, pois as distribuições marginais e o tempo até a primeira falha de um grupo também seguem a distribuição de Weibull. Por outro lado, a distribuição estável positiva tem a propriedade de que, além da função de risco condicional seguir o modelo de riscos proporcionais, a função marginal também o segue. Outro ponto apontado por Hougaard em vários artigos, como por exemplo em Hougaard (1991), foi o duplo papel da distribuição da variável de fragilidade com média finita em descrever algo além da dependência. Quando o interesse é modelar simultaneamente a dependência e a heterogeneidade deve-se tomar cuidado com o uso do modelo de fragilidade Gama já que ele só possui um único parâmetro, $\theta$, para representar ambas. Utilizando um resultado de Elbers \& Ridder (1982), Hougaard (1986a) sugere o uso da distribuição estável positiva para contornar esse problema. Uma aplicação dessa distribuição pode ser vista também em Wang, Klein \& Moeschberger (1995).

O uso da distribuição Gama também foi criticamente discutido por Yashin, Vaupel \& Iachine (1995) através de um conjunto de dados de gêmeos monózigotos e dizigotos. Nesse conjunto, foram feitas duas análises separadas, uma para cada tipo de gêmeo. O resultado encontrado foi um parâmetro de dependência $(\theta)$ maior e uma função de risco padrão com saltos maiores para gêmeos monozigotos do que para os dizigotos. Para considerar essas diferenças em um mesmo modelo, os autores sugeriram um "modelo de fragilidade correlacionado" onde a variável de fragilidade para o $j$-ésimo indivíduo do $i$-ésimo grupo é a soma de um termo específico para o par, $Z_{i 0}$, e um termo específico para o indivíduo, $Z_{i j}$, $i=1, \ldots, n$ e $j=1,2$, ambos com distribuição Gama independentes. O modelo para cada gêmeo é dado por:

$$
\begin{aligned}
& \lambda_{i 1}(t)=\left(Z_{i 0}+Z_{i 1}\right) Y_{i 1}(t) \alpha_{0 h}(t) \\
& \lambda_{i 2}(t)=\left(Z_{i 0}+Z_{i 2}\right) Y_{i 2}(t) \alpha_{0 h}(t)
\end{aligned}
$$

O modelo permite diferentes funções de risco padrão como, por exemplo, para gêmeos de sexos diferentes $(h=1,2)$. 
O modelo de fragilidade correlacionado foi um dos primeiros modelos de fragilidade mais complexos capaz de especificar tanto a natureza da heterogeneidade quanto a da dependência. Além disso, ele permite modelar dados em que os indivíduos apresentam vários graus de associação. Esse é o caso quando estudamos famílias contendo pais e filhos. É sabido que um casal compartilha vários tipos de exposições ambientais como hábitos alimentares, estilo de vida, poluição, níveis de radiação, entre outros que muitas vezes não podem ser observados e medidos. Da mesma forma, os filhos além de compartilharem tais exposições, também apresentam características genéticas semelhantes. Nesse caso, é razoável supor que os tempos de eventos entre irmãos sejam relacionados e que essa relação seja maior do que a encontrada entre seus pais. Em Petersen (1998), temos um bom exemplo para motivar o uso do modelo correlacionado para solucionar esse tipo de questão. Ele aborda um conjunto de dados onde o interesse principal é avaliar as influências genéticas e ambientais na morte prematura de adultos adotivos. Nesse estudo, foram analisados indivíduos que desde o nascimento foram afastados de seus pais biológicos e passaram a conviver com pais adotivos que não tinham nenhuma relação com eles (adoção extra-familiar). Ou seja, a semelhança dos filhos com os pais biológicos era devida apenas à herança genética enquanto que a semelhança com os pais adotivos era atribuída às características ambientais compartilhadas. Através do modelo de fragilidade correlacionado, foi possível avaliar tanto os componentes genéticos quanto os ambientais no desenvolvimento de algumas doenças. As funções de intensidade para a mãe adotiva, para o filho e para a mãe biológica, respectivamente, estão descritas a seguir, para $i=1, \ldots, n$,

$$
\begin{aligned}
& \lambda_{i 1}(t)=\left(Z_{i 1}+Z_{i 2}\right) Y_{i 1}(t) \alpha_{1}(t) \\
& \lambda_{i 2}(t)=\left(Z_{i 1}+Z_{i 3}+Z_{i 4}\right) Y_{i 2}(t) \alpha_{2}(t) \mathrm{e} \\
& \lambda_{i 3}(t)=\left(Z_{i 3}+Z_{i 5}\right) Y_{i 3}(t) \alpha_{3}(t)
\end{aligned}
$$

onde $Z_{i 1}$ representa as influências ambientais que o filho compartilha com a mãe adotiva, $Z_{i 3}$ as influências genéticas que o filho compartilha com a mãe biológica e as variáveis de fragilidade restantes $\left(Z_{i 2}, Z_{i 4}\right.$ e $\left.Z_{i 5}\right)$ são específicas para cada indivíduo.

A motivação desse modelo vem da divisão conceitual das variáveis de fragilidade em componentes genéticos e ambientais e a uma estrutura aditiva natural de acordo com a 
associação entre os tempos de evento devido a esses componentes.

A partir desse modelo, o autor chegou a conclusão de que a morte prematura de adultos devido a infeç̧ões como pneumonia, tuberculose e bronquite, tem uma forte relação com a carga genética enquanto que os componentes ambientais não tiveram uma influência significante.

Em seu artigo, Petersen também utiliza a distribuição Gama para as variáveis de fragilidade e salienta uma limitação do modelo de fragilidade correlacionado, que é a de impor uma associação positiva entre as observações. Ele destaca que devemos tomar cuidado quando as estimativas dos parâmetros de um modelo de fragilidade Gama estão na borda do espaço paramétrico, o que indicaria que existe uma associação negativa nos dados e que a distribuição Gama não deve ser empregada. Para esses casos, Genest \& Mackay (1986) estudaram a possibilidade de introduzir uma associação negativa e isso parece ser possível para um caso geral. Esse ainda é um assunto que está sendo investigado.

Li (1995) também tentou resolver essa limitação do modelo de fragilidade Gama de uma outra forma. Através de uma aproximação por Monte Carlo para o passo E do algoritmo EM, usado por Klein (1992) para estimar os parâmetros, Li calculou os estimadores sob um modelo de fragilidade multivariado bem mais complexo do que a distribuição Gama, mas que permite incorporar dois tipos de efeitos aleatórios: ambientais e genéticos. Seu algoritmo pode ser potencialmente aplicado a uma vasta variedade de modelos de fragilidade semiparamétricos.

Assim como Li (1995), Mack, Langholz \& Thomas (1990) também estudaram um modelo com dois tipos de fragilidade, um para fatores ambientais e outro para os genéticos. Entretanto, eles usaram a distribuição log-normal multivariada para as variáveis de fragilidade e definiram o modelo pela expressão:

$$
\lambda_{i j}\left(t \mid \mathbf{Z}_{A i}, \mathbf{Z}_{G i}, \mathbf{X}_{i j}\right)=Z_{A i j} Z_{G i j} Y_{i j}(t) \alpha_{0}(t) \exp \left(\boldsymbol{\beta}^{\prime} \mathbf{X}_{i j}\right)
$$

onde $\mathbf{Z}_{A i}$ e $\mathbf{Z}_{G i}$ são vetores das variáveis de fragilidade não observadas associados com a $i$-ésima família representando os fatores ambientais e genéticos respectivamente. 
McGilchrist \& Aisbett (1991) e McGilchrist (1993) também estudaram a distribuição log-normal em modelos de fragilidade semiparamétricos. McGilchrist (1993) apresentou um modelo com um vetor de variáveis de fragilidade com distribuição log-normal multivariada dado por:

$$
\lambda_{i j}\left(t \mid \mathrm{Z}_{i}, \mathbf{X}_{i j}\right)=Z_{i j} Y_{i j}(t) \alpha_{0}(t) \exp \left(\boldsymbol{\beta}^{\prime} \mathbf{X}_{i j}\right)
$$

onde $\mathrm{Z}_{i}=\left(Z_{i 1}, \ldots, Z_{i n_{i}}\right)^{\prime}$ é o vetor de variáveis de fragilidade não observadas associadas ao $i$-ésimo grupo. Esse modelo permite incorporar associações diferentes dentro de um mesmo grupo. Um exemplo é o caso do estudo de famílias contendo pares de irmãos que compartilham metade dos seus genes e primos que compartilham um quarto dos seus genes. McGilchrist \& Aisbett (1991) e McGilchrist (1993) fizeram uso do método de fatoração da verossimilhança usado por Gill (1992) para obter uma verossimilhança parcial integrada. Essa verossimilhança foi aproximada por técnicas descritas em Breslow \& Clayton (1993) e otimizada. Os estimadores resultantes são relativamente fáceis de calcular e parecem ter propriedades razoáveis em amostras finitas.

Ainda utilizando a distribuição log-normal, McGilchrist \& Yau (1994) descreveram um modelo de fragilidade dependente do tempo, enquanto que Paik et al. (1994) usaram a distribuição Gama em modelos desse tipo. Como dito no Capítulo 1, Chang \& Hsiung (1995) também propuseram modelos de riscos proporcionais com variáveis de fragilidade dependentes do tempo. Eles obtiveram um estimador eficiente para o parâmetro do risco relativo e mostraram que esse estimador é assintoticamente normal e eficiente.

Todos os modelos citados acima impõem algum tipo de estrutura de dependência que deve ser bem especificada, a fim de que os estimadores sejam válidos. Quando a estrutura de dependência não for o parâmetro de interesse, podemos modelar apenas as funções de risco marginais, evitando assim, erros na especificação dessa estrutura. 


\section{Capítulo 3}

\section{Modelo Semiparamétrico de Fragilidade Gama}

Nesse capítulo vamos abordar a teoria desenvolvida para o modelo de fragilidade Gama. A próxima seção contem em linhas gerais o modelo de regressão de Cox, para dados independentes, descrito em seu artigo de 1972. Na Seção 3.2 mostramos vários métodos de estimação para o modelo com dados dependentes que é o modelo de fragilidade propriamente dito.

\subsection{Dados Independentes}

O modelo de riscos proporcionais sugerido por Cox (1972) é uma maneira de se modelar a relação entre a função de risco de um indivíduo com covariáveis de interesse. Por ser um modelo de regressão ele também é conhecido como modelo de regressão de Cox. A razão de se incluir covariáveis no modelo pode estar no interesse em se comparar grupos ou estudar o efeito que essas covariáveis exercem sobre a função de risco. 
Vamos considerar uma amostra de $n$ indivíduos que são acompanhados no intervalo de tempo $[0, \tau]$, e observar $T_{1}, \ldots, T_{n}$, os tempos até a ocorrência de um determinado evento de interesse. Como já vimos no Capítulo $1,\left\{T_{l}, l=1, \ldots, n\right\}$ é uma sequência de variáveis aleatórias independentes não-negativas com função distribuição $F_{l}(\cdot)$ e função de risco definida por:

$$
\alpha_{l}\left(t \mid \mathbf{X}_{l}\right)=\lim _{\Delta t \rightarrow 0} \frac{1}{\Delta t} P\left(T_{l} \in[t, t+\Delta t) \mid T_{l} \geq t, \mathbf{X}_{l}\right)
$$

Existem modelos paramétricos encontrados por exemplo em Lawless (1982) que especificam a forma da função de risco padrão $\left(\alpha_{0}(t)\right)$. Entretanto, nesse trabalho serão considerados apenas os modelos semiparamétricos onde a forma da função de risco padrão $\alpha_{0}(t)$ é deixada totalmente arbitrária, apesar de assumirmos uma estrutura do tipo multiplicativa $\alpha_{l}\left(t \mid \mathbf{X}_{l}\right)=\alpha_{0}(t) g\left(\mathbf{X}_{l}\right)$.

Cox (1972) utilizou uma abordagem baseada em distribuições condicionais e na função de risco. Aqui vamos utilizar uma outra, que é baseada em processos de contagem pontuais através do modelo de intensidade multiplicativa e vamos estar sempre fazendo analogias com a metodologia de Cox. Apresentaremos uma abordagem intuitiva, sendo que os resultados mais formais podem ser encontrados em, por exemplo, Andersen et al. (1993).

Como explicado no Capítulo 2, vamos utilizar dois processos pontuais. O primeiro é o processo multivariado $\mathrm{N}(t)=\left\{N_{1}(t), \ldots, N_{n}(t)\right\}, t \geq 0$ contínuo à direita onde $N_{l}(t)$ foi definido em (2.1) sem o segundo índice $(j)$. E o outro processo é $Y_{l}(t)$, previsível, contínuo à esquerda e foi definido por (2.2). Esse último indica se o indivíduo está em risco no tempo $t$.

Quando observamos um intervalo de tempo bem pequeno $[t, t+d t)$ dada toda a história do processo até $t^{-}$, temos que a probabilidade de $N_{l}(t)$ saltar, ou seja, de se observar uma falha $\left(d N_{l}(t)=N_{l}(t)-N_{l}\left(t^{-}\right)=1\right)$, é igual a zero se uma falha ou censura já ocorreu antes de $t$ e nesse caso $Y_{l}(t)=0$, já que o indivíduo não está mais em risco nesse intervalo de tempo. Ou a probabilidade de $N_{l}(t)$ saltar é igual a $\alpha(t) d t$ se o indivíduo ainda estiver em 
risco no intervalo, o que significa que $Y_{l}(t)=1$. Podemos escrever então que

$$
P\left(d N_{l}(t)=1 \mid \mathcal{F}_{t^{-}}^{(l)}\right)=\alpha_{l}(t) Y_{l}(t) d t
$$

onde $\mathcal{F}_{t^{-}}^{(l)}$ representa toda a história do processo sobre o indivíduo $l$ até o instante $t^{-}$. Como o salto $d N_{l}(t)$ é uma variável que assume apenas os valores 0 ou 1 temos que,

$$
E\left(d N_{l}(t) \mid \mathcal{F}_{t^{-}}^{(l)}\right)=\alpha_{l}(t) Y_{l}(t) d t
$$

Podemos então introduzir o conceito de martingais que representam uma importante ferramenta dentro da abordagem de processos de contagem, já que toda a teoria desenvolvida para martingais pode ser aplicada para o modelo de intensidade multiplicativa. Dessa forma, para definir um martingal a partir de (3.1) temos que existe um único processo previsível $\Lambda_{l}$ tal que $N_{l}-\Lambda_{l}$ é um martingal. De maneira heurística temos que,

$$
E\left(d N_{l}(t) \mid \mathcal{F}_{t^{-}}^{(l)}\right)=E\left(d \Lambda_{l}(t) \mid \mathcal{F}_{t^{-}}^{(l)}\right)=d \Lambda_{l}(t)
$$

Podemos então considerar a partir de (3.1) e (3.2) que o processo de intensidade integrado, também chamado de compensador de $N_{l}(\cdot)$, é dado por:

$$
\Lambda_{l}(t)=\int_{0}^{t} \alpha_{l}(s) Y_{l}(s) d s=\int_{0}^{t} \lambda_{l}(s) d s .
$$

Se definirmos o martingal $M_{l}(t)$ como:

$$
M_{l}(t)=N_{l}(t)-\Lambda_{l}(t)
$$

isso nos leva a interpretar (3.4) como uma decomposição do processo de contagem $N_{l}(t)$, chamada Decomposição de Doob Meyer, em duas partes: o compensador $\Lambda_{l}(\cdot)$ e um processo de ruído, que é o martingal $M_{l}(t)$ de média zero, já que

$$
\begin{aligned}
d M_{l}(t) & =d N_{l}(t)-d \Lambda_{l}(t), \text { e assim } \\
E\left(d M_{l}(t) \mid \mathcal{F}_{t^{-}}^{(l)}\right) & =E\left(d N_{l}(t) \mid \mathcal{F}_{t^{-}}^{(l)}\right)-E\left(d \Lambda_{l}(t) \mid \mathcal{F}_{t^{-}}^{(l)}\right) \\
& =\alpha_{l}(t) Y_{l}(t) d t-\alpha_{l}(t) Y_{l}(t) d t \\
& =0
\end{aligned}
$$


Com isso, podemos usar os martingais para representar estimadores e estatísticas de teste e usar teoremas como, por exemplo, o Teorema do Limite Central de Rebolledo para martingais (Andersen et al. 1993), para derivar a teoria assintótica.

O modelo usual de Cox caracteriza-se pela modelagem da função de risco através da função:

$$
\alpha_{l}\left(t \mid \mathbf{X}_{l}\right)=\alpha_{0}(t) \exp \left(\boldsymbol{\beta}^{\prime} \mathbf{X}_{l}\right.
$$

onde

$\alpha_{0}$ é a função de risco padrão, arbitrária (taxa de risco condicional para $\mathrm{X}_{l}=0$ ),

$\boldsymbol{\beta}$ é o vetor de coeficientes de regressão desconhecidos de dimensão $p \times 1$,

$\mathrm{X}_{l}$ é o vetor de covariáveis para o indivíduo $l$ de dimensão $p \times 1$.

Esse modelo é denominado modelo de riscos proporcionais, pois, a razão entre as funções de riscos de dois indivíduos:

$$
\frac{\alpha_{l}(t \mid \mathbf{X})}{\alpha_{j}(t \mid \mathbf{X})}=\exp \left(\boldsymbol{\beta}^{\prime}\left[\mathbf{X}_{l}-\mathbf{X}_{j}\right]\right)
$$

não depende de $t$.

Através dos processos de contagem, modelamos o processo de intensidade de $N$. Nesse caso, temos que (3.5) pode ser reescrita por:

$$
\lambda_{l}(t \mid \mathbf{X})=Y_{l}(t) \alpha_{l}(t \mid \mathbf{X})=Y_{l}(t) \alpha_{0}(t) \exp \left(\boldsymbol{\beta}^{\prime} \mathbf{X}_{l},\right.
$$

onde:

$Y_{l}(t)$ é como definido em (2.2) sem o segundo índice e

$\mathrm{X}_{l}$ é o vetor de covariáveis para o indivíduo $l$ de dimensão $p \times 1$.

Andersen \& Gill (1982) construíram provas claras da consistência e normalidade assintótica dos estimadores usando a teoria de martingais, confirmando assim as justificativas heurísticas dadas por Cox (1972). 


\subsubsection{Estimação e Testes de hipóteses}

Os procedimentos de inferência usados para os modelos (3.5) e (3.6) são baseados em verossimilhanças parciais. Através de uma interpretação heurística da função de risco ou processo de intensidade condicionais construímos uma verossimilhança parcial. Usando as técnicas clássicas obtemos os estimadores e por suas representações martingais encontramos as distribuições assintóticas.

Usando (3.1) e (3.3) temos,

$$
P(\text { dados })=\prod_{0<l<\infty} \prod_{l}\left(\lambda_{l}(t) d t\right)^{d N_{l}(t)}(1-\lambda \cdot(t) d t)^{1-d N \cdot(t)}
$$

onde $\lambda .(t)=\sum_{l} \lambda_{l}(t)$ e $d N .(t)=\sum_{l} d N_{l}(t)$.

Podemos simplificar a expressão (3.7) usando as propriedades de produto integral (Andersen et al. 1993) e a aproximação $1-\lambda(t) d t \approx \exp (-\lambda(t) d t)$, de tal forma que,

$$
\pi_{0<t<\infty}(1-\lambda \cdot(t))^{1-d N \cdot(t)}=\exp \left(-\int_{0}^{\tau} \lambda \cdot(t) d t\right) .
$$

Com isso, a expressão (3.7) se transforma em

$$
L(\boldsymbol{\beta})=\prod_{t}\left\{\prod _ { l } ( \alpha _ { 0 } ( t ) Y _ { l } ( t ) \operatorname { e x p } ( \boldsymbol { \beta } ^ { \prime } \mathbf { X } _ { l } ) ^ { d N _ { l } ( t ) } \} \operatorname { e x p } \left(-\sum_{l=1}^{n} \int_{0}^{\tau} \alpha_{0}(u) Y_{l}(u) \exp \left(\boldsymbol{\beta}^{\prime} \mathbf{X}_{l} d u\right)\right.\right.
$$

Para um valor fixo de $\boldsymbol{\beta}$, a maximização de (3.8) com respeito a $d A_{0}(t)=\alpha_{0}(t)$ fornece (Andersen et al. 1993)

$$
d \widehat{A}_{0}(t, \boldsymbol{\beta})=\frac{d N .(t)}{\sum_{l=1}^{n} \exp \left(\widehat{\boldsymbol{\beta}}^{\prime} \mathbf{X}_{l}\right) Y_{l}(t)},
$$

ou seja, podemos estimar $A_{0}(t)$ pelo estimador de Nelson-Aalen sugerido por Aalen (1978) que é dado por:

$$
\widehat{A}_{0}(t)=\int_{0}^{t} \frac{J(s)}{\sum_{l=1}^{n} \exp \left(\widehat{\boldsymbol{\beta}}^{\prime} \mathbf{X}_{l}\right) Y_{l}(s)} d N \cdot(s)
$$

onde $J(s)=I(Y .(s)>0)$ e $Y .(s)=\sum_{l=1}^{n} Y_{l}(s)$. 
Definindo

$$
S(\boldsymbol{\beta}, t)=\sum_{l=1}^{n} \exp \left(\boldsymbol{\beta}^{\prime} \mathrm{X}_{l} Y_{l}(t)\right.
$$

e substituindo $\alpha_{0}(t)$ por (3.9) temos que (3.8) pode ser reescrita como

$$
\begin{aligned}
L(\boldsymbol{\beta}) & =\prod_{t}\left\{\prod_{l}\left(\frac{d N .(t)}{S(\boldsymbol{\beta}, t)} \exp \left(\boldsymbol{\beta}^{\prime} \mathbf{X}_{l}\right)^{d N_{l}(t)}\right\} \exp \left(-\int_{0}^{\tau} S(\boldsymbol{\beta}, u) \frac{d N .(u)}{S(\boldsymbol{\beta}, u)}\right)\right. \\
& =\prod_{t}\left\{d N \cdot(t)^{d N \cdot(t)} \prod_{l}\left(\frac{\exp \left(\boldsymbol{\beta}^{\prime} \mathbf{X}_{l}\right.}{S(\boldsymbol{\beta}, t)}\right)^{d N_{l}(t)}\right\} \exp (-d N \cdot(\tau)) \\
& =\left\{\prod_{t} \prod_{l}\left(\frac{\exp \left(\boldsymbol{\beta}^{\prime} \mathbf{X}_{l}\right.}{S(\boldsymbol{\beta}, t)}\right)^{d N_{l}(t)}\right\}\left\{\left(\prod_{t} d N .(t)^{d N \cdot(t)}\right) \exp (-d N .(\tau))\right\}
\end{aligned}
$$

Eliminando a parte que não depende de $\boldsymbol{\beta}$ e não é utilizada no processo de maximização, a verossimilhança parcial de Cox em termos de processos de contagem pode ser expressa como

$$
L(\boldsymbol{\beta})=\prod_{t} \prod_{l}\left(\frac{\exp \left(\boldsymbol{\beta}^{\prime} \mathrm{X}_{l} Y_{l}(t)\right.}{\sum_{l=1}^{n} \exp \left(\boldsymbol{\beta}^{\prime} \mathbf{X}_{l} Y_{l}(t)\right.}\right)^{d N_{l}(t)}
$$

já que se $Y_{l}(t)=0$ implica em $d N_{l}(t)=0$

A partir daí, podemos obter o estimador de $\beta$ maximizando (3.11). Isto é, através de processos iterativos temos que resolver a equação

$$
U(\beta)=0
$$

onde

$$
U(\boldsymbol{\beta})=\frac{\partial \log L(\boldsymbol{\beta})}{\partial \boldsymbol{\beta}}
$$

e obter $\widehat{\boldsymbol{\beta}}$. Além disso, temos que $\widehat{\boldsymbol{\beta}}$ tem distribuição assintótica dada por

$$
\widehat{\boldsymbol{\beta}} \sim N\left(\boldsymbol{\beta}, I^{-1}(\widehat{\boldsymbol{\beta}})\right)
$$

onde

$$
I(\boldsymbol{\beta})=-\frac{\partial^{2} \log L(\boldsymbol{\beta})}{\partial \boldsymbol{\beta} \partial \boldsymbol{\beta}^{\prime}}
$$

Uma vez obtida a estimativa $\widehat{\boldsymbol{\beta}}$ podemos testar hipóteses de interesse como

$$
\mathrm{H}_{0}: \boldsymbol{\beta}=\boldsymbol{\beta}_{0}
$$


usando estatísticas como a de Rao ou Escore, Wald e Razão da Verossimilhança definidas a seguir:

Estatística de Rao ou Escore:

$$
\mathrm{R}=U^{\prime}\left(\boldsymbol{\beta}_{0}\right) I^{-1}\left(\boldsymbol{\beta}_{0}\right) U\left(\boldsymbol{\beta}_{0}\right)
$$

Estatística de Wald:

$$
W=\left(\widehat{\boldsymbol{\beta}}-\boldsymbol{\beta}_{0}\right)^{\prime} I(\widehat{\boldsymbol{\beta}})\left(\widehat{\boldsymbol{\beta}}-\boldsymbol{\beta}_{0}\right)
$$

Estatística da Razão de Verossimilhança:

$$
\mathrm{RV}=2 \log \frac{L(\widehat{\boldsymbol{\beta}})}{L\left(\boldsymbol{\beta}_{0}\right)}=2\left(\log L(\widehat{\boldsymbol{\beta}})-\log L\left(\boldsymbol{\beta}_{0}\right)\right)
$$

As três estatísticas têm distribuição assintótica $\chi_{p}^{2}$ sob $\mathrm{H}_{0}$.

Utilizando as estimativas do vetor $\boldsymbol{\beta}$, podemos também estimar a função de sobrevivência através de uma relação entre a função de risco e a de sobrevivência

$$
\alpha_{l}(t)=\frac{f_{l}(t)}{S_{l}(t)}
$$

onde $f_{l}(t)$ é a função densidade de probabilidade de $T_{l}$ e $S_{l}(t)=1-F_{l}(t)$ é a função de sobrevivência de $T_{l}$. Dessa forma, podemos escrever $S_{l}(t)$ em função de $\alpha_{l}(t)$ da seguinte maneira

$$
S_{l}(t)=\exp \left(-\int_{0}^{t} \alpha_{l}(u) d u\right)
$$

A partir daí, podemos avaliar o efeito das covariáveis sobre a função de sobrevivência substituindo em (3.12) o modelo de Regressão de Cox dado por (3.5)

$$
\begin{aligned}
S_{l}(t \mid \mathbf{X}) & =\exp \left(-\int_{0}^{t} \alpha_{l}\left(u \mid \mathbf{X}_{l}\right) d u\right) \\
& =\exp \left(-\int_{0}^{t} \alpha_{0}(u) \exp \left(\boldsymbol{\beta}^{\prime} \mathbf{X}_{l} d u\right)\right.
\end{aligned}
$$




$$
\begin{aligned}
& =\exp \left(\exp \left(\boldsymbol{\beta}^{\prime} \mathbf{X}_{l} \log S_{0}(t)\right)\right. \\
& =\left\{e^{\log S_{0}(t)}\right\}^{\exp \left(\boldsymbol{\beta}^{\prime} \mathbf{x}_{l}\right.} \\
& =\left\{S_{0}(t)\right\}^{\exp \left(\boldsymbol{\beta}^{\prime} \mathbf{X}_{l}\right.}
\end{aligned}
$$

onde $S_{0}(t)=\exp \left(-A_{0}(t)\right)$ e $A_{0}(t)=\int_{0}^{t} \alpha_{l}(u) d u$ é a função de risco padrão acumulada. Com isso, através do estimador de Nelson-Aalen dado por (3.10) e de $\hat{\boldsymbol{\beta}}$, podemos obter uma estimativa da função de sobrevivência para o modelo de Regressão de Cox.

\subsection{Dados Dependentes}

\subsubsection{Definição do Modelo}

O modelo de fragilidade caracteriza-se pela introdução de um efeito aleatório no modelo de riscos proporcionais de Cox, descrito na seção anterior. Considere então, uma amostra de $n$ grupos de indivíduos que tenham alguma relação em comum. Além disso, considere também que cada grupo tenha um total de $n_{i}$ indivíduos. Reescrevendo (3.5) como a função de risco para o $j$-ésimo indivíduo do $i$-ésimo grupo temos: $\left(i=1, \ldots, n\right.$ e $\left.j=1, \ldots, n_{i}\right)$

$$
\alpha_{i j}\left(t \mid Z_{i}, \mathbf{X}_{i j}\right)=Z_{i} \alpha_{0}(t) \exp \left(\boldsymbol{\beta}^{\prime} \mathbf{X}_{i j}\right)
$$

ou em termos de processos de contagem:

$$
\lambda_{i j}\left(t \mid Z_{i}, \mathbf{X}_{i j}\right)=Y_{i j}(t) \alpha_{i j}\left(t \mid Z_{i}, \mathbf{X}_{i j}\right)=Y_{i j}(t) Z_{i} \alpha_{0}(t) \exp \left(\boldsymbol{\beta}^{\prime} \mathbf{X}_{i j}\right)
$$

onde

$\alpha_{0}(t)$ é a função de risco padrão desconhecida,

$\boldsymbol{\beta}$ é o vetor de coeficientes de regressão desconhecidos de dimensão $p \times 1$,

$\boldsymbol{X}_{i j}$ vetor de covariáveis para o indivíduo $j$ do grupo $i$, de dimensão $p \times 1$,

$Y_{i j}(t)$ é um processo previsível observável que indica se o indivíduo $j$ do grupo $i$ está em risco no tempo $t^{-} \mathrm{e}$

$Z_{i}$ é uma v.a. não negativa com distribuição conhecida de média 1 e variância qualquer. 
Lembre-se que os processos $\mathrm{N}$ e $\mathrm{Y}$ são dados por:

$$
N_{i j}(t)=\left\{\begin{array}{ll}
1 & \text { se } V_{i j} \leq t, \delta_{i j}=1 \\
0 & \text { c.c. }
\end{array} \text { e } Y_{i j}(t)= \begin{cases}1 & \text { se } V_{i j} \geq t \\
0 & \text { c.c. }\end{cases}\right.
$$

Apesar de existirem várias distribuições que podem ser usadas para descrever a variável de fragilidade $Z_{i}$, nesse trabalho vamos considerar a distribuição Gama, ou seja, para $i=$ $1, \ldots, n$ temos:

$$
Z_{i} \sim \operatorname{Gama}(\nu, \eta) \text { independentes } \operatorname{com} \nu \geq 0, \eta \geq 0 \text { e } \nu=\eta=\theta^{-1} .
$$

Dessa forma, $E\left(Z_{i}\right)=1$ e $\operatorname{Var}\left(Z_{i}\right)=\theta$.

O fato de considerarmos os parâmetros de locação e escala iguais $(\nu=\eta)$, é devido à identificabilidade do modelo, como foi comentado no primeiro capítulo. Vale ressaltar que, por simplicidade consideraremos que as covariáveis não variam com o tempo. O caso dependente do tempo é semelhante com complicações na notação.

\subsubsection{Estimação dos parâmetros}

Podemos identificar dois tipos de conjuntos de dados. O primeiro composto pelas variáveis aleatórias e processos $(\mathrm{Z}, \mathrm{N}, \mathrm{Y})$ que formam o conjunto de dados completos mas não observáveis (dada a presença da variável latente $\mathbf{Z}$ ) e o segundo, dado por $(\mathrm{N}, \mathrm{Y})$, que formam o conjunto de dados incompletos que são observáveis. Essa maneira de encarar os dados, sugere o uso do algoritmo EM (Dempster, Laird \& Rubin 1977) para estimação dos parâmetros. Ele é um processo iterativo para a obtenção de estimativas de Máxima Verossimilhança (MV), indicado para conjuntos com observações incompletas. No nosso caso as variáveis de fragilidade formam a parte não observável dos dados. Generalizando, seja $\mathrm{Y}$ o vetor contendo os dados observados, $\mathrm{Z}$ o vetor para os dados não-observáveis e $\beta$ o vetor de parâmetros a ser estimado. Para resolver o problema dos dados que não são observados, o algoritmo constrói a função de verossimilhança completa $L(\boldsymbol{\beta}, \mathrm{Z})$ como se os 
dados $\mathrm{Z}$ fossem observados. Ou seja, calcula essa verossimilhança condicionando em $\mathrm{Z}$ e multiplicando pela densidade de $\mathrm{Z}$ :

$$
L(\boldsymbol{\beta}, \mathbf{Z})=L(\boldsymbol{\beta} \mid \mathbf{Z}) f(\mathbf{Z})
$$

$\mathrm{O}$ passo $\mathrm{E}$ consiste em calcular a esperança dessa verossimilhança com relação a $\mathbf{Z}$, e no passo $\mathrm{M}$, é feita a maximização da expressão que foi obtida no passo $\mathrm{E}$. O algoritmo iterage até a diferença entre dois valores consecutivos do parâmetro $\beta$, ou seja, $\left\|\beta^{i+1}-\beta^{i}\right\|$, seja suficientemente pequena.

Esse tipo de tratamento para o processo de estimação, foi originalmente sugerido por Gill (1985) mas aqui vamos apresentar o procedimento desenvolvido por Nielsen et al. (1992). Para isso, considere primeiro, as seguintes suposições necessárias para a aplicação do algoritmo:

1. Condicional a $Z=z$, falha e censura são independentes;

2. Condicional a $Z=z$, a censura é não-informativa para $Z$.

Para iniciar o processo, considere, primeiro, a verossimilhança parcial condicional baseada em $\mathbf{N}$ dada por:

$$
L(\boldsymbol{\beta}, \theta \mid \mathrm{Z})=\prod_{0<t<\infty}\left(\left[\prod_{i} \prod_{j}\left(\lambda_{i j}\left(t \mid Z_{i}, \mathrm{X}_{i j}\right)\right)^{d N_{i j}(t)}\right](1-\lambda . .(t \mid \mathrm{Z}, \mathrm{X}) d t)^{1-d N . .(t)}\right)
$$

onde

$$
\begin{aligned}
& \lambda_{. .}=\sum_{i, j} \lambda_{i j}, \\
& d N_{. .}=\sum_{i, j} d N_{i j} \text { e } \\
& \lambda_{i j} \text { é dada por (3.14). }
\end{aligned}
$$

Usando novamente o fato: $\pi_{0<t<\infty}(1-\lambda(t) d t)=\exp \left(-\int_{0}^{\tau} \lambda(t) d t\right)$ (Andersen et al. 1993) temos que a expressão (3.15) fica:

$$
L(\boldsymbol{\beta}, \theta \mid \mathbf{Z})=\left[\prod_{t} \prod_{i} \prod_{j}\left(\lambda_{i j}\left(t \mid Z_{i}, \mathbf{X}_{i j}\right)\right)^{d N_{i j}(t)}\right] \exp \left(-\int_{0}^{\tau} \lambda . .(u \mid \mathrm{Z}, \mathbf{X}) d u\right)
$$




$$
\begin{aligned}
& =\left[\prod_{t} \prod_{i} \prod_{j}\left(\lambda_{i j}\left(t \mid Z_{i}, \mathrm{X}_{i j}\right)\right)^{d N_{i j}(t)}\right] \exp \left(-\sum_{i} \sum_{j} \int_{0}^{\tau} \lambda_{i j}\left(u \mid Z_{i}, \mathrm{X}_{i j}\right) d u\right) \\
& =\prod_{i} \prod_{j} \exp \left(-\int_{0}^{\tau} \lambda_{i j}\left(u \mid Z_{i}, \mathrm{X}_{i j}\right) d u\right) \prod_{t}\left(\lambda_{i j}\left(t \mid Z_{i}, \mathrm{X}_{i j}\right)\right)^{d N_{i j}(t)}
\end{aligned}
$$

Agora para obter a verossimilhança parcial conjunta temos que

$$
\begin{aligned}
& L(\boldsymbol{\beta}, \theta, \mathbf{Z})=L(\boldsymbol{\beta}, \theta \mid \mathbf{Z}) \prod_{i} f\left(Z_{i}, \theta\right) \\
& =L(\boldsymbol{\beta}, \theta \mid \mathbf{Z}) \prod_{i} \frac{Z_{i}^{\frac{1}{\theta}-1}\left(\frac{1}{\theta}\right)^{\frac{1}{\theta}} \exp \left(-Z_{i} \frac{1}{\theta}\right)}{\Gamma\left(\frac{1}{\theta}\right)} \\
& =\prod_{i}\left[Z_{i}^{\frac{1}{\theta}-1}\left(\frac{1}{\theta}\right)^{\frac{1}{\theta}} \exp \left(-Z_{i} \frac{1}{\theta}\right) \frac{1}{\Gamma\left(\frac{1}{\theta}\right)} \prod_{j} \exp \left(-\int_{0}^{\tau} Z_{i} Y_{i j}(u) \alpha_{0}(u) \exp \left(\boldsymbol{\beta}^{\prime} \mathbf{X}_{i j}\right) d u\right) \times\right. \\
& \left.\times \prod_{t}\left(Z_{i} Y_{i j}(t) \alpha_{0}(t) \exp \left(\boldsymbol{\beta}^{\prime} \mathbf{X}_{i j}\right)\right)^{d N_{i j}(t)}\right]
\end{aligned}
$$

A expressão (3.17) é a verossimilhança completa baseada em Z, N e Y. Se olharmos para essa verossimilhança apenas como função de $\mathrm{Z}$ vemos que:

$$
L(\boldsymbol{\beta}, \theta, \mathbf{Z}) \propto \prod_{i} Z_{i}^{\frac{1}{\theta}+N_{i}-1} \exp \left(-Z_{i}\left[\frac{1}{\theta}+\sum_{j} \int_{0}^{\tau} Y_{i j}(u) \alpha_{0}(u) \exp \left(\boldsymbol{\beta}^{\prime} \mathbf{X}_{i j}\right) d u\right]\right)
$$

onde $N_{i}=\sum_{j=1}^{n_{i}} N_{i j}(\tau)$ é o número de falhas no grupo $i$.

Em outras palavras, olhando como função de $\mathrm{Z}$, (3.17) corresponde à verossimilhança de uma distribuição Gama $\left(\frac{1}{\theta}+N_{i}, \frac{1}{\theta}+\Lambda_{i}(\boldsymbol{\beta})\right)$ onde:

$$
\begin{aligned}
\Lambda_{i}(\boldsymbol{\beta}) & =\int_{0}^{\tau} S_{i}^{(0)}(\boldsymbol{\beta}, u) \alpha_{0}(u) d u \\
S_{i}^{(0)}(\boldsymbol{\beta}, t) & =\sum_{j=1}^{n_{i}} Y_{i j}(t) \exp \left(\boldsymbol{\beta}^{\prime} \mathbf{X}_{i j}\right)
\end{aligned}
$$

Note que a expressão (3.18) equivale a um caso particular da expressão (3.3), avaliada em todo o intervalo $[0, \tau]$. Desta forma, utilizaremos a notação $\Lambda_{i}(\boldsymbol{\beta})$ para enfatizar a dependência com relação ao parâmetro $\boldsymbol{\beta}$. 
Assim, integrando (3.17) em relação a $Z$, obtemos a verossimilhança parcial marginal baseada nas observações N e Y. Gill (1992) mostra que, pela suposição 2, essa verossimilhança tem as mesmas propriedades das verossimilhanças parciais usuais, e assim podemos usá-la para a estimação e testes de hipóteses acerca dos parâmetros.

Efetuando-se os cálculos, temos:

$$
\begin{aligned}
L(\boldsymbol{\beta}, \theta)= & \int_{0}^{\infty} L(\boldsymbol{\beta}, \theta \mid \mathbf{Z}) \prod_{i} f\left(Z_{i} \mid \theta\right) d Z_{i} \\
= & \prod_{i}\left\{\frac{\left(\frac{1}{\theta}\right)^{\frac{1}{\theta}}}{\Gamma\left(\frac{1}{\theta}\right)}\left[\int_{0}^{\infty}\left(Z_{i}\right)^{\frac{1}{\theta}+N_{i}-1} \exp \left(-Z_{i}\left[\frac{1}{\theta}+\Lambda_{i}(\boldsymbol{\beta})\right]\right) d Z_{i}\right] \times\right. \\
& \left.\times \prod_{t} \prod_{j}\left[Y_{i j} \alpha_{0}(t) \exp \left(\boldsymbol{\beta}^{\prime} \mathbf{X}_{i j}\right)\right]^{d N_{i j}(t)}\right\} \\
= & \prod_{i} \frac{\left(\frac{1}{\theta}\right)^{\frac{1}{\theta}}}{\Gamma\left(\frac{1}{\theta}\right)} \frac{\Gamma\left(\frac{1}{\theta}+N_{i}\right)}{\left[\frac{1}{\theta}+\Lambda_{i}(\boldsymbol{\beta})\right]^{N_{i}+\frac{1}{\theta}}} \prod_{t} \prod_{j}\left[\alpha_{0}(t) Y_{i j}(t) \exp \left(\boldsymbol{\beta}^{\prime} \mathbf{X}_{i j}\right)\right]^{d N_{i j}(t)}
\end{aligned}
$$

Fixado o valor de $\theta$, calculamos no passo $\mathrm{E}$ as estimativas de $Z_{i}$ para serem usadas no passo $\mathrm{M}$ do algoritmo, já que as variáveis de fragilidade já foram eliminadas por integração. Dessa forma, o processo iterativo resume-se aos seguintes passos:

Passo E: Calcular $\hat{Z}_{i}=\frac{\frac{1}{\theta}+N_{i}}{\frac{1}{\theta}+\Lambda_{i}(\boldsymbol{\beta})}$, esperança de uma v.a. com distribuição

$\operatorname{Gama}\left(\frac{1}{\theta}+N_{i}, \frac{1}{\theta}+\Lambda_{i}(\boldsymbol{\beta})\right)$.

Passo M: Maximizar (3.19), obtida após o passo E, substituindo também o parâmetro nuisance $\alpha_{0}(t)=d A_{0}(t)$ pelo estimador de Nelson-Aalen modificado assumindo que $Z_{i}$ fosse igual a $\hat{Z}_{i}$,

$$
\hat{A}_{0}(t)=\int_{0}^{t} \frac{J(s)}{\sum_{i} \hat{Z}_{i} S_{i}^{0}(\boldsymbol{\beta}, s)} d N_{. .}(s)
$$

onde $J(s)=I\left(Y_{. .}(s)>0\right)$. 
Como valor inicial para o processo, consideramos $Z_{i}=1$, para todo $i=1, \ldots, n$, o que corresponde a ajustar um modelo de regressão de Cox para dados independentes, dado por (3.6). Com isso, teremos os valores iniciais do vetor $\beta$ dados pelas estimativas obtidas pelo modelo de Cox usual. O parâmetro $\theta$ pode receber qualquer valor maior que zero.

O algoritmo converge quando:

- $\Delta \log L(\boldsymbol{\beta}, \theta)=\log L\left(\boldsymbol{\beta}^{(k)}, \theta\right)-\log L\left(\boldsymbol{\beta}^{(k-1)}, \theta\right)<e_{1} \mathrm{e}$

- $\sum_{i} \Delta Z_{i}=\sum_{i}\left|Z_{i}^{(k)}-Z_{i}^{(k-1)}\right|<e_{2}$

onde $e_{1}$ e $e_{2}$ são constantes iguais a, por exemplo, $10^{-7}$.

Para obter as estimativas finais dos parâmetros, é necessário empregar o algoritmo EM para vários valores de $\theta$ e "plotar" a verossimilhança (3.19) como uma função de $\theta$. A partir daí, escolhemos numericamente ou graficamente o EMV $\hat{\theta}$ e calculamos o valor correspondente de $\hat{\boldsymbol{\beta}}$.

\subsubsection{Estimação sugerida por Klein (1992)}

Como já foi dito no segundo capítulo, Klein (1992) desenvolveu um outro processo de estimação utilizando a abordagem clássica que é bem semelhante ao de Nielsen et al. (1992). Nesse método, o algoritmo EM é aplicado diretamente na verossimilhança conjunta (3.17), que como já vimos, tem a forma de uma distribuição Gama. O processo consiste então em aplicar o log na verossimilhança (3.17):

$$
\begin{aligned}
\log L(\boldsymbol{\beta}, \theta, \mathbf{Z})= & \sum_{i}\left[\left(\frac{1}{\theta}-1\right) \log Z_{i}-\frac{1}{\theta} \log \theta-\frac{Z_{i}}{\theta}-\log \Gamma\left(\frac{1}{\theta}\right)+\right. \\
& +\sum_{j}\left[-\int_{0}^{\tau} Z_{i} Y i j(u) \alpha_{0}(u) \exp \left(\boldsymbol{\beta}^{\prime} \mathbf{X}_{i j}\right) d u+\right. \\
& \left.\left.+\sum_{t} d N_{i j}(t)\left\{\log Z_{i}+\log Y_{i j}(t)+\log \alpha_{0}(t)+\boldsymbol{\beta}^{\prime} \mathbf{X}_{i j}\right\}\right]\right]
\end{aligned}
$$


E depois dividí-la em duas partes: uma que só depende de $\theta$ e outra que depende de $\boldsymbol{\beta}$ e do parâmetro nuisance $\alpha_{0}$. Dessa forma, temos que $\log L(\boldsymbol{\beta}, \theta, \mathbf{Z})=L_{1}(\theta)+L_{2}\left(\boldsymbol{\beta}, \alpha_{0}\right)$ onde

$$
\begin{aligned}
L_{1}(\theta) & =-n\left(\frac{1}{\theta} \log \theta+\log \Gamma\left(\frac{1}{\theta}\right)\right)+\sum_{i}\left[\left(\frac{1}{\theta}-1+N_{i}\right) \log Z_{i}-\frac{Z_{i}}{\theta}\right] \\
L_{2}\left(\boldsymbol{\beta}, \alpha_{0}\right) & =\sum_{i}\left(-Z_{i} \Lambda_{i}(\boldsymbol{\beta})+\sum_{j} \sum_{t} d N_{i j}(t)\left[\boldsymbol{\beta}^{\prime} \mathbf{X}_{i j}+\log \alpha_{0}(t)\right]\right)
\end{aligned}
$$

com $N_{i}$ o número de falhas no grupo $i$ e $\Lambda_{i}(\boldsymbol{\beta})$ é dada por (3.18).

No passo E, a esperança dessa verossimilhança é calculada com respeito aos dados observados. Note que, nesse caso, temos que calcular também a esperança do log de uma distribuição Gama, já que em (3.21) aparece a função $\log \left(Z_{i}\right)$. Substituindo $E\left(Z_{i}\right)=A_{i} / C_{i}$ e $E\left(\log Z_{i}\right)=\psi\left(A_{i}\right)-\log \left(C_{i}\right) \operatorname{com}$

$$
A_{i}=\frac{1}{\theta}+N_{i} \quad \text { e } \quad C_{i}=\frac{1}{\theta}+\Lambda_{i}(\boldsymbol{\beta}),
$$

os parâmetros da distribuição Gama obtida pela verossimilhança (3.17) e $\psi(\cdot)$ a função digama, temos a expressão resultante após o passo $\mathrm{E}$ :

$$
\begin{aligned}
E\left(L_{1}(\theta)\right)= & \sum_{i}\left[\left(\frac{1}{\theta}-1+N_{i}\right)\left\{\psi\left(A_{i}\right)-\log \left(C_{i}\right)\right\}-\frac{A_{i}}{\theta C_{i}}\right]- \\
& -n\left(\frac{1}{\theta} \log \theta+\log \Gamma\left(\frac{1}{\theta}\right)\right) \\
E\left(L_{2}\left(\boldsymbol{\beta}, \alpha_{0}\right)\right)= & \sum_{i}\left(-\frac{A_{i}}{C_{i}} \Lambda_{i}(\boldsymbol{\beta})+\sum_{j} \sum_{t} d N_{i j}(t)\left[\boldsymbol{\beta}^{\prime} \mathbf{X}_{i j}+\log \alpha_{0}(t)\right]\right)
\end{aligned}
$$

$\mathrm{O}$ passo $\mathrm{M}$ consiste em maximizar as expressões acima com respeito aos parâmetros $\beta$ e $\theta$. Nesse passo, o parâmetro nuisance da função de risco padrão acumulada é obtido pelo estimador de Nelson-Aalen modificado, da mesma forma que no método sugerido por Nielsen et al. (1992), dado pela expressão (3.20).

Em resumo, o processo iterativo descrito por Klein (1992) tem os seguintes passos:

Passo 1: Estimativas iniciais de $\beta$ e $\alpha_{0}$ obtidas do ajuste de uma regressão de Cox padrão e um valor qualquer para $\theta$; 
Passo 2: (Passo E) Calcular $A_{i}$ e $C_{i}, i=1, \ldots, n$, dados por (3.22) baseado nos valores atuais dos parâmetros;

Passo 3: (Passo M) Atualizar as estimativas de $\beta$ e consequentemente de $\alpha_{0}$ usando a expressão (3.24) e o valor de $\theta$ usando (3.23);

Passo 4: Iterar os passos 2 e 3 até atingir a convergência.

A principal diferença dessa metodologia e a utilizada por Nielsen et al. (1992) é que Klein usa uma implementação completa do algoritmo EM, enquanto que, Nielsen et al. (1992) usam uma procura unidimensional para estimação dos parâmetros. Como consequência. o algoritmo de Klein demora mais para atingir a convergência.

Uma outra contribuição importante dada por Klein (1992) foi com relação ao risco relativo. É importante ressaltar que, quando $\theta \neq 0$, o vetor $\beta$ é interpretado diferentemente do caso para dados independentes. A interpretação só é a mesma se estivermos comparando dois indivíduos de um mesmo grupo, ou seja, dois indivíduos com variáveis de fragilidade iguais. Agora, se comparamos dois indivíduos com os mesmos valores das covariáveis mas que estão em grupos diferentes, o risco relativo de falhar não é mais igual a 1, e sim, igual a razão entre as variáveis de fragilidade não-observadas. Klein (1992) sugere um ajuste baseado na comparação das taxas de risco marginais incondicionais desses indivíduos para calcular a função de risco de dois indivíduos de grupos diferentes e com diferentes valores para as covariáveis.

Para isso, vamos obter a função de sobrevivência conjunta dos $n_{i}$ indivíduos do $i$-ésimo grupo:

$$
\begin{aligned}
& S\left(v_{i j}, j=1 \ldots, n_{i}\right)=P\left(V_{i j}>v_{i j}, j=1 \ldots, n_{i} \mid \mathbf{X}_{i j}, j=1 \ldots, n_{i}\right) \\
& =E\left[P\left(V_{i j}>v_{i j}, j=1 \ldots, n_{i} \mid \mathbf{X}_{i j}, Z_{i}, j=1 \ldots, n_{i}\right)\right] \\
& =\int_{0}^{\infty} P\left(V_{i j}>v_{i j}, j=1 \ldots, n_{i} \mid \mathbf{X}_{i j}, Z_{i}, j=1 \ldots, n_{i}\right) f\left(Z_{i}\right) d Z_{i} \\
& =\int_{0}^{\infty} \prod_{j=1}^{n_{i}} P\left(V_{i j}>v_{i j} \mid \mathbf{X}_{i j}, Z_{i}\right) f\left(Z_{i}\right) d Z_{i}
\end{aligned}
$$




$$
\begin{aligned}
& =\int_{0}^{\infty} \prod_{j=1}^{n_{i}} \exp \left(-\int_{0}^{v_{i j}} \lambda\left(u \mid \mathbf{X}_{i j}, Z_{i}\right) d u\right) f\left(Z_{i}\right) d Z_{i} \\
& =\int_{0}^{\infty} \prod_{j=1}^{n_{i}} \exp \left(-\int_{0}^{v_{i j}} Z_{i} Y_{i j}(u) \alpha_{0}(u) \exp \left(\boldsymbol{\beta}^{\prime} \mathbf{X}_{i j}\right) d u\right) f\left(Z_{i}\right) d Z_{i} \\
& =\int_{0}^{\infty} \prod_{j=1}^{n_{i}} \exp \left(-Z_{i} \Lambda_{0}\left(v_{i j}\right) \exp \left(\boldsymbol{\beta}^{\prime} \mathbf{X}_{i j}\right) d(u) \frac{Z_{i}^{\frac{1}{\theta}-1}\left(\frac{1}{\theta}\right)^{\frac{1}{\theta}} \exp \left(-Z_{i} \frac{1}{\theta}\right)}{\Gamma\left(\frac{1}{\theta}\right)} d Z_{i}\right. \\
& =\left(1+\theta \sum_{j=1}^{n_{i}} \Lambda_{0}\left(v_{i j}\right) \exp \left(\boldsymbol{\beta}^{\prime} \mathbf{X}_{i j}\right)\right)^{-\frac{1}{\theta}}
\end{aligned}
$$

Com isso, a função de sobrevivência no tempo $t$ do $j$-ésimo indivíduo do grupo $i$ é dada por:

$$
\left.S_{i j}(t)=P\left(V_{i j}>t\right) \mid \mathbf{X}_{i j}\right)=\left(1+\theta \Lambda_{0}(t) \exp \left(\beta^{\prime} \mathbf{X}_{i j}\right)\right)^{-\frac{1}{\theta}}
$$

Substituindo (3.25) na relação $S(t)=\exp \left(-\int_{0}^{t} \alpha(u) d u\right)$ temos que a função de risco incondicional no tempo $t$ do $j$-ésimo indivíduo do grupo $i$ é dada por:

$$
\alpha_{i j}(t)=\frac{\alpha_{0}(t) \exp \left(\boldsymbol{\beta}^{\prime} \mathbf{X}_{i j}\right)}{1+\theta \Lambda_{0}(t) \exp \left(\boldsymbol{\beta}^{\prime} \mathbf{X}_{i j}\right)}
$$

Ou seja, o risco de um indivíduo com vetor de covariáveis $\mathrm{X}_{1}$ falhar, quando relativo ao risco de um indivíduo de um outro grupo com vetor $\mathrm{X}_{2}$ falhar, é dado por:

$$
R(t)=\exp \left(\boldsymbol{\beta}^{\prime}\left[\mathbf{X}_{1}-\mathbf{X}_{2}\right]\right) \frac{\left(1+\theta \hat{\Lambda}_{0}(t) \exp \left(\boldsymbol{\beta}^{\prime} \mathbf{X}_{2}\right)\right)}{\left(1+\theta \hat{\Lambda}_{0}(t) \exp \left(\boldsymbol{\beta}^{\prime} \mathbf{X}_{1}\right)\right)}
$$

Note que agora o risco relativo é uma função que depende do tempo diferentemente do caso da regressão de Cox para dados independentes. Logo, para visualizar o comportamento é uma boa idéia construir gráficos e ver como o risco relativo se comporta no decorrer do tempo.

Estudando um pouco melhor o comportamento da função do risco relativo, observamos 
que ela tende a 1 quando $t \rightarrow \infty$, já que:

$$
\begin{aligned}
\lim _{t \rightarrow \infty} R(t) & =\lim _{t \rightarrow \infty} \exp \left(\boldsymbol{\beta}^{\prime}\left[\mathbf{X}_{1}-\mathbf{X}_{2}\right]\right)\left(\frac{1}{1+\theta \hat{\Lambda}_{0}(t) \exp \left(\boldsymbol{\beta}^{\prime} \mathbf{X}_{1}\right)}+\frac{\theta \hat{\Lambda}_{0}(t) \exp \left(\boldsymbol{\beta}^{\prime} \mathbf{X}_{2}\right)}{1+\theta \hat{\Lambda}_{0}(t) \exp \left(\boldsymbol{\beta}^{\prime} \mathbf{X}_{1}\right)}\right) \\
& =\lim _{t \rightarrow \infty} \exp \left(\boldsymbol{\beta}^{\prime}\left[\mathbf{X}_{1}-\mathbf{X}_{2}\right]\right)\left(\frac{1}{1+\theta \hat{\Lambda}_{0}(t) \exp \left(\boldsymbol{\beta}^{\prime} \mathbf{X}_{1}\right)}+\frac{\exp \left(\boldsymbol{\beta}^{\prime} \mathbf{X}_{2}\right)}{\frac{1}{\theta \hat{\Lambda}_{0}(t)}+\exp \left(\boldsymbol{\beta}^{\prime} \mathbf{X}_{1}\right)}\right) \\
& =\exp \left(\boldsymbol{\beta}^{\prime}\left[\mathbf{X}_{1}-\mathbf{X}_{2}\right]\right) \frac{1}{\exp \left(\boldsymbol{\beta}^{\prime}\left[\mathbf{X}_{1}-\mathbf{X}_{2}\right]\right)} \\
& =1
\end{aligned}
$$

independentemente de quais sejam os valores dos vetores das covariáveis. Além disso, conforme aumenta $\theta$ (parâmetro de dependência) mais rápido a função converge para 1. Esse comportamento pode ser verificado nos gráficos mostrados no Capítulo 4, relativos ao conjunto de dados do Exemplo 3.

\subsubsection{Proposta de um novo método de estimação}

Baseado em uma sugestão do artigo de Andersen et al. (1997) apresentamos um novo método de estimação. Eles sugerem substituir, na verossimilhança (3.19), a função de risco padrão acumulada reescrita como uma função escada do tipo:

$$
A_{0}(t)=\sum_{l: T_{l} \leq t} \alpha_{l}, l=1, \ldots, m
$$

onde $m$ é o número de tempos de falha distintos e $T_{l}, l=1, \ldots, m$ são os tempos de falha distintos ordenados. Se não há empates $m=\sum_{i} \sum_{j} N_{i j}(\tau)$, ou seja, $m$ é o número de falhas total.

Com isso, a função $\Lambda_{i}(\boldsymbol{\beta})$ também deve ser alterada pela expressão:

$$
\Lambda_{i}(\boldsymbol{\beta}, \boldsymbol{\alpha})=\sum_{l=1}^{m} S_{i}^{0}\left(\boldsymbol{\beta}, T_{l}\right) \alpha_{l}
$$

Observe agora que, o nosso vetor de parâmetros não conta apenas com $\beta$ e $\theta$, mas 
também com os parâmetros $\alpha$. Logo, no total temos $(m+p+1)$ parâmetros:

$$
\Phi=(\boldsymbol{\alpha}, \boldsymbol{\beta}, \theta)=\left(\alpha_{1}, \ldots, \alpha_{m}, \beta_{1}, \ldots, \beta_{p}, \theta\right)
$$

Substituindo as informações acima no $\log$ da verossimilhança (3.19) e aplicando a aproximação $\log \left\{\Gamma\left(N_{i}+1 / \theta\right) / \Gamma(1 / \theta)\right\} \approx \sum_{r=0}^{N_{i}-1} \log (r+1 / \theta)$, temos:

$$
\begin{aligned}
\log L(\Phi)= & \sum_{i=1}^{n}\left\{\sum_{r=0}^{N_{i}-1} \log \left(r+\frac{1}{\theta}\right)-\frac{1}{\theta} \log \theta-\left(N_{i}+\frac{1}{\theta}\right) \log \left(\frac{1}{\theta}+\Lambda_{i}(\boldsymbol{\beta}, \boldsymbol{\alpha})\right)+\right. \\
& \left.+\sum_{j=1}^{n_{i}} \sum_{l=1}^{m} d N_{i j}\left(T_{l}\right) \boldsymbol{\beta}^{\prime} \mathrm{X}_{i j}\right\}+\sum_{l=1}^{m} m_{l} \log \alpha_{l}
\end{aligned}
$$

onde $m_{l}=\sum_{i=1}^{n} \sum_{j=1}^{n_{i}} d N_{i j}\left(T_{l}\right)$ é o número de falhas em $T_{l}$.

Esse método consiste então em aplicar o processo iterativo de Newton Raphson diretamente na verossimilhança (3.28) para obtenção das estimativas dos parâmetros $\boldsymbol{\alpha}, \boldsymbol{\beta}$ e $\theta$. Ou seja, ao invés de usar o algoritmo EM, vamos resolver a equação:

$$
\Phi^{(k-1)}=\Phi^{(k)}-\left[\frac{\partial^{2} \log L\left(\Phi^{(k)}\right)}{\partial \Phi^{(k)} \partial \Phi^{(k) \prime}}\right]^{-1} \frac{\partial \log L\left(\Phi^{(k)}\right)}{\partial \Phi^{(k)}}
$$

onde $\Phi=(\boldsymbol{\alpha}, \boldsymbol{\beta}, \theta)=\left(\alpha_{1}, \ldots, \alpha_{m}, \beta_{1}, \ldots, \beta_{p}, \theta\right)$ e $\log L(\Phi)$ é dado por (3.28).

A convergência é atingida quando $\left|\Phi^{(k)}-\Phi^{(k-1)}\right|<10^{-7}$.

Observe que, nesse processo a função de risco não é mais um parâmetro nuisance, e sim um parâmetro que também é estimado durante o processo iterativo. Isso implica mais parâmetros a serem estimados, o que prejudica a estabilidade do processo. Como cada parâmetro $\alpha$ corresponde a um tempo de falha, temos que, quanto mais tempos de falhas distintos na amostra, mais parâmetros a serem estimados e mais instabilidade no processo de estimação. Essa é uma das grandes desvantagens desse método em relação ao sugerido por Nielsen et al. (1992).

Na primeira iteração, os chutes iniciais usados para os vetores $\beta$ e $\alpha$ são as estimativas finais obtidas pelo modelo de Cox para dados independentes. Já o parâmetro $\theta$ pode receber qualquer valor maior que zero, como no caso anterior. 
Para aplicar essa metodologia, foi elaborado um programa utilizando o software NTIA, desenvolvido pela Embrapa (versão 4.2.1). Os detalhes estão descritos no próximo capítulo.

\subsubsection{Estimação da variância}

A estimação da variância foi sugerida por Andersen et al. (1997) e obtidas através da inversa da matriz de informação observada, baseada em (3.28) e dada por:

$$
I(\Phi)=-\frac{\partial^{2} \log L(\Phi)}{\partial \Phi \partial \Phi^{\prime}}
$$

As expressões dessas derivadas estão apresentadas no Apêndice A.

\subsubsection{Testes de Hipóteses}

Observe que nos modelos (3.13) e (3.14), se $\nu \rightarrow \infty$ ou se $\theta \rightarrow 0$ (variância da variável de fragilidade) ficamos com um modelo onde todos os $Z_{i}$ 's são iguais a 1 , o que corresponde ao modelo de regressão de Cox usual para dados independentes. Esse é um submodelo que temos interesse em testar. Entretanto, como nessa situação estamos trabalhando com um valor para o parâmetro que está na borda do espaço paramétrico, o uso de testes da razão de verossimilhança generalizados ou escore podem ser criticados. Mas se parametrizamos por $\theta=1 / \eta$, o valor $\theta=0$ torna-se um valor permitido e mais ainda, valores de $\theta$ negativos próximos de zero também são válidos. O que não podemos fazer é estender a distribuição conjunta de $\mathbf{Z}, \mathbf{N}$ e $\mathbf{Y}$ para permitir valores negativos de $\theta$, pois assim, não existiria uma interpretação para a fragilidade (Oakes 1989). Podemos sim, estender a distribuição marginal de $\mathrm{N}$ e $\mathrm{Y}$, de tal forma que o teste escore baseado na teoria assintótica usual para a hipótese $\theta=0(\eta=\infty)$ seja válido, o mesmo ocorrendo para os testes bicaudais e unicaudais da razão de verossimilhança generalizados.

Como comentado no Capítulo 2, Murphy (1995) apresentou as distribuições assintóticas no contexto do modelo de fragilidade Gama sem covariáveis, além de mostrar a consistência 
dos estimadores das variâncias assintóticas. Ela também forneceu indicações de como tratar o cașo em que há covariáveis.

Do ponto de vista prático, o nosso primeiro interesse é testar se existe dependência entre as observações, ou seja, se devemos usar o modelo de fragilidade ou o modelo de regressão de Cox usual para dados indepedentes. Isso é feito através do teste $H_{0}: \theta=0$. As três estatísticas, usualmente consideradas em Análise de Sobrevivência para testar essa hipótese:

a) Estatística de Wald:

$$
W_{\theta}=\left(\hat{\theta}-\hat{\theta_{0}}\right)^{\prime} I(\hat{\theta})\left(\hat{\theta}-\hat{\theta_{0}}\right)
$$

onde $I(\hat{\theta})$ é a matriz de informação observada e as expressões de seus componentes estão descritas no Apêndice A. Sob $H_{0}$ e para $\hat{\theta}$ de dimensão $1, W_{\theta}$ pode ser escrita como $W_{\theta}=$ $\hat{\theta}^{2} / \hat{\operatorname{Var}}(\hat{\theta})$.

b) Estatística da Razão de Verossimilhanças:

$$
R V_{\theta}=2 \log \frac{L(\hat{\boldsymbol{\alpha}}, \hat{\boldsymbol{\beta}}, \hat{\theta})}{L^{*}\left(\hat{\boldsymbol{\alpha}}^{*}, \hat{\boldsymbol{\beta}}^{*}\right)}=2\left(\log L(\hat{\boldsymbol{\alpha}}, \hat{\boldsymbol{\beta}}, \hat{\theta})-\log L^{*}\left(\hat{\boldsymbol{\alpha}}^{*}, \hat{\boldsymbol{\beta}}^{*}\right)\right)
$$

onde,

$\log L(\hat{\boldsymbol{\alpha}}, \hat{\boldsymbol{\beta}}, \hat{\theta})$ é dado por (3.28) com $\hat{\boldsymbol{\alpha}}, \hat{\boldsymbol{\beta}}$ e $\hat{\theta}$ as estimativas do modelo de fragilidade (3.14)

$\log L^{*}\left(\hat{\boldsymbol{\alpha}}^{*}, \hat{\boldsymbol{\beta}}^{*}\right)$ é obtido através do mesmo modelo (3.14) só que considerando que todos os $Z_{i}$ 's, $i=1, \ldots, n$ são iguais a 1 , ou seja,

$$
\begin{aligned}
\log L^{*}\left(\boldsymbol{\alpha}^{*}, \boldsymbol{\beta}^{*}\right)= & \sum_{i=1}^{n} \sum_{j=1}^{n_{i}}\left(-\int_{0}^{\tau} Y_{i j}(u) \alpha_{0}^{*}(u) \exp \left(\boldsymbol{\beta}^{* \prime} \mathbf{X}_{i j}\right) d u+\right. \\
& \left.+\sum_{t} d N_{i j}(t)\left[\log \left(Y_{i j}(t) \alpha_{0}^{*}(t)\right)+\boldsymbol{\beta}^{* \prime} \mathbf{X}_{i j}\right]\right)
\end{aligned}
$$

Note, que temos que recalcular a verossimilhança sob $H_{0}$ e estimar os novos parâmetros $\hat{\boldsymbol{\alpha}}^{*}, \hat{\boldsymbol{\beta}}^{*}$, já que a verossimilhança (3.28) não pode ser calculada no ponto $\theta=0$. Vamos apresentar os cálculos da verossimilhança (3.29) para o novo método de estimação, mas eles também podem ser feitos para a abordagem de Nielsen ou a de Klein. 
Substituindo $A_{0}^{*}(t)=\sum_{l: T_{l} \leq t} \alpha_{l}^{*}, l=1, \ldots, m$ onde $m$ é o número de tempos de falha distintos e $T_{l}$ são os tempos de falha distintos ordenados em (3.29) temos:

$$
\begin{aligned}
\log L^{*}\left(\boldsymbol{\alpha}^{*}, \boldsymbol{\beta}^{*}\right)= & \sum_{i=1}^{n}\left(-\Lambda_{i}\left(\boldsymbol{\beta}^{*}, \boldsymbol{\alpha}^{*}\right)+\sum_{l=1}^{m} \sum_{j=1}^{n_{i}} d N_{i j}\left(T_{l}\right) \boldsymbol{\beta}^{* \prime} \mathbf{X}_{i j}\right)+ \\
& +\sum_{l=1}^{m} m_{l} \log \alpha_{l}^{*}
\end{aligned}
$$

onde $\Lambda_{i}(\boldsymbol{\beta}, \boldsymbol{\alpha})$ é dada em (3.27) e $m_{l}$ é o número de falhas no tempo $T_{l}$.

A estimação dos parâmetros sob $H_{0}$ é feita aplicando-se o processo de Newton-Raphson na verossimilhança (3.30) e usando como valores iniciais os resultados da regressão usual de Cox. Com isso, obtemos as estimativas finais $\hat{\boldsymbol{\beta}}^{*}$ e $\hat{\boldsymbol{\alpha}}^{*}$ necessárias para o cálculo do valor da estatística $R V_{\theta}$.

c) Estatística de Escore:

Commenges \& Andersen (1995) derivaram a estatística de Escore a partir da verossimilhança parcial marginal como proposto por Prentice \& Self (1985). A grande vantagem é que ela é válida para qualquer distribuição da variável de fragilidade, não apenas para a distribuição Gama, já que é calculada sob a hipótese nula (independência). Os autores sugerem aplicar a estatística de Escore para verificar se $\theta=0$. Se o resultado for significativo quantifica-se os parâmetros estimando-os por um modelo de fragilidade Gama, por exemplo.

O teste foi desenvolvido através do modelo de fragilidade descrito da seguinte forma

$$
\lambda_{i j}\left(t \mid w_{i}, \mathbf{X}_{i j}(t)\right)=Y_{i j}(t) \alpha_{0}(t) \exp \left(\sigma w_{i}+\boldsymbol{\beta}^{\prime} \mathbf{X}_{i j}\right)
$$

para $i=1, \ldots, n$ e $j=1, \ldots, n_{i}$ onde $w_{i}$ 's são as variáveis de fragilidade supostas independentes com distribuição qualquer de média 0 e variância 1.

Note que, quando $\sigma=0$, o modelo se reduz ao modelo de regressão de Cox para dados independentes. Além disso, o modelo (3.31) é equivalente ao modelo (3.14) e, consequentemente, testar que $\sigma=0$ é o mesmo que testar que $\theta=0$, que é a nossa hipótese de interesse. 
Para dar uma idéia de como Commenges \& Andersen (1995) obtiveram a expressão da estatística, considere a verossimilhança parcial de Cox para estimar $\beta$ e $\sigma$ denotando-a por Q.

$$
\log Q(\sigma)=\int_{0}^{\infty} \sum_{i=1}^{n} \sum_{j=1}^{n_{i}} \log \frac{\exp \left(\sigma w_{i}+\boldsymbol{\beta}^{\prime} \mathrm{X}_{i j}\right)}{\sum_{h=1}^{n} \sum_{k=1}^{n_{h}} Y_{h k}(s) \exp \left(\sigma w_{h}+\boldsymbol{\beta}^{\prime} \mathrm{X}_{h k}\right)} d N_{i j}(s)
$$

Entretanto, não conhecemos os valores dos $w_{i}$ 's, o que nos leva a usar a verossimilhança parcial marginal $L(\sigma)=E_{w}(Q(\sigma))$ no lugar de $Q$. Além disso, como

$$
\left.\frac{\partial \log L(\sigma)}{\partial \sigma}\right|_{\sigma=0}=0 \text {. }
$$

Prentice \& Self (1985) mostraram que o teste escore para a hipótese $\sigma^{2}=0$ é baseado na igualdade

$$
\lim _{\sigma \rightarrow 0} \frac{\partial \log L(\sigma)}{\partial \sigma^{2}}=\frac{1}{2} \lim _{\sigma \rightarrow 0} \frac{\partial^{2} \log L(\sigma)}{\partial \sigma^{2}}
$$

Assim, se omitirmos na expressão acima a constante $1 / 2$ e usarmos a relação (3.33) temos que

$$
\left.\frac{\partial^{2} \log L(\sigma)}{\partial \sigma^{2}}\right|_{\sigma=0}=\left.\frac{1}{L(0)} \frac{\partial^{2} L(\sigma)}{\partial \sigma^{2}}\right|_{\sigma=0}
$$

e como $Q(0)=L(0)$ implica que a estatística escore é dada por:

$$
T=\left.\frac{\partial^{2} \log L(\sigma)}{\partial \sigma^{2}}\right|_{\sigma=0}=E_{w}\left(\left.\frac{\partial \log Q(\sigma)}{\partial \sigma}\right|_{\sigma=0}\right)^{2}+E_{w}\left(\left.\frac{\partial^{2} \log Q(\sigma)}{\partial \sigma^{2}}\right|_{\sigma=0}\right) .
$$

Substituindo (3.32) na expressão acima e usando o estimador de Nelson-Aalen para a função de risco padrão acumulada e lembrando que $w_{i}$ tem média 0 e variância 1 , a estatística $T$ fica:

$$
T=\sum_{i=1}^{n}\left(\sum_{j=1}^{n_{i}} M_{i j}\right)^{2}-D+C
$$

onde

$D=\sum_{l=1}^{m} m_{l}$ é o número total de mortes,

$M_{i j}=\delta_{i j}-\hat{A}_{0}\left(T_{i j}\right) \exp \left(\hat{\boldsymbol{\beta}}^{\prime} \mathrm{X}_{i j}\right)$ é o resíduo martingal para o $j$-ésimo indivíduo do $i$ ésimo grupo com $\hat{A}_{0}(t)$ e $\hat{\beta}$ obtidos do ajuste do modelo de Regressão de Cox para dados 
independentes, e

$$
C=\sum_{i=1}^{n} \sum_{j=1}^{n_{i}} \frac{\delta_{i j}}{S^{(0)}\left(T_{i j}\right)^{2}} \sum_{h=1}^{n}\left(\sum_{k=1}^{n_{h}} Y_{h k}\left(T_{i j}\right) \exp \left(\hat{\boldsymbol{\beta}}^{\prime} \mathrm{X}_{h k}\right)\right)^{2}
$$

$\operatorname{com} S^{(0)}(t)=\sum_{i=1}^{n} S_{i}^{(0)}(\hat{\boldsymbol{\beta}}, t)=\sum_{j=1}^{n_{i}} Y_{i j}(t) \exp \left(\hat{\boldsymbol{\beta}}^{\prime} \mathbf{X}_{i j}\right)$.

Para estimar a variância de $T$ Commenges \& Andersen (1995) usaram um teorema apresentado em Commenges \& Andersen (1993) e argumentos de processos de contagem, concluindo que

$$
V=\sum_{i=1}^{n} \sum_{l=1}^{m} Q_{i}\left(T_{l}\right)^{2} \bar{p}_{i}\left(T_{l}\right) m_{l}+\sum_{h=1}^{p} \sum_{k=1}^{p} \gamma_{h} \gamma_{k} \hat{\sigma}_{h k}
$$

onde $T_{l}, l=1, \ldots, m$ são os tempos de falha ordenados, $\hat{\sigma}_{h k}, h=1, \ldots, p$ e $k=1, \ldots, p$ são os elementos da matriz de variância-covariância de $\hat{\boldsymbol{\beta}}$ e

$$
\begin{aligned}
\bar{p}_{i}(t) & =\sum_{j=1}^{n_{i}} p_{i j}(t)=\sum_{j=1}^{n_{i}} \frac{Y_{i j}(t) \exp \left(\hat{\boldsymbol{\beta}}^{\prime} \mathbf{X}_{i j}\right)}{S^{(0)}(t)} \\
Q_{i}\left(T_{l}\right) & =2\left(\bar{M}_{i}\left(T_{l-1}\right)-\sum_{g=1}^{n} \bar{M}_{g}\left(T_{l-1}\right) \bar{p}_{i}\left(T_{l}\right)+\sum_{g=1}^{n} \bar{p}_{g}\left(T_{l}\right)^{2}\right) .
\end{aligned}
$$

Além disso, $\bar{M}_{i}\left(T_{l}\right)=\sum_{j=1}^{n_{i}} M_{i j}\left(T_{l}\right)$ onde

$$
M_{i j}\left(T_{l}\right)=\left\{\begin{array}{ll}
\delta_{i j}-\hat{A}_{0}\left(T_{i j}\right) \exp \left(\hat{\boldsymbol{\beta}}^{\prime} \mathbf{X}_{i j}\right) & \text { se } T_{i j} \leq T_{l} \\
-\hat{A}_{0}\left(T_{l}\right) \exp \left(\hat{\boldsymbol{\beta}}^{\prime} \mathbf{X}_{i j}\right) & \text { se } T_{i j}>T_{l}
\end{array},\right.
$$

$\operatorname{com} \bar{M}_{i}\left(T_{0}\right)=0, i=1, \ldots, n \mathrm{e}$

$$
\gamma_{h}=\sum_{i=1}^{n} \sum_{l=1}^{m} Q_{i}\left(T_{l}\right) m_{l}\left(\sum_{j=1}^{n_{i}} p_{i j}\left(T_{l}\right) X_{i j h}\right), h=1, \ldots, p
$$

Commenges \& Andersen (1995) mostraram que a estatística de teste dada pela divisão de (3.34) pela raiz quadrada de (3.35), ou seja, $H_{\theta}=T / \sqrt{V}$, tem distribuição assintótica $N(0,1)$. 
Logo, $H_{\theta}^{2}$ tem distribuição assintótica $\chi_{1}^{2}$ sob $H_{0}$, bem como as estatísticas $W_{\theta}$ e $R V_{\theta}$.

Uma vez que o teste de dependência foi significante, temos interesse em testar hipóteses com o vetor de coeficientes de regressão do modelo de fragilidade. Isso é feito, testando-se $H_{0}: \boldsymbol{\beta}=\boldsymbol{\beta}_{0}$ através das seguintes estatísticas:

Estatística de Wald:

$$
W_{\beta}=\left(\hat{\boldsymbol{\beta}}-\boldsymbol{\beta}_{0}\right)^{\prime} I(\hat{\boldsymbol{\beta}})\left(\hat{\boldsymbol{\beta}}-\boldsymbol{\beta}_{0}\right)
$$

Estatística da Razão de Verossimilhanças:

$$
R V_{\beta}=2 \log \frac{L(\hat{\boldsymbol{\alpha}}, \hat{\boldsymbol{\beta}}, \hat{\theta})}{L\left(\hat{\boldsymbol{\alpha}}, \boldsymbol{\beta}_{0}, \hat{\theta}\right)}=2\left(\log L(\hat{\boldsymbol{\alpha}}, \hat{\boldsymbol{\beta}}, \hat{\theta})-\log L\left(\hat{\boldsymbol{\alpha}}, \boldsymbol{\beta}_{0}, \hat{\theta}\right)\right)
$$

com $\log L(\boldsymbol{\alpha}, \boldsymbol{\beta}, \theta)$ dado por (3.28) onde $\hat{\boldsymbol{\alpha}}, \hat{\boldsymbol{\beta}}$ e $\hat{\theta}$ são as estimativas do modelo de fragilidade (3.14).

$W_{\beta}$ e $R V_{\beta}$ têm distribuição assintótica $\chi_{p}^{2}$ sob $H_{0}$ (Klein \& Moeschberger 1997).

\subsubsection{Verossimilhança Penalizada}

Recentemente, com o trabalho ainda não publicado de Therneau \& Grambsch (1998), uma outra forma de abordar o modelo de fragilidade através da verossimilhança penalizada foi proposta. Nesse trabalho, os autores indicaram uma conexão muito interessante entre a regressão penalizada e os modelos de fragilidade. Na verdade, eles mostraram que o modelo de fragilidade Gama poder ser representado exatamente como um modelo de regressão penalizado da forma $L P=L_{C o x}(\boldsymbol{\beta}, \mathbf{Z})-f(\mathbf{Z}, \theta)$, onde $L_{C o x}$ é a verossimilhança padrão de Cox com $\log Z$ considerado como um offset e $f$ é a função de penalização. Eles introduziram essa metodologia em uma rotina para o S-Plus chamada Survival5.

Therneau \& Grambsch (1998) sugeriram que a estimação do modelo seja feita usando o algoritmo EM exatamente da mesma forma como feito por Klein (1992) e descrito na seção 
(3.2.3). Eles apontaram que o resultado do valor esperado da verossimilhança $\log L(\boldsymbol{\beta}, \theta, \mathbf{Z})$, dado pela soma das expressões (3.23) e (3.24), pode ser reescrito da seguinte forma:

$$
\begin{aligned}
Q= & E\left(L_{1}(\theta)\right)+E\left(L_{2}\left(\boldsymbol{\beta}, \alpha_{0}\right)\right) \\
= & \sum_{i}\left[\left(\frac{1}{\theta}-1+N_{i}\right)\left\{\psi\left(A_{i}\right)-\log \left(C_{i}\right)\right\}-\frac{A_{i}}{\theta C_{i}}-\frac{1}{\theta} \log \theta-\log \Gamma\left(\frac{1}{\theta}\right)-V_{i} \log \frac{A_{i}}{C_{i}}+\right. \\
& \left.+\sum_{j} \sum_{t} d N_{i j}(t)\left\{\left[\boldsymbol{\beta}^{\prime} \mathbf{X}_{i j}+\log \hat{Z}_{i}+\log \alpha_{0}(t)\right]-\int_{0}^{\tau} \hat{Z}_{i} Y_{i j}(t) \alpha_{0}(t) \exp \left(\boldsymbol{\beta}^{\prime} \mathbf{X}_{i j}\right)\right\}\right]
\end{aligned}
$$

$\operatorname{com} \hat{Z}_{i}=A_{i} / C_{i}$, e usando que $\Lambda_{i}(\boldsymbol{\beta})=\int_{0}^{\tau} \sum_{j} Y_{i j}(u) \alpha_{0}(u) \exp \left(\boldsymbol{\beta}^{\prime} \mathbf{X}_{i j}\right) d u$.

O motivo de reescrevermos o modelo dessa forma é que assim fica fácil visualizar que a última linha de (3.36) é exatamente igual ao log da verossimilhança para o modelo completo com $\log \hat{Z}_{i}$ considerado como um offset. Ou seja, a maximização de (3.36) pode ser feita utilizando um procedimento de modelo de Cox para dados independentes. Assim. a cada iteração do algoritmo EM podemos calcular o novo valor dessa parte da expressão usando um programa padrão para dados independentes e maximizando $Q$ com relação a $\theta$, usando qualquer outro método. Na verdade, a solução pode ser encontrada usando apenas os resultados do procedimento padrão. Tome o caso em que $\theta$ é fixo. As quantidades $N_{i}$ e a soma dos resíduos martingais para cada grupo $M_{i}=N_{i}-E_{i}$ onde $E_{i}=\int_{0}^{\tau} \sum_{j} Y_{i j}(u) \hat{Z}_{i} \alpha_{0}(u) \exp \left(\boldsymbol{\beta}^{\prime} \mathrm{X}_{i j}\right) d u$ são obtidos diretamente dos dados e do programa. Os valores de $\Lambda_{i}(\boldsymbol{\beta})$ vêm do cálculo de $E_{i}=\hat{Z}_{i} \Lambda_{i}(\boldsymbol{\beta})$ e dos valores atuais de $A_{i}$ e $C_{i}$. Finalmente o $\log \hat{Z}_{i}$ é usado como offset na nova chamada do procedimento padrão. Para $\theta$ fixo esse processo converge de 4 a 6 iterações.

Após a última iteração devemos obter o valor correto da verossimilhança (3.36). Como mostram Dempster et al. (1977), isso é feito pelo cálculo de $L_{g}=Q-H$, onde $\mathrm{H}$ é o valor esperado do $\log$ da distribuição condicional de $Z_{i}$ dado os dados, ou seja, de uma distribuição $\operatorname{Gama}\left(1 / \theta+N_{i}, 1 / \theta+\Lambda_{i}(\boldsymbol{\beta})\right)$ :

$$
\begin{aligned}
H= & \sum_{i}\left\{\left(\frac{1}{\theta}+N_{i}-1\right) E\left(\log Z_{i}\right)-\left(\frac{1}{\theta}+N_{i}\right) \log \left(\frac{1}{\theta}+\Lambda_{i}(\boldsymbol{\beta})\right)-\right. \\
& \left.-E\left(Z_{i}\right)\left(\frac{1}{\theta}+\Lambda_{i}(\boldsymbol{\beta})\right)-\log \Gamma\left(\frac{1}{\theta}+N_{i}\right)\right\}
\end{aligned}
$$




$$
\begin{aligned}
= & \sum_{i}\left\{\left(\frac{1}{\theta}+N_{i}-1\right)\left\{\psi\left(A_{i}\right)-\log \left(C_{i}\right)\right\}-\left(\frac{1}{\theta}+N_{i}\right) \log \left(\frac{1}{\theta}+\Lambda_{i}(\boldsymbol{\beta})\right)-\right. \\
& \left.-\frac{A_{i}}{C_{i}}\left(\frac{1}{\theta}+\Lambda_{i}(\boldsymbol{\beta})\right)-\log \Gamma\left(\frac{1}{\theta}+N_{i}\right)\right\}
\end{aligned}
$$

A função $H$ não precisa fazer parte do processo de maximização mas é necessária para a correção do valor da verossimilhança.

Com isso, $L_{g}$ que é o log da verossimilhança parcial marginal pode ser calculada como:

$$
\begin{aligned}
L_{g}= & \sum_{i}\left\{\frac{1}{\theta} \log \left(\frac{\frac{1}{\theta}}{\frac{1}{\theta}+N_{i}}\right)+\log \left(\frac{\Gamma\left(\frac{1}{\theta}+N_{i}\right)}{\Gamma\left(\frac{1}{\theta}\right)}\right)+\right. \\
& \left.+\sum_{j} \sum_{t} d N_{i j}(t)\left[\boldsymbol{\beta}^{\prime} \mathbf{X}_{i j}+\log \alpha_{0}(t)\right]-N_{i} \log \left(\frac{1}{\theta}+\Lambda_{i}(\boldsymbol{\beta})\right)\right\} \\
= & L_{\text {Cox }}+\sum_{i}\left\{\frac{1}{\theta} \log \left(\frac{\frac{1}{\theta}}{\frac{1}{\theta}+N_{i}}\right)+\log \left(\frac{\Gamma\left(\frac{1}{\theta}+N_{i}\right)}{\Gamma\left(\frac{1}{\theta}\right)}\right)-N_{i} \log \left(\frac{1}{\theta}+N_{i}\right)\right\}
\end{aligned}
$$

onde $L_{C o x}$ é a verossimilhança padrão de Cox com $\log Z_{i}$ considerado como um offset.

Entretanto, devemos tomar cuidado ao calcular o $\log$ da verossimilhança quando $\theta \rightarrow 0$ $(\nu \rightarrow \infty)$ que é o caso onde as variáveis de fragilidade estão próximas de 1 e o resultado deve convergir para os mesmos resultados de um modelo de Cox para dados independentes. Quando isso acontece a expressão (3.37) converge para $L_{C o x}-\sum_{i} N_{i}$ quando a aproximação $\log \left\{\Gamma\left(N_{i}+1 / \theta\right) / \Gamma(1 / \theta)\right\} \approx \sum_{r=0}^{N_{i}-1} \log (r+1 / \theta)$ é feita. Por essa razão os autores adicionaram $\sum_{i} N_{i}$ no valor de $L_{g}$ no código do S-Plus para que os resultados dos modelos com e sem fragilidade possam ser comparados.

A conexão entre os modelos de fragilidade e os de verossimilhança penalizada é baseada no seguinte argumento: considere o caso de uma função de penalização $f$ dada pelo log da distribuição incondicional de uma distribuição $\operatorname{Gama}(1 / \theta, 1 / \theta)$ :

$$
-f\left(z ; \frac{1}{\theta}\right)=\left(\frac{1}{\theta}-1\right) \log z-\frac{1}{\theta} \log \theta-z \frac{1}{\theta}-\log \Gamma\left(\frac{1}{\theta}\right)
$$

Os autores descobriram que, para um valor fixo de $\theta$, o algoritmo EM e a verossimilhança penalizada têm a mesma solução. 
Segundo Gray (1992) a matriz de segundas derivadas para a verossimilhança penalizada $L P$ é dada por:

$$
\mathbf{G}=\mathbf{I}-\left(\begin{array}{cc}
0 & 0 \\
0 & f^{\prime \prime}
\end{array}\right)
$$

onde I é a matriz de informação do modelo de Cox para dados independentes. Gray (1992) sugere estimar a variância dos parâmetros através de:

$$
\mathrm{V}=\mathrm{G}^{-1} \mathbf{I G}^{-1}
$$

Note que pela teoria assintótica dos estimadores de máxima verossimilhança temos que para $\phi=\left(\boldsymbol{\beta}^{\prime}, \mathbf{Z}^{\prime}\right)$

$$
\begin{aligned}
\mathrm{S}(\phi) & =\frac{\partial}{\partial \phi} L P(\phi)=\frac{\partial}{\partial \phi} L_{C o x}-\frac{\partial}{\partial \phi} f(\mathrm{Z}, \theta) \\
\mathrm{G}(\phi) & =-\frac{\partial^{2}}{\partial \phi^{2}} L P(\phi)=\mathrm{I}(\phi)+\frac{\partial^{2}}{\partial \phi^{2}} f(\mathrm{Z}, \theta) .
\end{aligned}
$$

Fazendo a expansão de Taylor de $\hat{\phi}$ em torno de $\phi_{0}$ temos:

$$
0=\left.\frac{\partial}{\partial \phi} L P(\phi)\right|_{\phi=\hat{\phi}}=\left.\frac{\partial}{\partial \phi} L P(\phi)\right|_{\phi=\phi_{0}}+\left.\left(\hat{\phi}-\phi_{0}\right) \frac{\partial^{2}}{\partial \phi^{2}} L P(\phi)\right|_{\phi=\phi .}
$$

$\operatorname{com} \phi_{*}$ entre $\hat{\phi}$ e $\phi_{0}$. Usando outros argumentos da teoria assintótica como $\mathrm{S}(\phi) \sim N(0, n \mathrm{G}(\phi))$ e $1 / n\left\{\partial^{2} L P(\phi) / \partial \phi^{2}\right\} \rightarrow-G(\phi)$ temos que:

$$
\left(\hat{\phi}-\phi_{0}\right) \cong \mathrm{S}(\phi) \mathrm{G}^{-1}(\phi)
$$

Com isso, $\sqrt{n}\left(\hat{\phi}-\phi_{0}\right)$ tem assintoticamente distribuição normal com média 0 e matriz de covariância $\lim n \mathrm{~V}$ onde:

$$
\mathbf{V}=\operatorname{Var}\left(\hat{\phi}-\phi_{0}\right)=\operatorname{Var}\left(\mathbf{S}(\phi) \mathbf{G}^{-1}\right)=\mathbf{G}^{-1}(\phi) \operatorname{Var}(\mathbf{S}(\phi)) \mathbf{G}^{-1}(\phi)
$$

Além disso, Gray (1992) afirma que $\operatorname{Var}(\mathbf{S}(\phi))$ pode ser consistentemente estimada por $\mathrm{I}(\hat{\phi})$ e que, portanto,

$$
\hat{\mathrm{V}}=\mathrm{G}^{-1}(\hat{\phi}) \mathbf{I}(\hat{\phi}) \mathrm{G}^{-1}(\hat{\phi})
$$


Além disso, para a hipótese de interesse $\mathbf{b}=\left(\boldsymbol{\beta}^{\prime}, \mathbf{Z}^{\prime}\right) \mathbf{c}=0$, com $\mathbf{c}$ um vetor de constantes, Therneau \& Grambsch (1998) indicaram o uso da estatística de Wald dada por:

$$
W=\mathbf{b}^{\prime}\left(\mathbf{c}^{\prime} \mathbf{G}^{-1} \mathbf{c}\right)^{-1} \mathbf{b},
$$

usando como aternativa de estimador para a variância diretamente a matriz $\mathrm{G}^{-1}$ que tende a ser maior que V, deixando o teste mais conservativo. Entretanto, eles ressaltaram que a estatística do teste não segue necessariamente uma $\chi^{2}$ padrão e sim uma distribuição mais compacta. A solução encontrada para adequar o teste foi fazer uma modificação nos graus de liberdade da distribuição de $\chi^{2}$ da seguinte forma:

$$
d f=\operatorname{traço}\left[\left(\mathbf{c}^{\prime} \mathbf{G}^{-1} \mathbf{c}\right)^{-1}\left(\mathbf{c}^{\prime} \mathbf{V} \mathbf{c}\right)\right]
$$

Essa metodologia também foi aplicada nos três conjuntos de dados e os resultados estão apresentados no próximo capítulo. 


\section{Capítulo 4}

\section{Aplicações}

\subsection{Introdução}

Em termos computacionais, a estimação dos parâmetros em modelos de fragilidade Gama apresentam um certo grau de instabilidade. Algumas vezes podem ocorrer problemas de não convergência ou valores inválidos. Mais recentemente, como discutido no capítulo anterior Therneau \& Grambsch (1998) apresentaram um método aproximado que se mostra promissor apesar de pouco estudado.

Neste trabalho utilizamos 4 programas para obter as estimativas dos parâmetros de interesse $\boldsymbol{\beta}$ e $\theta$. O primeiro deles foi desenvolvido por Nielsen et al. (1992) usando as linguagens $\mathrm{C}$ e FORTRAN. Esse programa implementa o algoritmo EM como descrito no Capítulo 3, Seção 3.2.2, para estimar os parâmetros e o processo presente na Seção 3.2 .5 para estimar a variância das estimativas. Para testar se os parâmetros do modelo são iguais a 0 , ele apenas fornece a estatística de Wald. O programa foi rodado no sistema UNIX em uma estação de trabalho do Instituto de Matemática e Estatística da Universidade de São Paulo. 
O segundo programa é uma macro desenvolvida por Klein (1992), para o sistema SAS, que utiliza a metodologia citada na Seção 3.2.3. A saída do programa contém os testes de Wald para os parâmetros $\boldsymbol{\beta}$ e $\theta$ e o da razão de verossimilhanças para o parâmetro $\theta$.

O terceiro programa foi desenvolvido no software NTIA da Embrapa versão 4.2.1. Ele utiliza o novo método de estimação descrito na Seção 3.2.4, onde a função de verossimilhança sugerida por Andersen et al. (1997) é usada para estimar os parâmetros e a matriz de variância-covariância. É o único programa que gera os valores das três estatísticas (Wald, razão de verossimilhanças e escore) para o parâmetro $\theta$ e a de Wald e da razão de verossimilhanças para $\boldsymbol{\beta}$. O código do programa está a disposição no endereço ftp://ftp.ime.usp.br/pub/acarlos/frailty. Esse programa foi rodado em um Pentium 133 MHZ com 64 MB de memória RAM, bem como a macro do SAS.

O último programa foi elaborado por Therneau \& Grambsch (1998) e é uma rotina do S-Plus de nome Survival5. A descrição da metodologia foi brevemente apresentada na Seção 3.2.7 do Capítulo 3.

Aplicamos esses 4 programas aos conjuntos de dados dos exemplos citados no Capítulo 1, e os resultados serão apresentados nas próximas seções. O principal interesse está na comparação dos resultados dos programas para cada um dos conjuntos de dados sem perder de vista a conclusão prática para o pesquisador. Vamos construir a curva do risco relativo em função do tempo, utilizando a função (3.26), que representa o risco de falha entre observações de grupos diferentes, e vamos compará-la com o risco relativo do modelo de independência.

Para esses programas, como os valores inicias de $\beta$ e $\alpha$ são fornecidos pelo modelo de Cox independente, temos apenas que nos preocupar com o chute inicial de $\theta$. A macro do SAS exige que esse valor inicial seja bem pequeno como por exemplo 0,001. O programa do Nielsen funciona bem para diferentes valores de $\theta$, entretanto, quanto maior o valor mais demorado fica o processo de estimação. Testamos até para o valor 5,0 e o programa convergiu sem problemas. Já o programa do NTIA precisa iniciar o processo iterativo com valor pequeno para o $\theta$, pois dependendo do valor inicial o programa não converge. A sugestão é que se use por exemplo os valores 0,1 ou 0,01 que funcionou bem para a maioria dos exemplos. 
Em geral, os programas forneceram estimativas muito parecidas e as vezes até iguais para os parâmetros diferenciando mais nas estimativas dos erros padrões. Com relação a $\boldsymbol{\beta}$, todos eles geraram estimativas e erros padrões bem parecidos, mas quando se trata do parâmetro de dependência, o de Nielsen é sempre o mais preciso. O programa feito no NTIA calcula um erro padrão bem maior do que o de Nielsen o que prejudica a tomada de decisão através do resultado da estatística de Wald. Isso ocorre, provavelmente, pelo fato desse programa estimar mais parâmetros. O programa de Therneau é o que mostra o maior erro padrão para a estimativa de $\theta$ mas o cálculo desse valor é feito de forma diferente dos outros programas. Como na maioria das vezes estamos interessados em estimar $\boldsymbol{\beta}$, esses resultados não parecem tão ruins já que os 4 programas trazem estimativas bem próximas para esse parâmetro.

O programa fornecido por Nielsen é o único que permite estimar os parâmetros através de amostras com estratos enquanto que a nova metodologia e os programas de Klein e Therneau não estão programadas para tal. Entretanto, esse não é um sério problema já que os programas podem ser facilmente adaptados para permitir estratos.

\subsection{Exemplo dos ratos}

Esse conjunto de dados é um dos mais citados na literatura. Ele contém informações de 150 ratos fêmeas de 50 ninhadas. O evento de interesse é dado pelo tempo, em semanas, até a formação de um certo tipo de tumor e o objetivo foi estudar o efeito de uma droga carcinogênica no desenvolvimento desse tumor. Ao todo foram observadas 40 falhas, ou seja, o tumor se desenvolveu em 40 ratas. Isso implica que ocorreram 110 censuras $(73,3 \%)$. A covariável tratamento foi categorizada da seguinte forma:

$$
\text { Tratamento }= \begin{cases}1 & \text { Droga } \\ 0 & \text { Placebo }\end{cases}
$$

Na Tabela 4.1 temos os resultados dos 4 programas e também do modelo usual de Cox 
para dados independentes. Apresentamos as estimativas dos parâmetros com os respectivos erros padrões (EP), além do valor do estimador não-paramétrico baseado no coeficiente de concordância $\tau$ de Kendall, dado por (2.5), e das estatísticas descritas na Seção 3.2.6.

Essa tabela mostra que as estimativas de $\beta$ para o modelo de fragilidade foram as mesmas em 3 programas $(0,9036)$ e um pouco maior no programa de Therneau diferenciando dos outros apenas na terceira casa decimal (0,9060). Os erros padrões de $\hat{\beta}$ foram muito semelhantes sendo que o encontrado pelo programa do Klein é um pouco maior que o dos outros três, diferenciando apenas na terceira casa decimal. Note também, que as estimativas relacionadas ao parâmetro $\beta$ são muito parecidas com a obtida pelo modelo de independência $(0,8975)$, o que pode ser um indício de que não há dependência entre as observações. Os testes de Wald e da razão de verossimilhanças para esse parâmetro foram significantes, implicando que existe diferença entre dar placebo e droga para os animais.

O parâmetro de dependência $(\theta)$ também foi estimado pelo mesmo valor nos três primeiros programas sendo que o de Nielsen apresentou o menor erro padrão $(0,4623)$ e a nova proposta de estimação o maior deles (0.5214). Já o programa de Therneau forneceu uma estimativa para $\theta$ maior do que as outras novamente a partir da terceira casa decimal com um erro padrão bem maior do que o dos outros programas $(0,6885)$. Essa parece uma diferença considerável mostrando que o método de estimação de Nielsen parece ser o mais preciso para estimar $\theta$. O valor do $\tau$ de Kendall foi de aproximadamente 0.19 (erro padrão 0,43 quando usamos os resultados do programa de Nielsen). Todas as estatísticas foram concordantes e indicaram que não existe dependência entre as observações. Isso implica que devemos utilizar as estimativas do modelo de Cox padrão.

A Figura 4.1 mostra o gráfico do risco relativo de formação de tumor da droga em relação ao placebo sob o modelo de fragilidade e sob o modelo de independência $(\exp (\beta))$ utilizando as estimativas fornecidas pelo programa de Nielsen. As duas curvas estão muito próximas, mostrando que o modelo de fragilidade não parece ser mesmo necessário. Além disso, elas estão bem distantes da reta onde o risco dos tratamentos são iguais $(y=1)$.

Diante desses resultados podemos concluir que ratas de uma mesma ninhada não apre- 


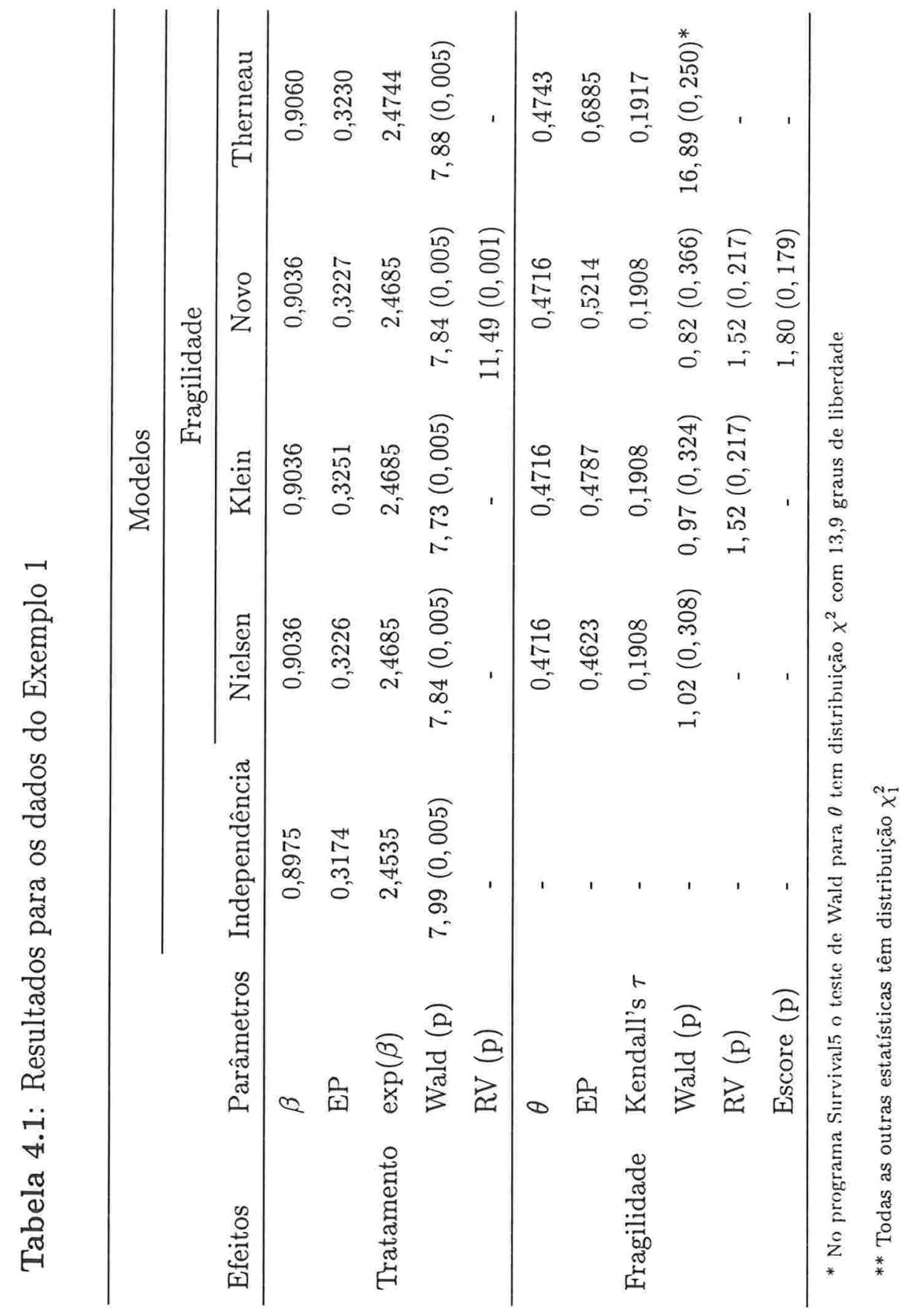




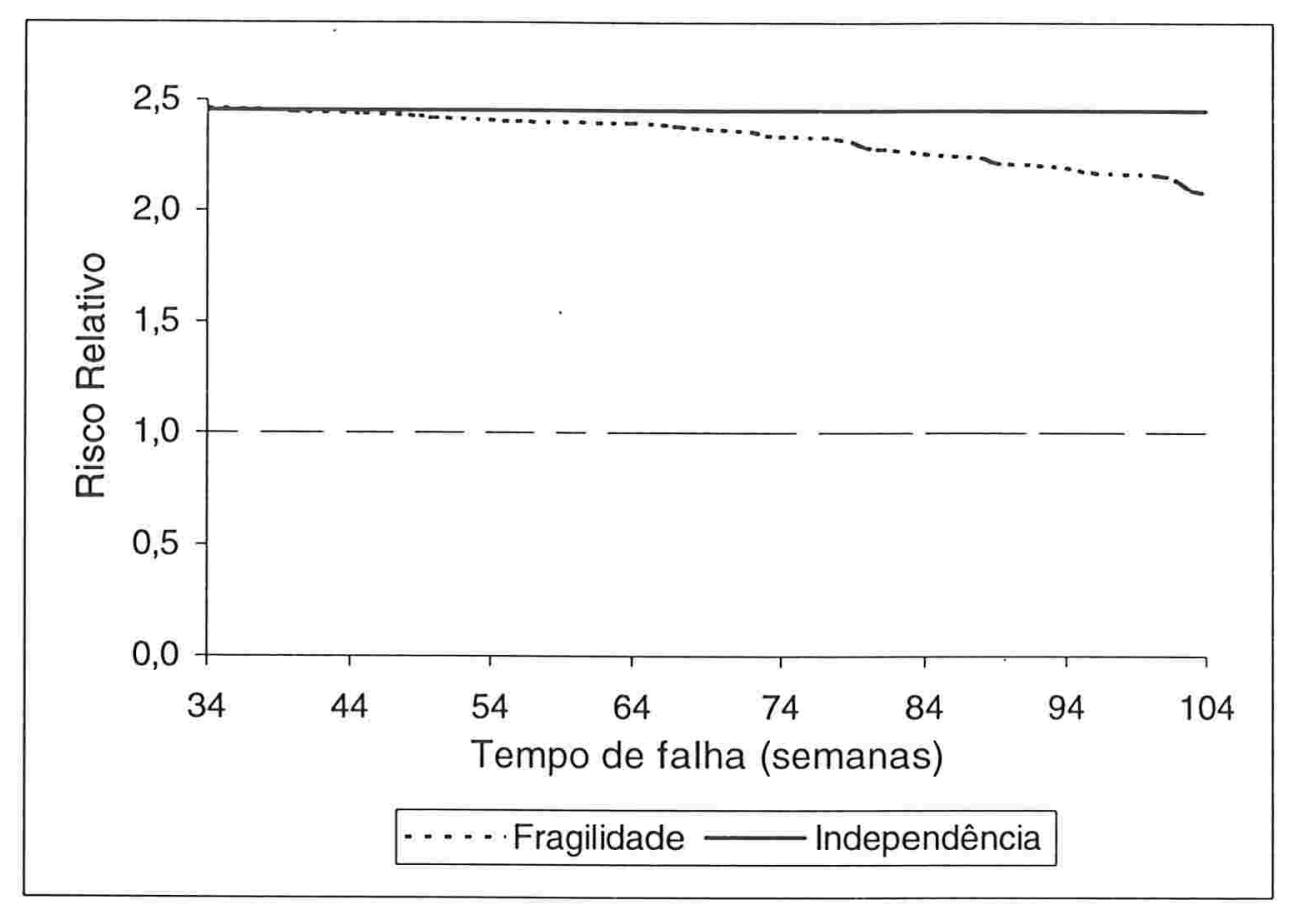

Figura 4.1: Risco relativo da droga em relação ao placebo

sentam tempos até a formação de tumor correlacionados e aquelas que receberam a droga têm 2,5 vezes mais chance de desenvolver o tumor do que as que receberam placebo.

\subsection{Exemplo dos dentes}

O principal objetivo desse estudo foi o de avaliar se o novo selante Optibond permanece mais tempo intacto nos dentes das crianças, protegendo-as melhor, do que o selante Delton. O tempo de evento é dado pelo tempo, em meses, até a detecção de perda parcial ou total do selante. No total são 171 observações de 37 crianças. Foram observadas 43 falhas, ou seja, em 43 dentes ocorreu perda parcial ou total do selante. O número restante, igual a 128 , foram de censuras, o equivalente a $74,8 \%$. Nessa análise vamos considerar apenas a 
covariável tratamento categorizada da seguinte forma:

$$
\text { Tratamento }= \begin{cases}1 & \text { Optibond } \\ 0 & \text { Delton }\end{cases}
$$

A Tabela 4.2 mostra os ajustes de todos os modelos. Novamente o valor de $\hat{\beta}$ foi igual nos três programas $(-1,3956)$ e um pouco diferente no caso do programa de Therneau $(-1,4)$. Esses valores já são bem diferentes do encontrado sob o modelo de independência. Os erros padrões também são bem parecidos sendo que o programa do Therneau foi o que apresentou a menor estimativa $(0,3610)$ e o de Nielsen a maior delas $(0,3707)$. Todas as estatísticas para o teste de $\beta=0$ foram significantes, indicando que existe diferença entre os dois tipos de selantes, no que se refere a retenção.

Os quatro programas também forneceram a mesma estimativa para o parâmetro de dependência $(\theta)$ sendo que o de Nielsen apresentou o menor erro padrão $(0,4316)$. Já o de Therneau foi bem maior igual a $(0,5408)$. Essa diferença parece considerável, mostrando novamente que o método de estimação de Nielsen é mais preciso para estimar $\theta$. Usando os resultados do programa do Nielsen, o valor do $\tau$ de Kendall foi 0,26 com erro padrão igual a 0,12. A estatística de Wald em três casos (Nielsen, Klein e Novo) não foi significante, entretanto, para o programa de Therneau que usa uma correção para a distribuição dessa estatística o resultado foi o oposto indicando que existe dependência entre as observações. As outras estatísticas que são calculadas pelo novo programa e pelo de Klein foram altamente significantes e estão de acordo com o resultado fornecido pelo programa de Therneau.

Como ainda não existe um estudo detalhado do comportamento dessas estatísticas não podemos dizer com precisão qual delas é a melhor. Entretanto, pela diferença entre os resultados dos modelos de fragilidade e o de independência parece que o programa de Therneau e as estatísticas da razão de verossimilhança e Escore mostram um resultado mais coerente. O que tentamos fazer foi um pequeno estudo de sensibilidade das estatísticas utilizando o programa do NTIA, que é o único que fornece todas elas, mas infelizmente não foi possível concluir o estudo pelo fato do programa ser muito sensível a alterações na estrutura de falha e censura dos conjuntos de dados. 


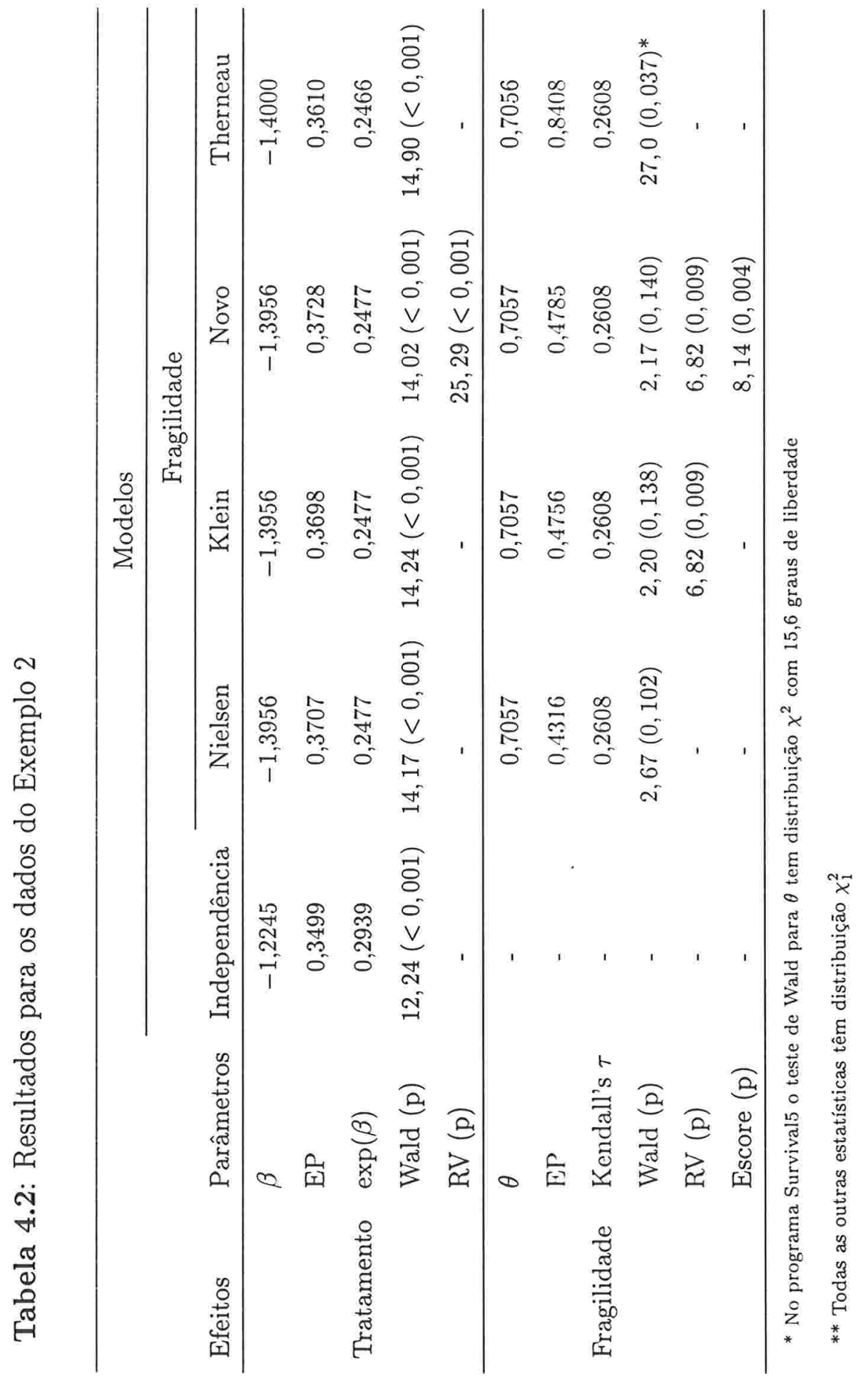




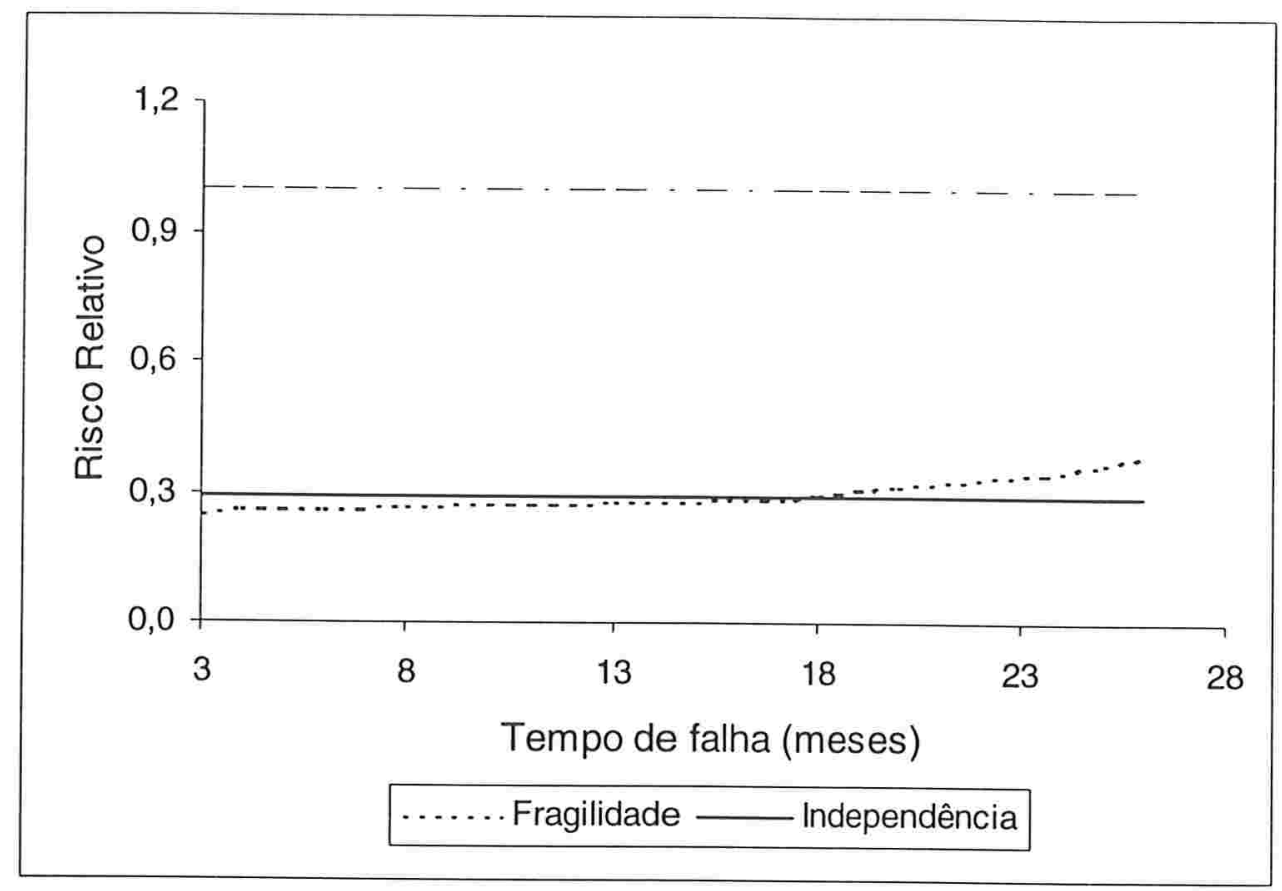

Figura 4.2: Risco relativo do Optibond em relação ao Delton

A Figura 4.2 mostra o gráfico do risco relativo do selante Optibond em relação a Delton sob o modelo de fragilidade e de independência utilizando as estimativas do programa de Nielsen. As duas curvas estão bem próximas e distantes da reta onde o risco entre tratamentos é igual $(y=1)$. Note que existe um ponto en que as curvas se cruzam. ou seja, o risco relativo do modelo de fragilidade é crescente sendo que até aproximadamente o $18^{\underline{0}}$ mês ele é um pouco menor do que o do modelo de independência e a partir desse mesmo ponto ele fica maior. Por esse gráfico, a nossa conclusão seria provavelmente de que não existe dependência entre as observações, já que as curvas dos dois modelos são muito semelhantes. 


\subsection{Exemplo do vírus da hepatite C}

Esse conjunto de dados contém 132 observações de 15 indivíduos positivos para o vírus da hepatite C. O objetivo é comparar o tempo até a detecção da positividade de três gerações de testes que existem no mercado. Ao todo são 9 testes diferentes agrupados em três grupos. Com isso, temos que o evento de interesse é o tempo, em dias, até a detecção da positividade para HCV. Foram observadas 120 falhas, ou seja, os testes deram positivos para um total de 120 amostras de sangue, o que implica apenas 12 censuras $(9,1 \%)$. Para analisar os dados vamos considerar apenas a covariável de tipo de teste representada por duas variáveis dummy definidas por Trat1 e Trat2:

$$
\text { Trat } 1=\left\{\begin{array}{ll}
1 & \text { Teste da } 1 \underline{\mathrm{a}} \text { geração } \\
0 & \text { Teste da } 2 \underline{\mathrm{a}} \text { ou } 3 \underline{\mathrm{a}} \text { geração }
\end{array} \text { Trat } 2= \begin{cases}1 & \text { Teste da } 2 \underline{\mathrm{a}} \text { geração } \\
0 & \text { Teste da } 1 \underline{\mathrm{a}} \text { ou } 3 \underline{\mathrm{a}} \text { geração }\end{cases}\right.
$$

Dessa forma, temos:

- Trat $1=1$ e Trat $2=0 \Rightarrow$ aplicado teste da 1 a geração;

- Trat $1=0$ e Trat $2=1 \Rightarrow$ aplicado teste da $2^{\underline{a}}$ geração;

- Trat $1=0$ e Trat $2=0 \Rightarrow$ aplicado teste da 3 a geração.

Na Tabela 4.3 temos os resultados do ajuste do modelo usual de Cox para dados independentes e também do modelo de fragilidade pelo programa de Nielsen e de Therneau. Os outros dois programas não conseguiram estimar os parâmetros. É certo que o programa do NTIA não convergiu devido à grande quantidade de falhas, o que resulta em muitos parâmetros a serem estimados. Já o programa do Klein gerou um erro interno que não foi possível de ser solucionado.

Analisando as estimativas encontradas, vemos que existe dependência entre as observações, já que o teste de Wald foi significante para os dois programas e que elas são bem diferentes das do modelo de independência. Devemos então considerar as estimativas do 


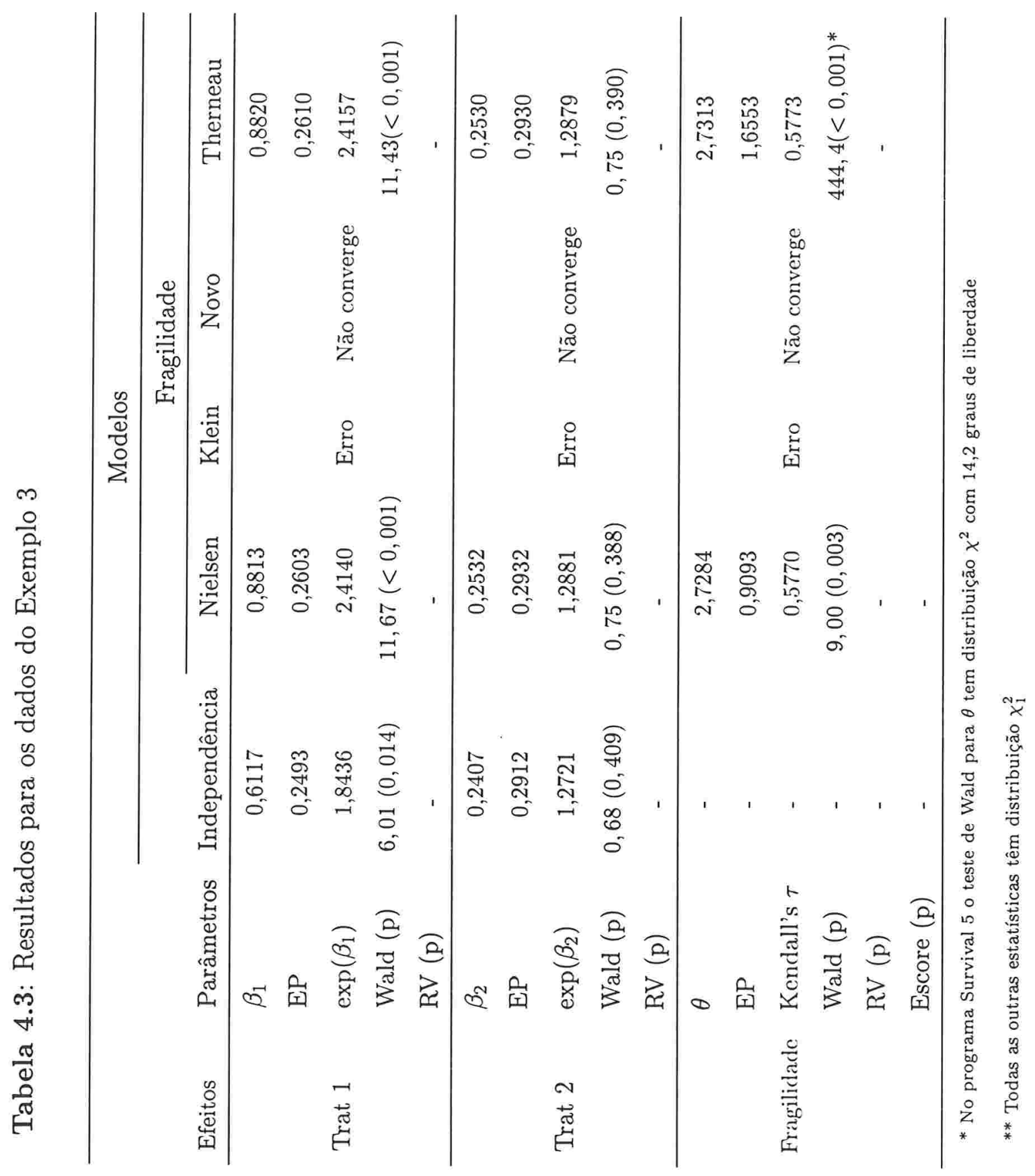




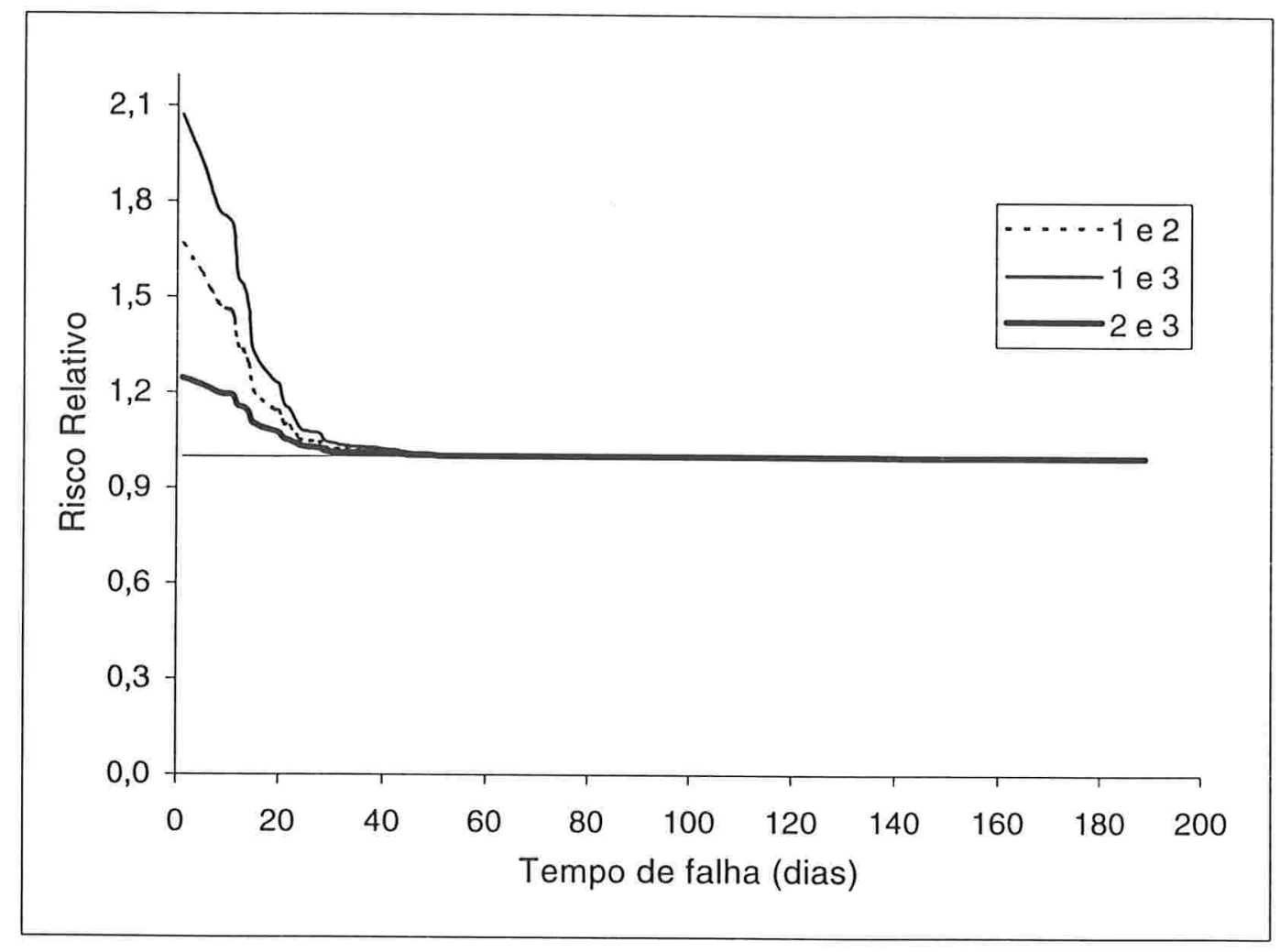

Figura 4.3: Risco relativo entre os tratamentos

parâmetro $\boldsymbol{\beta}$ corrigidas através do modelo de fragilidade. Os dois programas fornecem resultados muito semelhantes sendo que a covariável que define o grupo de testes da $2 \underline{a}$ geração não foi significante $(p=0,39)$. Com isso, temos que os testes de $2 \underline{a}$ e $3 \underline{a}$ gerações são iguais e apresentam o mesmo tempo de detecção para o vírus da hepatite C.

A figura 4.3 mostra as curvas dos riscos relativos entre os três tratamentos utilizando as estimativas do programa de Nielsen. A curva do risco entre os grupos de $2^{\underline{a}}$ e $3 \underline{a}$ gerações (mais grossa) está muito próxima da reta $y=1$, que indica igualdade dos tratamentos.

Ajustando um novo modelo sem a covariável Trat2 obtivémos os resultados dispostos na Tabela 4.4.

Nesse novo modelo a dependência entre as observaçôes continua sendo significativa e 


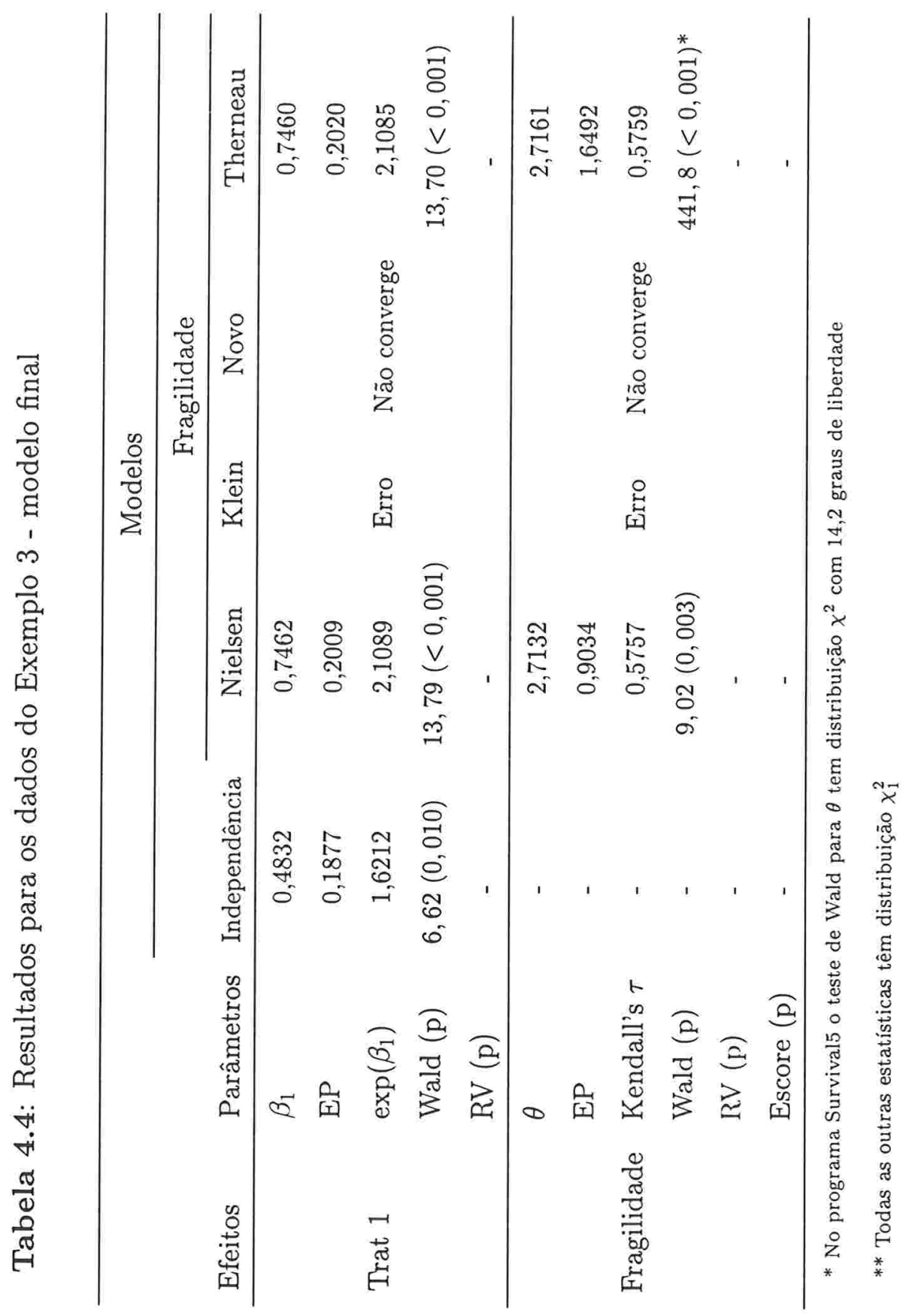




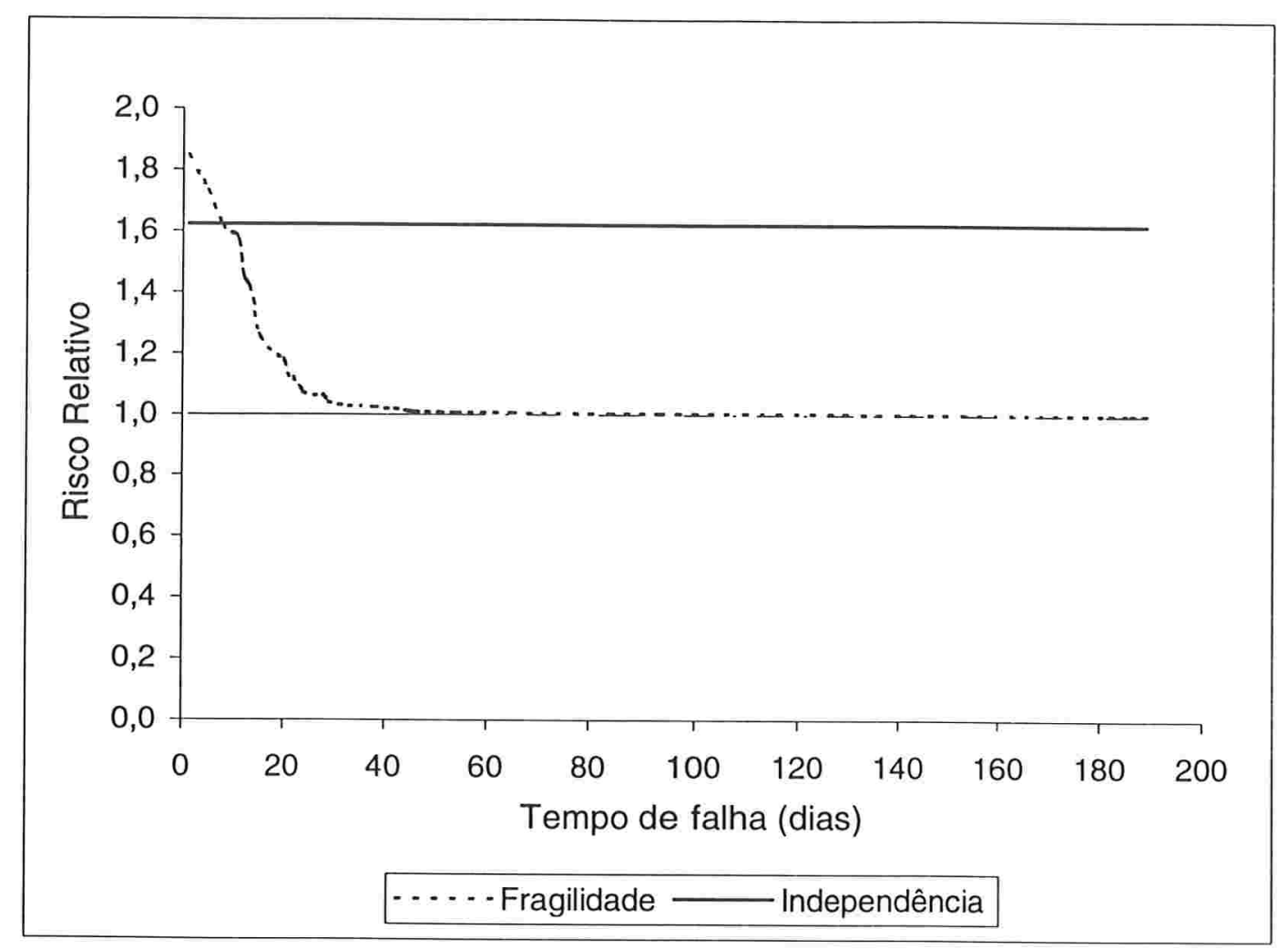

Figura 4.4: Risco relativo do Tratamento 1 em relação ao 2 e 3

o valor do parâmetro $\theta$ mudou muito pouco. O $\tau$ de Kendall foi 0,57 com erro padrão de 0,05 usando os resultados de Nielsen. Esse valor é bem maior do que os encontrados nos outros exemplos, e nos dá mais uma indicação de que as respostas dos testes de um mesmo indivíduo são correlacionadas.

A figura 4.4 mostra o risco relativo do tratamento 1 com relação aos outros dois sob os modelos de independência e fragilidade usando as informações do programa de Nielsen. A curva do modelo de fragilidade mostra que para indivíduos diferentes, os testes da $1 \underline{\text { a }}$ geração detectam a positividade com maior chance do que os outros testes e que esse risco é decrescente. Entretanto, a partir de 20 dias todos eles detectam com a mesma rapidez. Lembre-se que esse é um comportamento esperado da curva, já que essa função tende a 1 quando o tempo cresce (Seção 3.2.3). Note também que essa curva representa o risco 
entre tratamentos aplicados a indivíduos diferentes. No entanto, se quisermos calcular o risco para observações dentro do mesmo grupo que, nesse caso, corresponde a observações de um mesmo indivíduo, esse valor é dado por $\exp (\beta)=2,11$. Isso ocorre porque, dentro do grupo, o risco entre tratamentos é proporcional e independente do tempo, como no modelo de independência.

Podemos dizer então, que existe dependência entre os tempos de deteç̧ão de positividade para amostras de sangue de um mesmo indivíduo. Além disso, não há diferença entre os testes de $2^{\underline{a}}$ e $3 \underline{\underline{a}}$ gerações. Os testes de $1 \underline{a}$ geração têm uma chance 2 vezes maior de detectarem a positividade para o HCV do que os outros dois quando comparados em amostras de um mesmo indivíduo. Já se comparamos resultados de indivíduos diferentes, temos que após 20 dias os testes passam a ter uma chance igual de detectarem a positividade para HCV.

Observamos que o novo programa apresenta uma limitação importante: a amostra não pode conter muitos tempos distintos de falhas. Quando isso ocorre, o valor de $m$ é grande e, consequentemente, a quantidade de parâmetros a serem estimados cresce de tal forma que a tornar o algoritmo muito instável. Com o intuito de obter as estimativas para esse programa, aumentamos artificialemnte o número de censuras. Das 120 falhas que tínhamos originalmente passamos a um novo conjunto de dados com apenas 47 , o que corresponde a aproximadamente $65 \%$. Antes tínhamos um total de $9 \%$ de censura. Na Tabela 4.5 temos os resultados dos programas e do modelo de independência para os dados alterados. Novamente o programa do Klein gerou um erro e não estimou os parâmetros.

Pela Tabela 4.5, vemos que os programas de Nielsen e o Novo geraram as mesmas estimativas para os parâmetros e o de Therneau apresentou diferença apenas na terceira casa decimal. Com relação a $\theta$, o programa do Nielsen apresentou um erro padrão bem menor do que os outros dois. Como consequência disso, as estatísticas de Wald calculadas pelo programa de Nielsen e o Novo foram divergentes, sendo que a de Nielsen foi significante $(\mathrm{p}=0,045)$ e a do NTIA não $(\mathrm{p}=0,102)$. Já no programa de Therneau, que usa uma aproximação para a distribuição da estatística de Wald, o resultado foi altamente significante. 


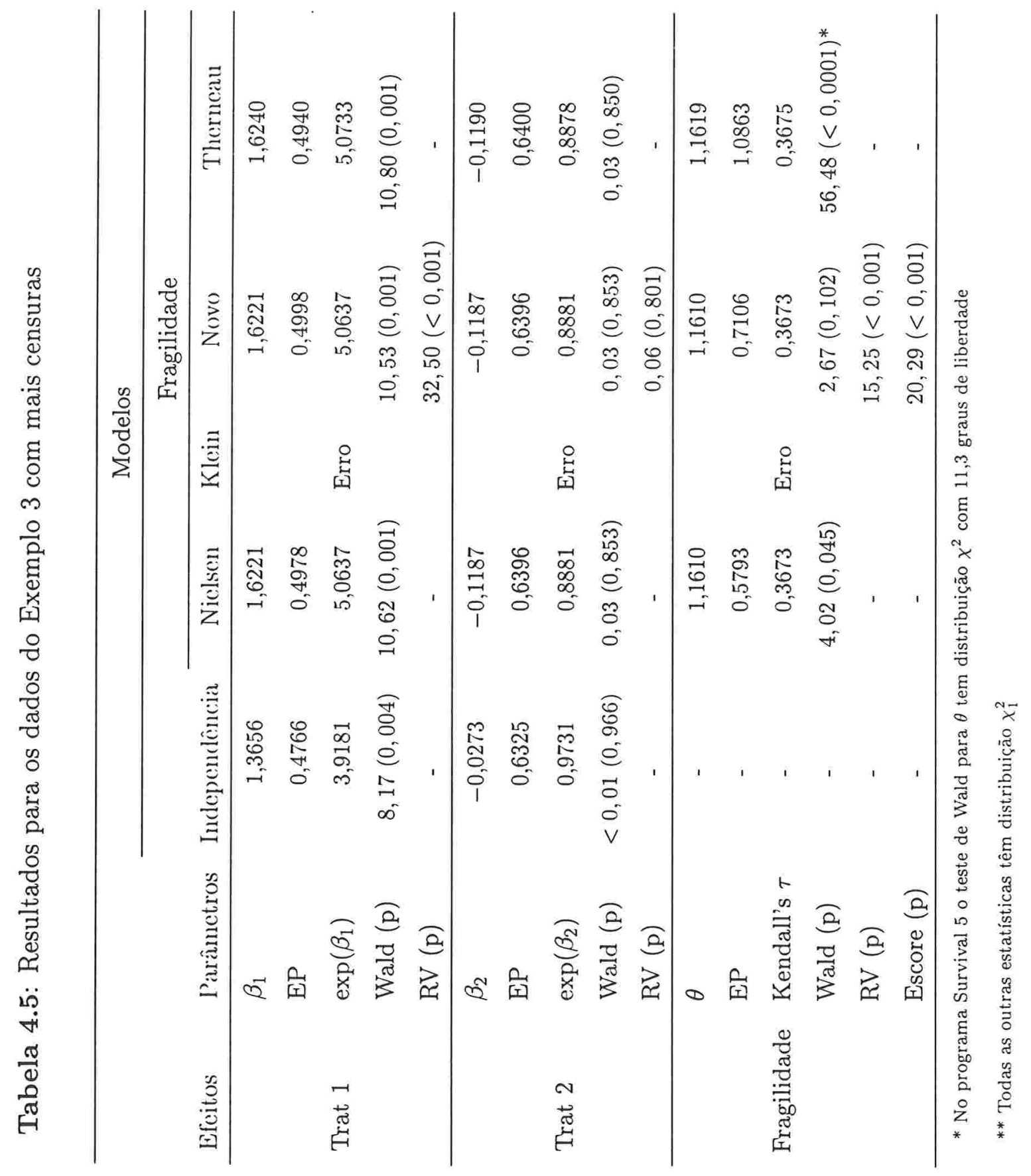




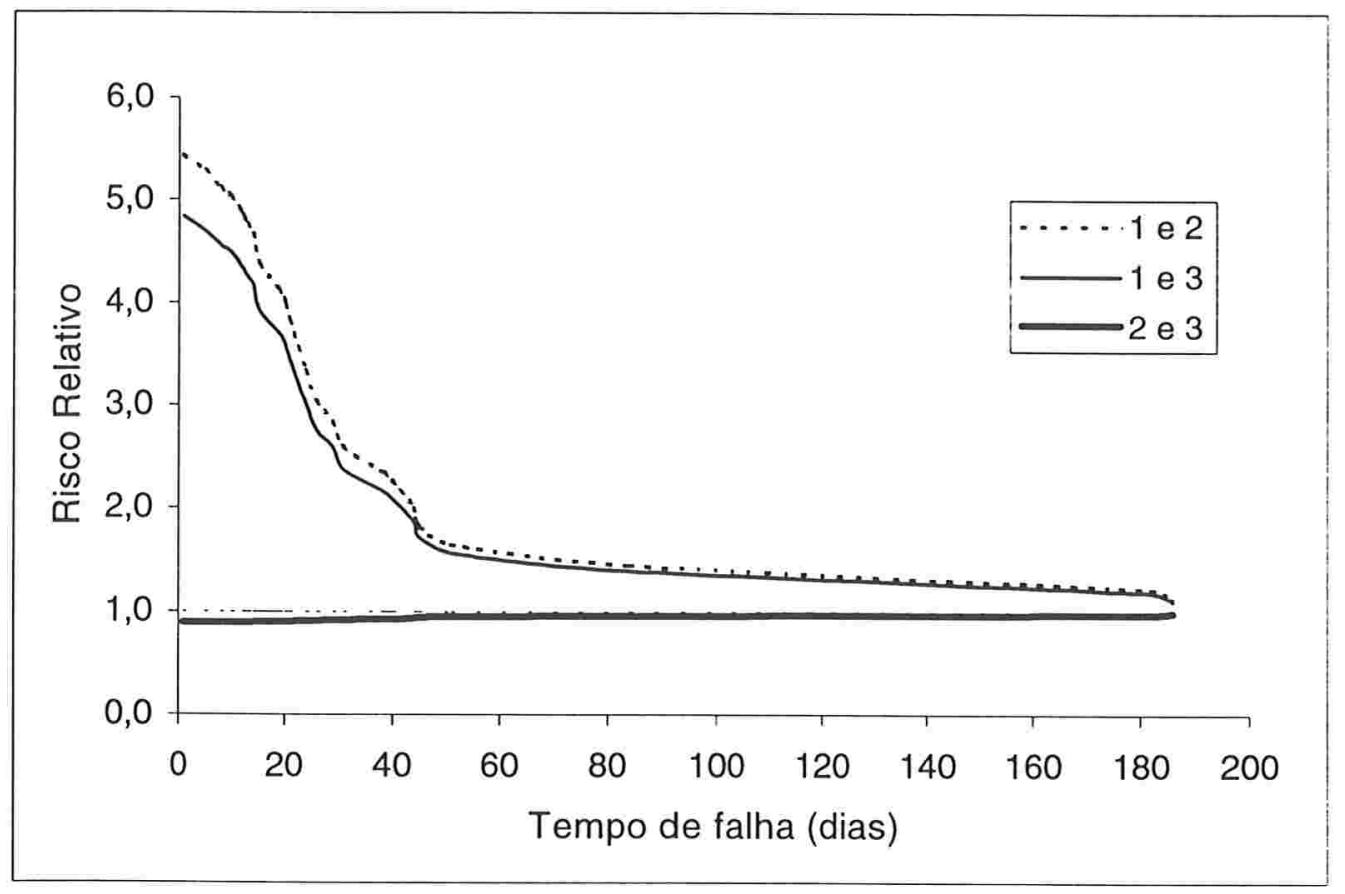

Figura 4.5: Risco relativo entre os tratamentos

Entretanto, as outras estatísticas que só são calculadas pelo novo programa estão de acordo com os resultados dos outros programas e indicam que existe dependência $(\mathrm{p}<0,001)$. Outra fato que nos leva a dizer que existe dependência é o valor do $\tau$ de Kendall, 0,37 com erro padrão igual a 0,25 , e da diferença das estimativas do modelo de fragilidade e do modelo de independência.

Sobre o parâmetro $\boldsymbol{\beta}$, temos que a covariável que define o grupo de testes da $2 \underline{\mathrm{a}}$ geração novamente não foi significante $(\mathrm{p}=0,853)$. Além disso as estimativas dos erros padrões para Trat1 e Trat2 foram muito parecidas nos três programas.

Na figura 4.5 estão as curvas dos riscos relativos entre os três tratamentos. Note que a curva dos grupos 2 e 3 (mais grossa) está muito próxima da reta $y=1$ o que também indica que não há diferença entre esses tratamentos.

Na Tabela 4.6 temos os resultados do noro ajuste sem a covariável Trat2. Ela mostra 
que houve diferenças nas estimativas dos parâmetros do novo programa com relação aos outros dois. Esse é um resultado interessante, pois em todas as outras tabelas as estimativas foram idênticas, mudando apenas as estimativas dos erros padrões. Com relação ao parâmetro de dependência, o programa de Nielsen e o de Therneau chegaram a um valor um pouco maior que o programa do NTIA (1,16 aproximadamente contra 1,1057$)$. Novamente a estimativa do erro padrão de $\theta$ através do programa do Nielsen foi a menor delas, o que gerou resultados diferentes para a estatística de Wald do novo programa e o de Nielsen. Já o programa de Therneau e as estatísticas da razão de verossimilhanças e Escore indicam que existe dependência entre as observaçoes $(p<0,001)$. O $\tau$ de Kendall foi muito semelhante ao do modelo com o Trat2, mudando apenas para o novo programa devido a nova estimativa de $\theta$.

Com relação ao parâmetro $\beta_{1}$ todos os programas apresentaram estimativas bem diferentes da encontrada pelo modelo de independência. Todas as estatísticas mostram que existe diferença entre o tempo de detecção da positividade nos testes de $1 \underline{a}$ geração em relação aos outros dois $(\mathrm{p}<0,001)$.

A figura 4.6 mostra mais um indício da dependência entre os dados, já que as curvas do risco relativo para os modelos de fragilidade e independência são bem distintas. Aproximadamente depois de 50 dias a curva para o modelo de fragilidade vai se aproximando da reta $y=1$ mostrando que para indivíduos diferentes os testes da $1 \underline{\mathrm{a}}$ geração detectam a positividade com mais rapidez que os demais, apesar do risco ir decrescendo.

Para amostras de sangue do mesmo indivíduo podemos concluir que os testes de $1 \underline{\mathrm{a}}$ geração têm 4,5 a 5 vezes mais chance de detectar a positividade para HCV do que os das outras gerações. Já se comparamos resultados de indivíduos diferentes, temos que após 50 dias os testes passam a ter uma chance praticamente igual de detectarem a positividade para $\mathrm{HCV}$.

De um modo geral, observe que em nenhum dos exemplos os resultados do modelo de independência geraram conclusões distintas dos do modelo de fragilidade. Veja também que as estimativas do modelo de independência parecem ser sempre subestimadas quando 


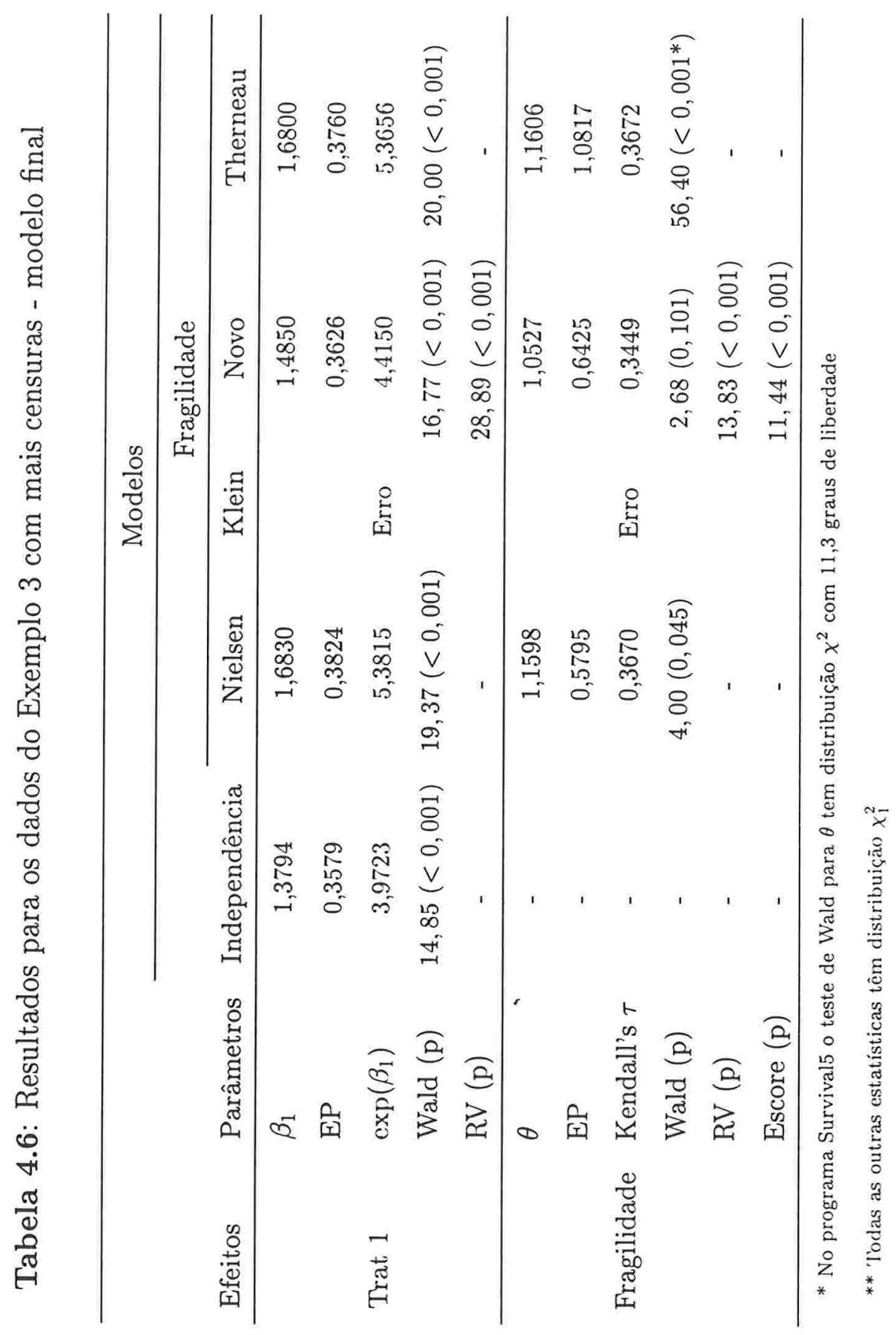




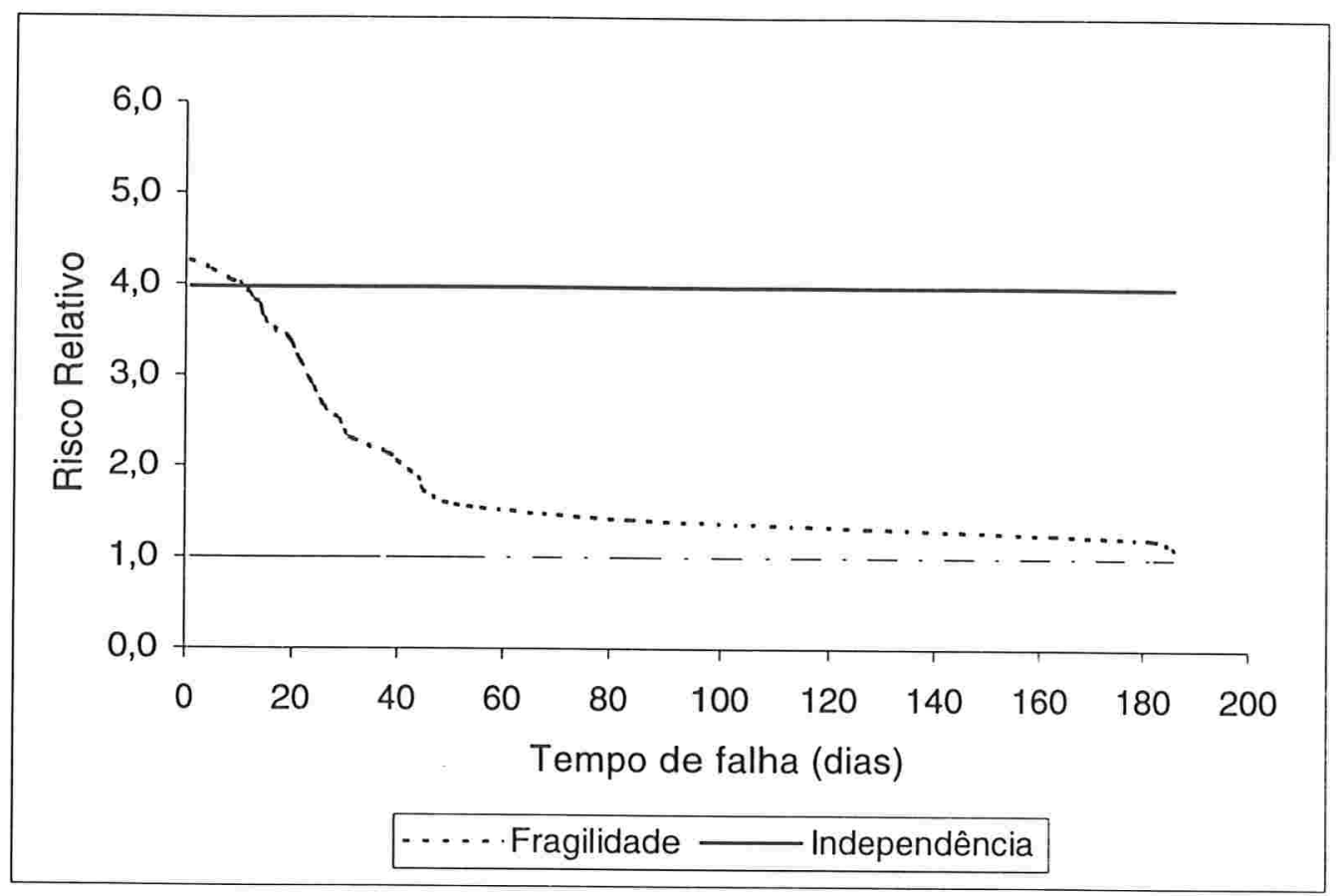

Figura 4.6: Risco relativo do Tratamento 1 em relação ao 2 e 3

comparadas com as do modelo de fragilidade, principalmente quando existe dependência entre as observações.

O programa de Nielsen e o de Therneau parecem ser os melhores já que foram os únicos que geraram estimativas para todos os conjuntos de dados e os resultados mais coerentes. Os outros programas são mais limitados e apresentaram alguns problemas para estimar os parâmetros. No entanto, o programa de Nielsen tem uma grande desvantagem sobre os outros já que só pode ser rodado no sistema UNIX. 


\section{Capítulo 5}

\section{Conclusão}

Nessa dissertação, apresentamos vários processos de estimação descritos na literatura para os modelos de fragilidade Gama. Além disso, discutimos o uso das três estatísticas mais usadas para testes de hipóteses (Wald, Escore e Razão de Verossimilhanças).

Com relação a essas estatísticas, notamos que existe divergência nos resultados num mesmo conjunto de dados. Provavelmente, isso ocorre pelo fato das estatísticas Escore e Razão de Verossimilhanças trabalharem na borda do espaço paramétrico. É possível que elas não tenham distribuição de $\chi^{2}$ padrão como na situação de independência. A abordagem feita por Therneau \& Grambsch (1998) apresenta uma correção da distribuição de $\chi^{2}$ para a estatística de Wald e os resultados parecem ser mais coerentes. Portanto, a alternativa encontrada usando a teoria de verossimilhança penalizada mostra-se promissora e deve ser estudada com mais detalhes.

Iniciamos um estudo de sensibilidade para avaliar esse problema da divergência das estatísticas, entretanto, o único programa que calcula as três, feito para rodar no NTIA, mostrou-se muito instável às alterações na estrutura de falha e censura inviabilizando uma avaliação mais aprofundada. 
Outro ponto que merece ser investigado é a análise de resíduos. Será que a distribuição Gama é a mais indicada para modelar a dependência entre as observações? Recentemente, Glidden (1999) indicou técnicas gráficas e numéricas para avaliar a adequacidade da distribuição Gama aos dados. Esse é um assunto muito atual que merece ser mais estudado.

Os modelos de fragilidade com certeza são muito interessantes para resolver o problema da dependência em estudos de Análise de Sobrevivência. Contudo, maiores investigações devem ser realizadas principalmente no que se refere às estatísticas para teste de hipóteses. Isso poderia ser feito através de estudos de simulação utilizando o programa desenvolvido no NTIA.

Todos os programas computacionais considerados trabalham na estimação dos parâmetros de regressão e de determinação da estrutura de dependência (parâmetros de fragilidade). Como notado no Capítulo 4, os programas podem apresentar problemas numéricos dependendo da estrutura dos dados. Este fato, no entanto, ocorreu com menor frequência nos programas de Nielsen (UNIX) e de Therneau (Survival5 / S-PLUS) e, portanto, no atual estágio de desenvolvimento, estes são a escolha natural em se tratando da estimação dos modelos. Deve ser notado também que nos casos em que todos os programas forneceram estimativas, os valores de $\hat{\boldsymbol{\beta}}$ não diferiram consideravelmente. 


\section{Apêndice A}

\section{Cálculo da Matriz de Informação}

Segue abaixo os cálculos das derivadas de primeira ordem da verossimilhança (3.28):

$$
\begin{aligned}
\frac{\partial \log L(\Phi)}{\partial \alpha_{l}}= & \sum_{i=1}^{n}\left\{\frac{-\left(N_{i}+\frac{1}{\theta}\right)}{\frac{1}{\theta}+\Lambda_{i}(\boldsymbol{\beta}, \boldsymbol{\alpha})} S_{i}^{(0)}\left(\boldsymbol{\beta}, T_{l}\right)\right\}+\frac{m_{l}}{\alpha_{l}} \\
\frac{\partial \log L(\Phi)}{\partial \beta_{\nu}}= & \sum_{i=1}^{n}\left\{\frac{-\left(N_{i}+\frac{1}{\theta}\right)}{\frac{1}{\theta}+\Lambda_{i}(\boldsymbol{\beta}, \boldsymbol{\alpha})} \sum_{l=1}^{m} S_{i \nu}^{(1)}\left(\boldsymbol{\beta}, T_{l}\right) \alpha_{l}+\sum_{j=1}^{n_{i}} \sum_{l=1}^{m} d N_{i j}\left(T_{l}\right) X_{i j \nu}\right\} \\
\frac{\partial \log L(\Phi)}{\partial \theta}= & \sum_{i=1}^{n}\left\{\sum_{r=0}^{N_{i}-1} \frac{-1}{\theta^{2} r+\theta}-\frac{1}{\theta^{2}}(1-\log \theta)+\frac{N_{i}+\frac{1}{\theta}}{\theta+\theta^{2} \Lambda_{i}(\boldsymbol{\beta}, \boldsymbol{\alpha})}+\right. \\
& \left.+\frac{1}{\theta^{2}} \log \left(\frac{1}{\theta}+\Lambda_{i}(\boldsymbol{\beta}, \boldsymbol{\alpha})\right)\right\}
\end{aligned}
$$

onde $S_{i \nu}^{(1)}(\boldsymbol{\beta}, t)=\sum_{j=1}^{n_{i}} Y_{i j}(t) X_{i j \nu} \exp \left(\boldsymbol{\beta}^{\prime} \mathrm{X}_{i j}\right)$ é a derivada de $S_{i}^{(0)}(\boldsymbol{\beta}, t)$ com respeito a $\beta_{\nu}$.

Com isso, as derivadas de segunda ordem são dadas por: 


$$
\begin{aligned}
& \frac{\partial^{2} \log L(\Phi)}{\partial \alpha_{l} \partial \alpha_{k}}=\sum_{i=1}^{n}\left\{\frac{\left(N_{i}+\frac{1}{\theta}\right) S_{i}^{(0)}\left(\boldsymbol{\beta}, T_{l}\right) S_{i}^{(0)}\left(\boldsymbol{\beta}, T_{k}\right)}{\left[\frac{1}{\theta}+\Lambda_{i}(\boldsymbol{\beta}, \boldsymbol{\alpha})\right]^{2}}\right\}-I(l=k) \frac{m_{l}}{\alpha_{l}^{2}} \\
& \frac{\partial^{2} \log L(\Phi)}{\partial \alpha_{l} \partial \beta_{\nu}}=\sum_{i=1}^{n}\left\{\frac { N _ { i } + \frac { 1 } { \theta } } { [ \frac { 1 } { \theta } + \Lambda _ { i } ( \boldsymbol { \beta } , \boldsymbol { \alpha } ) ] ^ { 2 } } \left(S_{i}^{(0)}\left(\boldsymbol{\beta}, T_{l}\right) \sum_{l=1}^{m} \alpha_{l} S_{i \nu}^{(1)}\left(\boldsymbol{\beta}, T_{l}\right)-\right.\right. \\
& \left.\left.-\left[\frac{1}{\theta}+\Lambda_{i}(\boldsymbol{\beta}, \boldsymbol{\alpha})\right] S_{i \nu}^{(1)}\left(\boldsymbol{\beta}, T_{l}\right)\right)\right\} \\
& \frac{\partial^{2} \log L(\Phi)}{\partial \alpha_{l} \partial \theta}=\sum_{i=1}^{n}\left\{S_{i}^{(0)}\left(\boldsymbol{\beta}, T_{l}\right) \frac{\Lambda_{i}(\boldsymbol{\beta}, \boldsymbol{\alpha})-N_{i}}{\left[1+\theta \Lambda_{i}(\boldsymbol{\beta}, \boldsymbol{\alpha})\right]^{2}}\right\} \\
& \frac{\partial^{2} \log L(\Phi)}{\partial \beta_{\nu} \partial \beta_{\mu}}=\sum_{i=1}^{n} \frac{N_{i}+\frac{1}{\theta}}{\left[\frac{1}{\theta}+\Lambda_{i}(\boldsymbol{\beta}, \boldsymbol{\alpha})\right]^{2}}\left\{\left(\sum_{l=1}^{m} \alpha_{l} S_{i \nu}^{(1)}\left(\boldsymbol{\beta}, T_{l}\right)\right)\left(\sum_{l=1}^{m} \alpha_{l} S_{i \mu}^{(1)}\left(\boldsymbol{\beta}, T_{l}\right)\right)-\right. \\
& \left.-\left(\frac{1}{\theta}+\Lambda_{i}(\boldsymbol{\beta}, \boldsymbol{\alpha})\right) \sum_{l=1}^{m} \alpha_{l} S_{i \nu \mu}^{(2)}\left(\boldsymbol{\beta}, T_{l}\right)\right\} \\
& \frac{\partial^{2} \log L(\Phi)}{\partial \beta_{\nu} \partial \theta}=\sum_{i=1}^{n} \frac{\left(\Lambda_{i}(\boldsymbol{\beta}, \boldsymbol{\alpha})-N_{i}\right) \sum_{l=1}^{m} \alpha_{l} S_{i \nu}^{(1)}\left(\boldsymbol{\beta}, T_{l}\right)}{\left[1+\theta \Lambda_{i}(\boldsymbol{\beta}, \boldsymbol{\alpha})\right]^{2}} \\
& \frac{\partial^{2} \log L(\Phi)}{\partial \theta^{2}}=\sum_{i=1}^{n}\left\{\sum_{r=0}^{N_{i}-1} \frac{2 \theta r+1}{\left(\theta^{2} r+\theta\right)^{2}}-\frac{2 \log \theta-3}{\theta^{3}}-\frac{2}{\theta^{3}} \log \left(\frac{1}{\theta}+\Lambda_{i}(\boldsymbol{\beta}, \boldsymbol{\alpha})\right)-\right. \\
& \left.-\frac{\frac{3}{\theta}+N_{i}+2 \Lambda_{i}(\boldsymbol{\beta}, \boldsymbol{\alpha})\left[2+\theta N_{i}\right]}{\left[\theta+\theta^{2} \Lambda_{i}(\boldsymbol{\beta}, \boldsymbol{\alpha})\right]^{2}}\right\}
\end{aligned}
$$

onde $S_{i \nu \mu}^{(2)}(\boldsymbol{\beta}, t)=\sum_{j=1}^{n_{i}} Y_{i j}(t) X_{i j \nu} X_{i j \mu} \exp \left(\boldsymbol{\beta}^{\prime} \mathbf{X}_{i j}\right)$ é a derivada de $S_{i \nu}^{(1)}(\boldsymbol{\beta}, t)$ com respeito a $\beta_{\mu}$. 


\section{Referências Bibliográficas}

Aalen, O. O. (1978). Nonparametric inference for a family of counting processes, The Annals of Statistics 6(4): 701-726.

Andersen, P. K., Borgan, O., Gill, R. D. \& Keiding, N. (1993). Statistical Model Based on Counting Processes, Springer-Verlag: New York.

Andersen, P. K. \& Gill, R. D. (1982). Cox's regression model for counting processes: A large sample study, The Annals of Statistics 10: 1100-1120.

Andersen, P. K., Klein, J. P., Knudsen, K. M. \& Palacios, R. T. (1997). Estimation of variance inCox's regression model with shared gamma frailties, Biometrics 53: 14751484.

Breslow, N. E. \& Clayton, D. G. (1993). Approximate inference in generalized linear mixed models, Jounal of American Statistical Association 88: 9-25.

Chang, I. S. \& Hsiung, C. A. (1995). An efficient estimator for proportional hazards models with frailties. Unpublished Manuscript.

Clayton, D. (1978). A model for association in bivariate life tables and its application in epidemiological studies of familial tendency in chronic disease incidence, Biometrika 65: $141-151$.

Clayton, D. (1991). A Monte Carlo method for Bayesian inference in frailty models, Biometrics 47: 467-485. 
Clayton, D. G. \& Cuzick, J. (1985). Multivariate generalizations of the proportional hazards model, Journal of the Royal Statistical Society A 148: 82-117.

Commenges, D. \& Andersen, P. K. (1993). Score test of homogeneity for survival data, Technical Report 93/5, Statistical Research Unit, University of Copenhaguen.

Commenges, D. \& Andersen, P. K. (1995). Score test of homogeneity for survival data, Lifetime Data Analysis 1: 145-156.

Cox, D. R. (1972). Regression models and life tables (with discussion), Journal of the Royal Statistical Society B 34: 187-220.

Dempster, A. P., Laird, N. M. \& Rubin, D. R. (1977). Maximum likelihood estimation from incomplete data via the em algorithm (with discussion), Journal of the Royal Statistical Society B 39: 1-38.

Ducrocq, V. \& Sölkner, J. (1994). "the survival kit", a FORTRAN package for the analysis of survival data, in S. H. Moolgavkar \& R. L. Prentice (eds), 5th World Cong. Genet. Appl. Livest. Prod., Vol. 22, Dep. Anim. Poultry Sci., University of Guelph, Guelph, Ontario, Canada, pp. 51-52.

Ducroq, V. \& Sölkner, J. (1998). "the Survival Kit V3.0", a package for large analysis of survival data, in S. H. Moolgavkar \& R. L. Prentice (eds), 6th World Cong. Genet. Appl. Livest. Prod., Vol. 27, Anim. Genetics and Breeding Unit, University of New England, Armidale, Australia, pp. 447-448.

Elbers, C. \& Ridder, G. (1982). True and spurius duration dependence: (t)he identifiability of the proportional hazard model, Review of Economic Studies XLIX: 403-409.

Feller, W. (1971). An introduction to probability theory and its applications, 2nd edn, New York: Wiley.

Genest, C. \& Mackay, R. J. (1986). The joy of copulas: (b)ivariate distributions with uniform marginal, The American Statistician 40: 280-283. 
Gill, R. D. (1985). Discussion on the paper by D. Clayton and J. Cuzick, Journal of the Royal Statistical Society A 148: 108-109.

Gill, R. D. (1992). Marginal partial likelihood, Scandinavian Journal of Statistics 79: 133137.

Glidden, D. V. (1999). Checking the adequacy of the gamma frailty model for multirariate failure times, Biometrika 86: 381-393.

Grande, R. H. M., Lima, A. C. P., Rodrigues Filho, L. E. \& Witzel, M. F. (1999). A universal adhesive used for sealing: Clinical evaluation, A aparecer no American Journal of Dentistry .

Gray, R. J. (1992). Flexible methods for analyzing survival data using splines, with applications breast cancer prognosis, Journal of the American Statistical Association 87: 942951.

Hougaard, P. (1984). Life table methods for heterogeneous populations: Distributions describing the heterogeneity, Biometrika 71: 75-83.

Hougaard, P. (1986a). A class of multivariate failure time distributions, Biometrika 73: 671678.

Hougaard, P. (1986b). Survival models for heterogeneous populations derived from stable distributions, Biometrika 73: 387-396.

Hougaard, P. (1991). Modelling heterogeneity in survival data, Journal of Applied Probability 28: 695-701.

Johansen, S. (1983). An extension of Cox's regression model, International Statistical Review 51: $165-174$.

Kendall, M. G. (1962). Rank correlation methods, 3rd edn, London: Griffin.

Klein, J. P. (1992). Semiparametric estimation of random effects using Cox model based on the EM algorithm, Biometrics 48: 795-806. 
Klein, J. P. \& Moeschberger, M. L. (1997). Survival Analysis - Techniques for censored and truncated data, Springer - Verlag New York, Inc.

Klein, J. P., Moeschberger, M. L., Li, Y. H. \& Wang, S. T. (1992). Estimating random effects in the Framingham Heart Study., Boston: Kluwer Academic Publishers. pp. 99-120.

Lawless, J. F. (1982). Statistical Models and Methods for Lifetime Data, New York: Wiley.

Li, H. (1995). Semiparametric estimation of major gene and random environmental effects for age of onset, $\mathrm{PhD}$ thesis, Department of Statistics, University of Washington.

Liang, K., Self, S. G., Bandeen-Roche, K. J. \& Zeger, S. L. (1995). Some recent development for regression analysis of multivariate failure time data, Lifetime data analysis 1: 403415.

Mack, W., Langholz, B. \& Thomas, D. C. (1990). Survival models for familial aggregation of cancer, Environmental Health Perspective 87: 27-35.

Mantel, N., Bohidar, N. R. \& Ciminera, J. L. (1977). Mantel-haenzel analysis of littermatched time-to-response data, with modifications for recovery of interlitter information, Cancer Research 37: 3863-3868.

McGilchrist, C. A. (1993). REML estimation for survival models with frailty, Biometrics 49: 221-225.

McGilchrist, C. A. \& Aisbett, C. W. (1991). Regression with frailty in survival analysis, Biometrics 47: 461-466.

McGilchrist, C. A. \& Yau, K. K. W. (1994). Estimation of survival with time dependent frailty, ASA Proceedings of the section on Epidemiology, pp. 88-90.

Murphy, S. A. (1994). Consistency in a proportional hazards model incorporating a random effect, The Annals of Statistics 22: 712-731.

Murphy, S. A. (1995). Asymptotic theory for the frailty model, The Annals of Statistics 23: $182-198$. 
Nielsen, G. G., Gill, R. D., Andersen, P. K. \& Sørensen, T. I. A. (1992). A counting process approach to maximum likelihood estimation in frailty models, Scandinavian Journal of Statistics 19: 25-43.

Oakes, D. (1982). A model for association in bivariate survival data, Journal of the Royal Statistical Society B 44: 414-422.

Oakes, D. (1989). Bivariate survival models induced by frailties, Jounal of American Statistical Association 84: 487-493.

Paik, M. C., Tsai, W. Y. \& Ottman, R. (1994). Multivariate survival analysis using piecewise constant gamma frailty, Biometrics 50: 978-988.

Petersen, J. H. (1998). An additive frailty model for correlated life times, Biometrics 54: 646661.

Prentice, R. L. (1978). Linear rank test with right censored data, Biometrika 65: 167-179.

Prentice, R. L. \& Self, S. G. (1985). Contribution to the discussion of the paper by D. G. Clayton and J. Cuzick, Journal of the Royal Statistical Society A 148: 112-113.

Robins, J. \& Greenland, S. (1989). The probability of causation under a stochastic model for individual risk, Biometrics 45: 1125-1138.

Robins, J. \& Greenland, S. (1991). Estimability and estimation of expected years of life lost due to a hazardous exposure, Statistics in Medicine 10: 79-83.

Self, S. G. \& Prentice, R. L. (1986). Incorporating random effects into multivariate relative risk regression models, in S. H. Moolgavkar \& R. L. Prentice (eds), Modern Statistical Methods in Chronic Disease Epidemiology, New York: Wiley, pp. 167-177.

Sinha, D. \& Dey, D. K. (1997). Semiparametric bayesian analysis of survival data, Journal of the American Statistical Association 92: 1195-1212.

Therneau, T. M. \& Grambsch, P. M. (1998). Penalized cox models and frailty, Relatório Técnico ainda não publicado. 
Vaupel, J. W., Manton, K. G. \& Stallard, E. (1979). The impact of heterogeneity in individual frailty on the dynamics of mortality, Demography 16: 439-454.

Wang, S. T., Klein, J. P. \& Moeschberger, M. L. (1995). Semiparametric estimation of covariate effects using the positive stable frailty model, Applied Stochastic Models and Data Analysis 11: 121-133.

Yashin, A., Vaupel, J. \& Iachine, I. (1995). Correlated individual frailty: An advantageous approach to survival analysis of bivariate data, Mathematical Population Studies 5(2): 145-159.

Yau, K. K. W. \& McGilchrist, C. A. (1998). ML and REML estimation in survival analysis with time dependent correlated frailty, Statistics in Medicine 17: 1201-1213. 